\title{
Effects of telemonitoring in patients with heart failure
}

Citation for published version (APA):

Boyne, J. J. J. (2013). Effects of telemonitoring in patients with heart failure. [Doctoral Thesis, Maastricht University]. Datawyse / Universitaire Pers Maastricht. https://doi.org/10.26481/dis.20131213jb

Document status and date:

Published: 01/01/2013

DOI:

10.26481/dis.20131213jb

Document Version:

Publisher's PDF, also known as Version of record

\section{Please check the document version of this publication:}

- A submitted manuscript is the version of the article upon submission and before peer-review. There can be important differences between the submitted version and the official published version of record.

People interested in the research are advised to contact the author for the final version of the publication, or visit the DOI to the publisher's website.

- The final author version and the galley proof are versions of the publication after peer review.

- The final published version features the final layout of the paper including the volume, issue and page numbers.

Link to publication

\footnotetext{
General rights rights.

- You may freely distribute the URL identifying the publication in the public portal. please follow below link for the End User Agreement:

www.umlib.nl/taverne-license

Take down policy

If you believe that this document breaches copyright please contact us at:

repository@maastrichtuniversity.nl

providing details and we will investigate your claim.
}

Copyright and moral rights for the publications made accessible in the public portal are retained by the authors and/or other copyright owners and it is a condition of accessing publications that users recognise and abide by the legal requirements associated with these

- Users may download and print one copy of any publication from the public portal for the purpose of private study or research.

- You may not further distribute the material or use it for any profit-making activity or commercial gain

If the publication is distributed under the terms of Article $25 \mathrm{fa}$ of the Dutch Copyright Act, indicated by the "Taverne" license above, 


\section{Effects of telemonitoring in patients with heart failure}


(C) Copyright Josiane J.J. Boyne, Maastricht 2013

ISBN 9789461592705

Production: Datawyse | Universitaire Pers Maastricht 


\title{
Effects of telemonitoring in patients with heart failure
}

\author{
PROEFSCHRIFT \\ ter verkrijging van de graad van doctor aan de Universiteit Maastricht \\ op gezag van de Rector Magnificus, Prof. dr. L.L.G. Soete \\ volgens het besluit van het college van Decanen, \\ in het openbaar te verdedigen \\ op vrijdag 13 december 2013 om 12.00 uur \\ door \\ Josiane Josephine Jeannine Boyne \\ geboren op 13 december 1953 te Rotem (B)
}

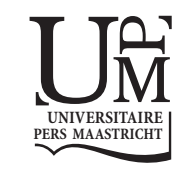




\section{Promotoren}

Prof. dr. A.P.M. Gorgels

Prof. dr. H.J.M. Vrijhoef

\section{Beoordelingscommissie}

Prof. dr. H.P. Brunner la Rocca (voorzitter)

Prof. dr. T. Jaarsma, Linköping University, Norrköping, Zweden

Prof. dr. D. Ruwaard

Prof. dr. J.W.M.G. Widdershoven, Tweestedenziekenhuis Tilburg

Dr. R.A.G. Winkens

The study in this thesis was supported by the Province of Limburg, the Annadal Foundation Maastricht, the Rescar Foundation and an unrestricted grant from Astra Zeneca.

Financial support by the Maastricht University Medical Centre and Sananet, specialist in eHealth, is gratefully acknowledged. 


\section{Content}

$\begin{array}{lll}\text { Chapter } 1 & \text { General Introduction } & 7\end{array}$

Chapter 2 Telemonitoring in patients with heart failure, the TEHAF- 23 study: Study protocol of an on-going prospective randomised trial

Chapter 3 Preliminary results regarding adherence among telemonitored patients with heart failure to pharmacological and nonpharmacological recommendations

Chapter 4 Effects of telemonitoring on heart failure patients' knowledge, self-care, self-efficacy, and adherence: a randomised controlled trial

Chapter 5 Tailored telemonitoring in patients with heart failure: Results of a multicenter randomised controlled trial

Chapter 6 Cost-effectiveness analysis of telemonitoring versus usual care in patients with heart failure (the TEHAF-study)

Chapter 7 Effects of telemonitoring on heart failure patients' quality of life and depression: a randomised controlled trial

Chapter 8 Implementing telemonitoring in heart failure care: Barriers from the perspectives of patients, healthcare professionals, and healthcare organisations

Chapter 9 General discussion

Chapter 10 Summary

Samenvatting

Dankwoord

Curriculum vitae

List of publications 

CHAPTER 1

General introduction 
CHAPTER 1 


\section{Preface}

Long-term medical conditions negatively affect the lives of older people and those caring for them. Their prevalence increases with the aging of the population presenting substantial challenges to providers of health and social care. Telemonitoring has the potential to overcome the expected shortage in medical staff over the next decades. This novel modality regards the remote monitoring of vital signs and symptoms in people with acute or chronic conditions. This enables care providers to identify at a distance signs of deterioration, to intervene promptly and in this way prevent hospital admissions [1].

This thesis focuses on redesigning health care by introducing telemonitoring in patients with heart failure and assessing its cost-effectiveness. Effectiveness is addressed as the primary endpoint of this study, in terms of heart failure hospitalisation and all cause death. Secondary endpoints are defined as the extent to which patients' disease specific knowledge, self-care, therapy adherence, experienced quality of life, anxiety and depression were influenced by telemonitoring. Cost-effectiveness is analysed in terms of costs per Quality-Adjusted Life Year (QALY).

\section{Heart failure: definition, classification, aetiology and epidemiology}

Heart failure (HF) is a chronic syndrome as complication of a cardiac disease leading to pump dysfunction. The European Society of Cardiology [2] defines HF as: "HF is an abnormality of cardiac structure or function, leading to failure of the heart to deliver oxygen at a rate commensurate with the requirements of the metabolising tissues."

Clinically, HF is defined as a syndrome in which patients have typical signs and symptoms of breathlessness and fluid retention, such as ankle oedema, elevated jugular venous pressure, hepatomegaly, ascites, pleural effusion and pulmonary crackles. Frequently, many of these signs resolve on diuretic therapy [2].

$\mathrm{HF}$ is classified based on severity of symptoms and restriction of physical activity and graded according to the New York Heart Classification (NYHA), from NYHA class I to IV, the latter being the most severe (Table 1) [3, 4].

Table 1 NYHA Classifications [3, 4]

\begin{tabular}{ll}
\hline & NYHA classification \\
\hline Class I & No limitation of physical activity. Ordinary physical activity does not cause undue breathless- \\
& ness, fatigue, or palpitations. \\
Class II & Slight limitation of physical activity. Comfortable at rest, but ordinary physical activity results \\
& in undue breathlessness, fatigue, or palpitations. \\
Class III & Marked limitation of physical activity. Comfortable at rest, but less than ordinary physical \\
& activity results in undue breathlessness, fatigue, or palpitations. \\
Class IV & Unable to carry on any physical activity without discomfort. Symptoms at rest can be present. \\
& If any physical activity is undertaken, discomfort is increased. \\
\hline
\end{tabular}


In industrialised countries, coronary artery disease, either alone or in combination with hypertension, is the most common cause of HF. Both prevalence and incidence increase with age. The former is also increased due to improved survival of acute cardiovascular events and better medical treatment [5].

In European countries the prevalence increases from 0.6 cases per 1000 in individuals below 65 to 28 per 1000 in those above 65 years $[5,6]$.

In the Netherlands, prevalence figures per 1000 are 10 above 65, 25 above 75 and 100 above 85 years of age [7].

The growing number of chronically ill patients, including those with HF, is already now leading to a capacity problem, in terms of numbers of care providers needed, and is claiming an increasing portion of the available financial resources [8].

In many European countries $>2 \%$ of the total health care budget is related to $\mathrm{HF}$ management, and up to $70 \%$ of this costs is related to the high rate of hospital readmissions, $[2,9,10]$. As an underlying mechanism failed self-care plays an important role $[11,12]$. Although multiple factors precipitate hospitalisation for HF exacerbation, most commonly it regards non-adherence to prescribed medications and diet, and failure to timely seek medical care in case of increasing symptoms [13, 14, 15, 16]. Both aspects are prominent examples of poor self-care. Accordingly, it is of great importance to improve self-care, and to support patients in their home situation to prevent hospital admissions.

\section{Heart failure management programs: components and effectiveness}

In Europe the first HF management program started in Sweden in the early 1990's, and this expanded to $60 \%$ of the European countries during the first years of this century [17].

HF management programs are designed to improve outcomes through structured follow-up with patient education, optimisation of medical treatment, psychosocial support, and access to care. Although the components of a HF program are well described in the guidelines (Table 2), HF management programs vary regarding content, type and number of caregivers involved. It is unknown which HF program is the most appropriate given a specific context [18].

As is clear from the listed components, patient education and patient involvement are indispensable and highly important (Table 2). Therefore a framework is created to guide and support caregivers and patients. Listed below are the essential topics that should be covered during patient education, and the skills and self-care behaviours that should be taught in relation to these topics (Table 3 ). 
Table 2 Components of a HF management program (ref 2)

\begin{tabular}{ll}
\hline Characteristics & Should employ a multidisciplinary approach (cardiologists, primary care physicians, nurs- \\
es, pharmacists, etc.) & Should target high-risk symptomatic patients \\
& Should include competent and professionally educated staff \\
Components & Adequate patient education, with special emphasis on adherence and self-care \\
& Patient involvement in symptom monitoring and flexible diuretic use \\
& Follow-up after discharge (regular clinic and/or home-based visits; possibly telephone \\
& support or remote monitoring) \\
& Increased access to healthcare (through in-person follow-up and by telephone contact; \\
& possibly through remote monitoring) \\
& Optimised medical and device management \\
& Facilitated access to care during episodes of decompensation \\
& Assessment of (and appropriate intervention in response to) an unexplained increase in \\
& weight, nutritional status, functional status, quality of life, and laboratory findings \\
& Access to advanced treatment options \\
& Provision of psychosocial support to patients and family and/or caregivers
\end{tabular}

HF management programs were developed in the 1990's to improve outcomes via education, support and optimisation of medicine regimens. From the start, evidence of the positive effects of programs was encouraging [19]. The critical components of a disease management program include: multidisciplinary team input with primary roles for the HF physicians, general practitioners and the specialised nurse; education in selfcare matters for patients and their families; appropriate use of evidence-based therapies; and early response to emerging features of clinical deterioration [20].

Randomised clinical trials have established that certain management programs for $\mathrm{HF}$ improve prescribing practices and reduce the risk of hospitalisation, costs, and mortality; successful programs have included patient education, multidisciplinary teams, and specialised follow-up procedures [21, 22, 23]. In contrast, telephone-based systems designed to enhance follow-up with primary care providers have yielded mixed results and the effectiveness of these programs has not been fully established [21, 22, 24, 25]. The composition of HF programs shows large differences regarding number and type of settings, professionals involved, number of components according Wagner's chronic care model, a widely adopted evidence-based tool to improve chronic care [26] and length of follow-up $[19,27]$. 
Table 3 Essential topics of nursing education (ref 2)

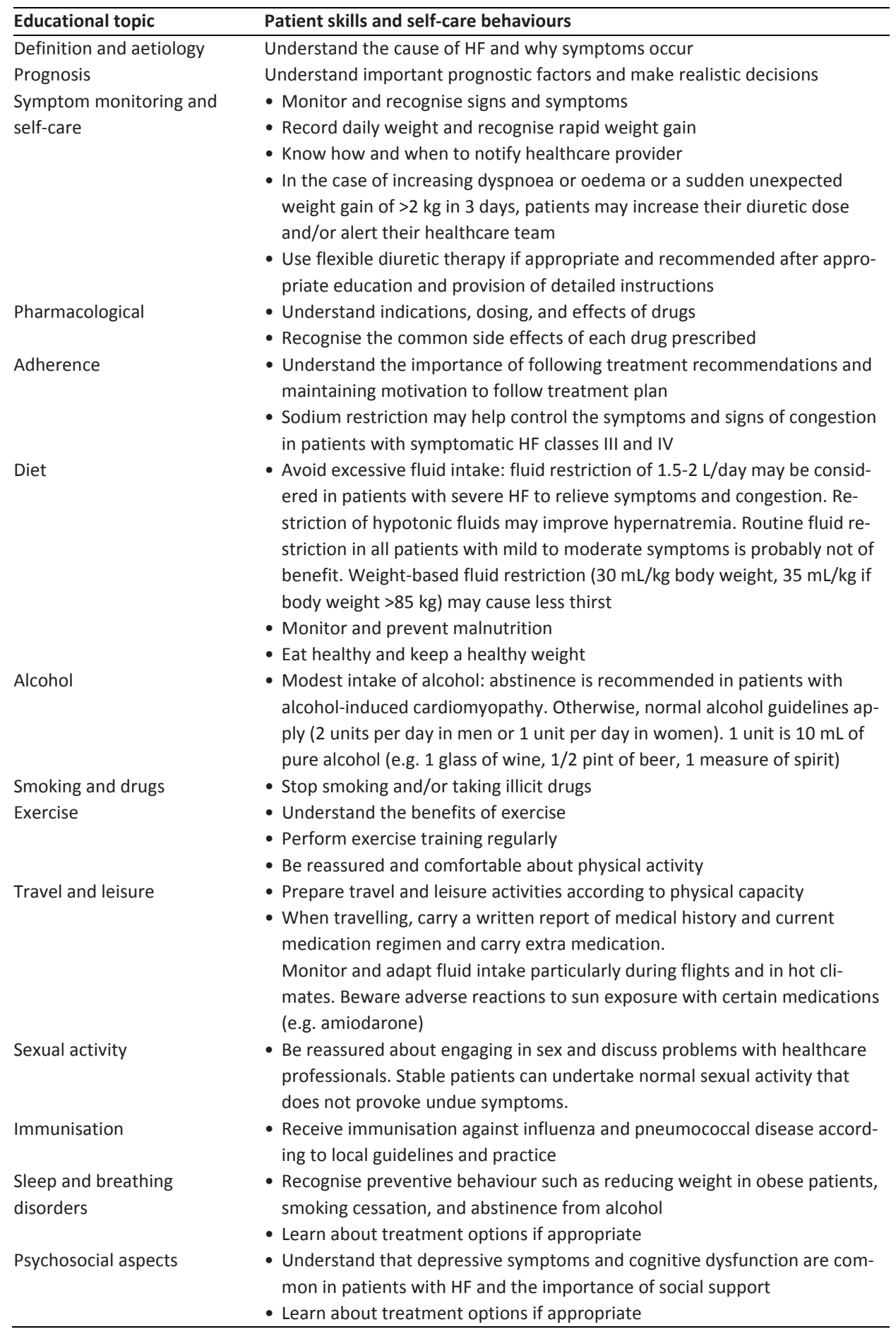




\section{Patient education and involvement}

Patient education and involvement are essential components of a HF management program, yet also the most difficult as they are highly individual patient related. Patient education requires an individualised approach, taking into account patients' learning barriers [28] and educational level, health status, communication, functional limitations, co-morbidities, psychosocial and socioeconomic factors [29].

Innovation of care is mostly driven by an increasing burden on health delivery and costs [30]. To save money and reduce costs, specialised care in Western countries is more and more transferred from the hospital to the home situation, including increased patient involvement. However, regarding the latter many patients will need support, which could be offered by technical developments such as telemonitoring. The evaluation of a particular telemonitoring system, i.e. the Health Buddy ${ }^{\circledR}$, is the subject of this thesis.

\section{e-Health, telehealth, telecoaching and telemonitoring: definition and effectiveness}

The language used to describe a relatively new service in terms of e-Health, telehealth, telecoaching and telemonitoring is still evolving. In the next paragraph definitions and related terms are provided, followed by the benefits of telemonitoring in HF.

$e$-Health is an emerging field in the intersection of medical informatics, public health and business, referring to health services and information delivered or enhanced through the Internet and related technologies. In a broader sense, the term characterises not only a technical development, but also a state-of-mind, a way of thinking, an attitude, and a commitment for networked, global thinking, to improve health care locally, regionally, and worldwide by using information and communication technology [31].

Telehealth, just one part of 'eHealth', is a broad term that refers to the use of technology to enable the remote delivery of healthcare or promotion of well-being. Under the umbrella term of telehealth, there are a range of specific applications, such as telemedicine, telecoaching and telemonitoring. One of the problems in understanding and using telehealth is a lack of consensus regarding terminology, and a tendency to use names interchangeably. The descriptions below are widely adopted [32].

Telemedicine-sometimes called teleconsultation-is the use of technology (usually a video-link) to facilitate health-related communication between practitioners or between practitioners and patients [32].

Telecoaching is the use of structured telephone support to underpin assessment of need, behaviour modification or rehabilitation. Examples include telephone-based smoking cessation support [32].

Telemonitoring is the remote monitoring of vital signs and symptoms in people with acute or chronic conditions. The most common applications of telemonitoring are in patients with HF or respiratory conditions who are living independently. Abnormal 
findings are flagged by telemonitoring systems, alerting practitioners who can intervene early and-in this way-may avert the need for hospital admission [32].

In the present study, telemonitoring of the HF situation was not based on transfer of vital signs, yet on patient reported weight and patients' experienced HF symptoms. Abnormal findings elicited flags to alert caregivers to intervene. Moreover the system offered disease specific education and support of self-management, based on the concept that more knowledge will lead to better self-care and adherence and therefore to improved HF status. The additional surplus of the telemonitoring system in our randomised trial was the robust tailor made approach due to our development of four different programs instead of the original single program available in the system. These four programs were based on the results of our feasibility study, preceding the randomised trial (Table 4).

Telemonitoring is recognised to be one of the technical possibilities to support patients intensively in their home situation. Patients are requested to provide information about their health state and HF complaints, and from the other side they receive daily manageable and dosed education about their disease and are stimulated regarding their self-care activities [33].

At the time of starting our evaluation of the telemonitoring system (Health Bud$\left.d y^{\circledR}\right)$, few robust telemonitoring studies had been performed. Cleland et al. [34] reported on the TEN-HMS study comparing patients in three arms: telemonitoring, usual care, nurse telephone management. As soon as possible after randomization patients of the telemonitoring group were equipped with an electronic, weighing scale, an automated sphygmomanometer, and a single-lead electrocardiogram using wristband electrodes. Patients' weight, blood pressure, heart rate, and rhythm were monitored twice daily. Values greater or less than pre-set limits were notified automatically to the study nurses, who then reviewed the information and took action either directly for any shortterm advice or through the primary care physician if long-term changes in therapy were required. Nurses also could scan patient data manually to identify any trends that they considered as requiring action. A total of $81 \%$ of patients had $80 \%$ compliance with at least one daily measurement (weight or blood pressure), and $55 \%$ had $80 \%$ compliance with twice daily measurements. Home telemonitoring was associated with a nonsignificant decrease in mortality, a trend to more hospital admissions with heart failure but a significant reduction in the average duration of admissions compared with nurse telephone support. It may be concluded that a frequent and intensive follow-up does not necessarily leads to improved outcomes, and even results in a decreased compliance of system use. Balk et al. [35] studied an elderly patient group with a mean age of 66 years. Their system included a secured broadband home TV-channel providing educational material, reminders of medication, health related surveys and motivational messages to encourage the prescribed lifestyle regimen. A subgroup of patients (Intervention-plus), who had been in hospital for HF treatment in the year preceding enrolment, were also given automated devices for daily measurements of blood pressure 
and weight. Tele-guidance and monitoring of daily measurements were performed by medical service centre (MSC) nurses, trained in heart failure management and supervised by physicians. The guidance provided to each patient by the MSC followed a personalized plan (medication and lifestyle regimen), which was specified by the treating cardiologist and hospital-based HF-nurse at the start of the study. Additionally, the medical history of the patient and information about his/her social environment was provided. For the patients equipped with the measurement devices, ranges were set for blood pressure as well as weight. Changes in treatment were only made in consultation with the hospital based cardiologist or HF-nurse. Patients in the intervention group had no direct contact with their cardiologist or hospital-based HF-nurse between outpatient clinic visits. No differences were found for the primary endpoint of days in hospital for all causes and days alive out-of-hospital, or for the secondary endpoints quality of life and self-care. Patients in the telemonitoring group revealed significantly more disease specific knowledge. Balk et al. concluded that teleguidance might play a role in the management of HF patients since it takes over some of the tasks of HF-nurses. Two other studies included only approximately 20 patients, just focusing on feasibility [36, 37]. It was reported that home telemonitoring is an acceptable and reliable intervention with an improved compliance for medication, still being present after one year. Gattis et al. [38] reported about improved results in the telemonitoring group, however it was found that this was rather the effect of higher dose of angiotensin-converting enzyme inhibitors. No differences for medication were found between the groups at baseline, yet patients in the telemonitoring group used significantly more ACEinhibitors after 12 months. It remains unclear if improvement was due to telemonitoring or not.

The Health Buddy ${ }^{\circledR}$ appliance (Figure 1 ) is at the patients' end an easy-to-use device connected to the telephone, consisting of a liquid crystal display screen and four buttons enabling to answer questions provided by the system in daily dialogues. The responses to the dialogues are sent to a protected server and successively to the caregivers' i-Care desktop. Patients' responses to the dialogues are transferred into risk profiles (low, medium or high) and ordered according to risk level. Consequently, care providers are able to quickly select high-risk patients and to anticipate to their problem. The involved HF nurses in our study were highly trained in the management of chronic HF and had a 5 to 10 years' experience regarding HF care. Besides, the nurses of the academic centre were educated at the level of advanced medical students. The involved nurse assistant was educated as an elderly caregiver. She was instructed before and coached during the study by a HF nurse. 


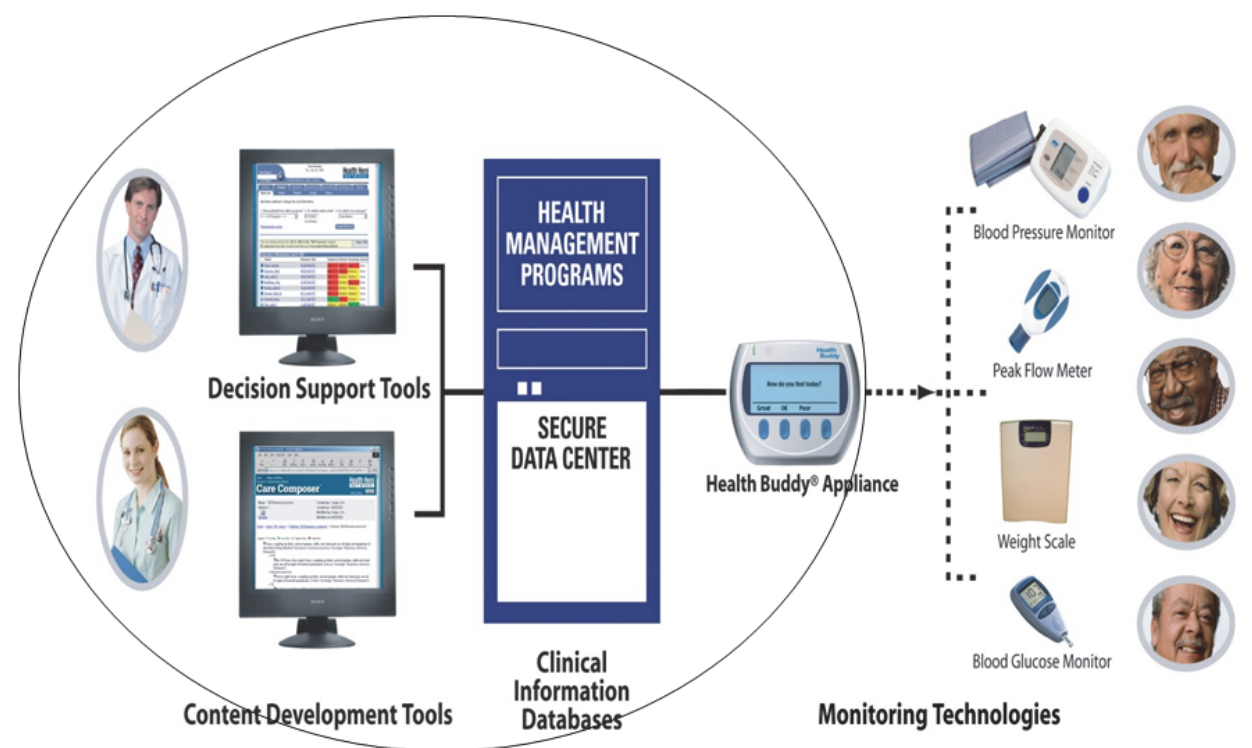

Figure 1 The Health Buddy ${ }^{\circledR}$ system (The devices outside of the ellipse are optional peripherals, however not used in this study)

\section{Evaluation of the Health Buddy ${ }^{\circledR}$ system}

The Health Buddy ${ }^{\circledR}$ system was evaluated in two phases: a feasibility study between September 2004 and March 2005, and the topic of this thesis, a randomised controlled trial, performed between September 2007 and January 2010.

\section{Results of the feasibility study $[39,40]$}

During six months, hundred and one patients of three centres participated in a pilotstudy with a pre-post design, exploring feasibility and acceptability of telemonitoring in patients and caregivers. Two centres were general hospitals; the other centre was a university hospital and functioned as the leading centre. Every hospital has a HF outpatient clinic with specialised cardiologists and HF nurses. Involved patients received the Health Buddy ${ }^{\circledR}$ device, consisting of one single program which was similar for all participants.

During follow-up baseline measurements were performed by means of written questionnaires. After six months the measurements were repeated, supplemented with focus interviews to patients and caregivers.

Written questionnaires assessed disease specific knowledge level, depression, adherence to therapy and self-reported care consumption. Results showed that 108 patients with HF had an improved disease specific knowledge and therapy adherence. 
Patients reported 30\% fewer admissions for HF during follow-up compared to their hospitalisations during the last six months prior to study participation. However, patients' mood was negatively affected as more patients expressed signs of depression.

The focus interviews demonstrated that both patients and caregivers were generally positive about this system. The main finding of the patients was that the Health Bud$d y^{\circledR}$ was user friendly, that they felt safe and experienced a gain in disease specific knowledge. Caregivers were positive about the amount of available information about the patients' condition and about the reliability of the information given by the patients. They were surprised about their misconceptions i.e. overestimation of patients' knowledge and behaviour level, and positive about the insight the system provided into the shortcomings in patients' education. However the time needed to monitor all patients and alerts, and to take action was disappointingly long. This was due to factors as the learning curve to get acquainted with the system and its implementation on top of the regular care. Also during use of the system adjustments were made. Another major time-consuming issue regarded the adjustment of the threshold of the alerts. Inaccurate thresholds led to either the risk for selection or neglecting of the alerts at the caregivers' site. Therefore during the pilot study, the performance of alerts was adjusted to an acceptable, sufficiently safe level.

Both, patients and caregivers independently from each other, asked to pay attention to adjustment of the content of the dialogues, because it was experienced that a single program for all patients did not fit with the needs of many particular patients.

Caregivers desired an integrated algorithm allowing single patient specific sets of dialogues enabling to connecting seamlessly with their conditions and needs at any moment. However, technical developments were not as far developed to be realised yet.

Instead we developed four different programs based on patients' symptoms and behaviour (Table 4) to allow a more tailor made dialogues program for every patient. While no literature was available regarding discriminating patient characteristics to create a tailor made content, a practical approach was chosen. It was realised that patient groups could be discriminated regarding symptoms of heart failure or disease specific knowledge and adherence. Therefore 4 programs were developed putting more or less emphasis on either symptoms or education and adherence (see Table 4) and running over different periods of time. In all patients it was started with a general, 90 days lasting, program (1) with equal emphasis on symptoms and education/adherence. Thereafter it was decided, depending upon the patient needs, to repeat program 1, or move to a program with more emphasis on symptoms (program 2) or on education/adherence (program 3). The length of the programs was variable. Programs focusing on education and lifestyle change had a longer duration than the program solely focusing on symptoms, because an exacerbation mostly is temporary whereas adopting a lifestyle change needs some time. At last a maintenance program (4) was added for patients without symptoms and an excellent education and self-care. 
Program 1: contained a high level of monitoring symptoms and a high level of education: at the start all patients are allocated at this program. Program 2: contained a high level of monitoring symptoms and a lower level of education: patients allocated at this program are indicated for intensive monitoring because of severe HF or many complaints. Their disease specific education level allows a less intensive education program. Program 3: contained a low level of monitoring symptoms and a high level of education: patients with few complaints and a low disease specific education level are allocated to this program. Program 4: contained a low level of monitoring symptoms and a low level of education: patients with few complaints and a high level of disease specific education are allocated to this program.

Table 4 four programs with the focus on symptoms or education

\begin{tabular}{lccc}
\hline & Symptoms & Education / Adherence & Days \\
\hline Program 1 & + & + & 90 \\
Program 2 & + & $+/-$ & 30 \\
Program 3 & - & + & 90 \\
Program 4 & - & - & 180 \\
\hline
\end{tabular}

+ strong focus on; +/- moderate focus on; -less focus on

As a result of the positive experience of the feasibility study it was decided to carry out a multi-centre randomised controlled trial as described in this thesis, regarding aspects such as cost-effectiveness, patient adherence, quality of life, depression and users satisfaction.

\section{Hypothesis and research questions}

The main hypothesis of the study is that telemonitoring of patients with HF is associated with improved outcomes compared to usual care. The overall aim of this thesis is to evaluate the (cost) effectiveness of telemonitoring of patients with HF compared with usual care.

The research questions addressed are:

1. What are the effects of telemonitoring on disease specific knowledge, self-care and adherence of patients with HF? (Chapter 3, 4)

2. What are the effects on care consumption of patients with HF receiving telemonitoring compared with patients receiving usual care? (Chapter 5 )

3. Is telemonitoring of patients with HF more cost effective than usual care? (Chapter 6)

4. What are the effects of telemonitoring on quality of life and depression in patients with HF? (Chapter 7) 
5. What are barriers for implementing telemonitoring in patients with heart failure, from the perspectives of patients, healthcare professionals and health care organisations? (Chapter 8)

After completion of the study, the telemonitoring system was indeed introduced into clinical practice, however slowly and without broad implementation. This led to the additional question regarding the related implementation barriers from different perspectives.

\section{Outline of this thesis}

A general introduction with an overview about the HF syndrome and its impact on patients' daily life, definitions of telemonitoring, and a summary of the feasibility study is given in Chapter 1. It also highlights the importance of patients' involvement in the management for the disease. The design of the study, the methodology and description of the intervention are described in Chapter 2. Chapter 3 describes the results about disease specific knowledge, self-care and depression in one hundred patients during the first three months of the study. Chapter 4 reports about the effects on patients' disease specific knowledge, self-care, self-efficacy and adherence during whole study follow-up. The main results of this study in terms of hospitalisations for HF and mortality are described in Chapter 5. Cost-effectiveness is reported in Chapter 6, whereas Chapter 7 describes effects on quality of life and depression. Chapter 8 describes the barriers on patient, caregivers and organisational level, hindering implementation of telemonitoring. Chapter 9 consists of the general discussion, including methodological considerations as well as implications for clinical practice and recommendations for future research. The thesis is completed with the Summary, CV of the author and the list of publications. 


\section{References}

1. Barrett $D$. The role of telemonitoring in caring for older people with long-term conditions. Nursing Older People 2012; 24(7): 21-5.

2. Dickstein K, Cohen-Solal A, Filippatos G, McMurray JJ, Ponikowski P, Poole-Wilson PA, et al., ESC Committee for Practice Guidelines (CPG). ESC guidelines for the diagnosis and treatment of acute and chronic heart failure 2012: The task force for the diagnosis and treatment of acute and chronic heart failure 2012 of the European society of cardiology. Developed in collaboration with the heart failure association of the ESC (HFA) and endorsed by the European society of intensive care medicine (ESICM). The European Heart Journal 2012; 33: 1787-1847.

3. AHA Science Advisory. Assessment of functional capacity in clinical and research applications. Circulation 2000; 102:1591-7.

4. Kubo SH, Schulman S, Starling RC, Jessup M, Wentworth D, Burkoff D: Development and Validation of a Patient Questionnaire to Determine New York Heart Association Classification. Journal of Cardiac Failure 2004; 10: 3.

5. McMurray JJ, Stewart S. Heart failure: epidemiology, aetiology, and prognosis of heart failure. Heart 2000; 83: 596-602.

6. Stewart S, Maclntyre K, Capewell S, McMurray J. Heart failure and the aging population: an increasing burden in the 21st century? Heart 2003; 89: 49-53.

7. http://www.rivm.nl/bibliotheek/rapporten/260401006.pdf

8. Vrijhoef HJ. Chronicaly ill are the future (in Dutch: Chronisch zieken hebben de toekomst), inaugural speech Tilburg, The Netherlands: Tilburg University 2010.

9. Liao L, Allen LA, Whellan DJ. Economic Burden of Heart Failure in the Elderly. Pharmacoeconomics 2008; 26(6): 447-462.

10. Stewart S, Jenkins A, Buchan S, et al. The current cost of heart failure to the National Health Service in the UK. The European Journal of Heart Failure 2002; 4: 361-71.

11. Formiga F, Chivite D, Manito N, Casas S, Llopis F, Pujol R. Hospitalization due to acute heart failure. Role of the precipitating factors. International Journal of Cardiology 2007; 120(2): 237-41.

12. Tsuyuki RT, McKelvie RS, Arnold JM, Avezum Jr A, Barretto AC, Carvalho AC, Isaac DL, Kitching AD, Piegas LS, Teo KK, et al. Acute precipitants of congestive heart failure exacerbations. Archives Internal Medicine 2001; 161(19): 2337-42.

13. Evangelista LS, Dracup K. A closer look at compliance research in heart failure patients in the last decade. Progress Cardiovascular Nursing 2000; 15: 97-103.

14. Van der Wal MH, Jaarsma T, van Veldhuisen DJ. Non-compliance in patients with heart failure; how can we manage it? The European Journal of Heart Failure 2005; 7: 5-17.

15. Ghali JK. Heart failure and noncompliance in the elderly. Archives Internal Medicine 994; 154(18): 2109-10.

16. Bennett SJ, Huster GA, Baker SL, Milgrom LB, Kirchgassner A,Birt J, Pressler ML. Characterization of the precipitants of hospitalization for heart failure decompensation. American Journal Critical Care 1998; 7(3): 168-74.

17. Jaarsma T, Strömberg A, De Geest S, Fridlund B, Heikkila J, Mårtensson J, Moons P, Scholte op Reimer W, Smith K, Stewart S, Thompson DR: Heart failure management programmes in Europe: European Journal of Cardiovascular Nursing 2006; 5: 197-205.

18. T. Jaarsma: Heart failure management programs: how far should we go? The European Journal of Heart Failure 2003; 5; 215-216.

19. Savard LA, Thompson DR, Clark AM: A meta review of evidence on heart failure disease management programs; the challenges of describing and synthesizing evidence on complex interventions. Trial 2011; 12: 194.

20. McDonald K: Disease Management Programs for Heart Failure Current Treatment Options in Cardiovascular Medicine 2010; 12: 578-586.

21. McAlister FA, Lawson FM, Teo KK, Armstrong PW. A systematic review of randomized trials of disease management programs in heart failure. American Journal of Medicine 2002; 110: 378 -384. 
22. McAlister FA, Stewart S, Ferrua S, McMurray JJ. Multidisciplinary strategies for the management of heart failure patients at high risk for admission: a systematic review of randomized trials. Journal of American College of Cardiology 2004; 44: 810-819.

23. Phillips CO, Wright SM, Kern DE, Singa RM, Shepperd S, Rubin HR. Comprehensive discharge planning with postdischarge support for older patients with congestive heart failure: a meta-analysis. Journal of the American Medical Association 2004; 291: 1358-1367.

24. Galbreath AD, Krasuski RA, Smith B, Stajduhar KC, Kwan MD, Ellis R, Freeman GL. Long-term healthcare and cost outcomes of disease management in a large, randomized, community based population with heart failure. Circulation 2004; 110: 3518 -3526.

25. DeBusk RF, Miller NH, Parker KM, Bandura A, Kraemer HC, Cher DJ, West JA Fowler MB, Greenwald G. Care management for low-risk patients with heart failure: a randomized, controlled trial. Annals of Internal Medicine 2004; 141: 606-613.

26. Wagner EH, Austin BT, Davis C, Hindmarsh M, Schaefer J, Bonomi A "Improving Chronic Illness Care: Translating Evidence into Action." Health Affairs 2001; 20(6): 64-78.

27. Drewes HW, Steuten LM, Lemmens LC, Baan CA, Boshuizen HC, Elissen AM, Lemmens KM, Meeuwissen $\mathrm{JA}$, Vrijhoef HJ. The effectiveness of chronic care management for heart failure: meta-regression analyses to explain the heterogeneity in outcomes. Health Services Research 2012; 47(5): 1926-59.

28. Strömberg A. The crucial role of patient education in heart failure: The European Journal of Heart Failure 2005; 7: 363- 369.

29. McEntee ML, Cuomo LR, Dennison CR. Patient-, provider-, and system-level barriers to heart failure care. Journal of Cardiovascular Nursing 2009; 24(4): 290-8.

30. Shortell SM, Gillies R, Wu F: United States Innovations in Healthcare Delivery; Public Health Reviews 2010; 32(1): 190-212.

31. G Eysenbach. What is e-health? Journal Medical Internet Research 2001; 3(2): e20.

32. http://www2.hull.ac.uk/administration/business/centre-for-telehealth/about-telehealth/what-istelehealth.aspx.

33. Boyne JJJ, Vrijhoef HJM, Spreeuwenberg M, De Weerd GJ, Kragten J, Gorgels APM. Effects of tailored telemonitoring on heart failure patients' knowledge, self-care, self-efficacy, and adherence: a randomized controlled trial. The Journal of Cardiovascular Nursing: DOI: 10.1177/1474515113487464.

34. Cleland JG, Louis AA, Rigby AS, Janssens U, Balk AH; TEN-HMS Investigators. Noninvasive home telemonitoring for patients with heart failure at high risk of recurrent admission and death: the Trans-European Network-Home-Care Management System (TEN-HMS) study. Journal of American College of Cardiology 2005; 45(10): 1654-64.

35. Balk AH, Davidse W, van Dommelen P, Klaassen E, Caliskan K, van der Burgh P, Leenders CM. Teleguidance of chronic heart failure patients enhances knowledge about the disease. A multicentre, randomised controlled study. The European Journal of Heart Failure 2008; 10: 1136-1142.

36. de Lusignan S, Wells S, Johnson P, Meredith K, Leatham : Compliance and effectiveness of 1 year's home telemonitoring. The report of a pilot study of patients with chronic heart failure. The European Journal of Heart Failure 2001; 3(6): 723-30.

37. de Lusignan S, Meredith K, Wells S, Leatham E, Johnson P: A controlled pilot study in the use of telemedicine in the community on the management of heart failure -a report of the first three months. Studies in Health Technology and Informatics 1999; 64: 126-37.

38. Gattis WA, Hasselblad V, Whellan DJ, O'Connor CM. Reduction in heart failure events by the addition of a clinical pharmacist to the heart failure management team: results of the Pharmacist in Heart Failure Assessment Recommendation and Monitoring (PHARM) Study. Archives of Internal Medicine 1999; 159(16): 1939-45.

39. Vrijhoef HJM, Janssen-Boyne JJJ, Engering G., Kragten JA, De Weerd GJ, Frederix M, Gorgels APM. The Health Buddy: telemonitoring system for patients with heart failure. The European Journal of Heart Failure Supplements: June 2006; published online June 2006.

40. http://www.onderzoeksbanklimburg.nl/onderzoeksbank/onderzoek/evaluatie-telebegeleiding-bijhartfalen-tehaf- 



\section{CHAPTER 2}

Telemonitoring in patients with heart failure, the TEHAF-study:

Study protocol of an on-going prospective randomised trial

Josiane J.J.Boyne, Hubertus J.M.Vrijhoef, R.de Wit, Anton P.M.Gorgels

International Journal of Nursing Studies 48 (2011) 94-99 


\section{Abstract}

Background: As the prevalence of heart failure (HF) rises sharply, the costs related to the care of these patients increases in parallel. Considering the already limited resources and manpower, in the future the demand for care may exceed the supply. Therefore, health care systems are encouraged to develop innovative strategies to deal with the burden of HF to improve the quality of care in order to medical outcomes and patients' quality of life. For that reason new management systems - such as telemonitoring - have to be explored.

Objectives: This paper outlines the study protocol of a tailor made telemonitoring program in ambulant patients with HF.

Design and methods: A prospective randomised controlled trial is carried out at 3 hospitals in the South-Limburg area in the Netherlands. Primary outcome measures are hospital admissions and cost effectiveness. Secondary outcomes are effects on therapy compliance, level of disease specific knowledge and quality of life. Also determinants are studied of most and less benefited patients in the intervention group.

Power calculation: It is estimated that 390 patients have to be included in the study, with 185 in each arm.

Results: Inclusion started in September 2007 with a follow up time of 12 months. First results are expected at the end of 2010.

What is already known about this topic?

- Non-adherence resulting in increased hospitalisations is common in patients with HF.

- Telemonitoring is recently developed as part of chronic care management systems in patients with HF; however randomised controlled trials are lacking to proof its (cost-) effectiveness.

- The majority of the telemonitoring systems focuses on vital signs such as blood pressure, rate control and weight.

What does this paper add?

- This paper presents a study of the value of a telemonitoring system, using a randomised controlled trial design.

- It focuses on education, adherence and self-management as a means to reduce symptoms or detect those at an early stage, rather than monitoring just vital signs by using communication programs, tailored to the patients needs.

- To better meet with the specific patient needs, four telemonitoring programs were designed with different emphasis on the dialogues about knowledge, compliance and symptoms respectively. 


\section{Introduction}

The most effective strategies to control chronic diseases contain multiple components as recommended by the European Society Guidelines [1, 2]. Of these components, the most challenging is patient education [3, 4]. Patient education is based on the assumption that giving information results in knowledge and skills gain. The majority of studies shows positive influences on the outcome of HF patients, although it is not clear which information is best for which patient [4]. Although the body of educational programs for heart failure patients is extensive [1], knowledge is limited how these methods match with the patients needs. Moreover, the majority of patients with HF is 65 years of age or older, being a possible challenge for education programs to be effective [4]. Co-morbidities such as diabetes, chronic lung and renal failure, peripheral atherosclerosis, depression and/or personality disorders are additional hurdles for patients to deal with (new) information and about how to deal best with health issues [5, 6].

Patient education is an important component in the management of $\mathrm{HF}$ and should be provided through effective and well-evaluated integrated care strategies. HF education can further be improved by combining oral or written communication with new technologies such as telemonitoring (TM) [7]. Trying to make TM applications generalizable to the HF population at large, may often fail to meet particular patient needs. Therefore subpopulations have been suggested to be categorized based on variables such as age, gender, specific medical problems, chronic disease, or cultural aspects and accordingly education should be adjusted to these categories [8].

This article describes the design of a randomised controlled trial aiming at evaluating a TM system the Health Buddy ${ }^{\circledR}$ in HF patients, using tailor-made TM programs for patients with HF as the intervention, the TEHAF study. The development of the tailormade program is based on the experience with the Health Buddy ${ }^{\circledR}$ in a preceding pilot study in the participating centres of Heerlen (Atrium Medical Centre), Maastricht (University Medical Centre) and Sittard (Orbis Medical and Care Concern), situated in the South-Limburg, the Netherlands [9].

\section{Methods}

\subsection{Study population}

Eligible for inclusion are patients with chronic HF New York Heart Association (NYHA) class II-IV treated by a cardiologist and in care of a HF nurse (HFN). Selection of patients occurs in the outpatient clinic from one of the participating centres and in the home situation when patients are visited by a HFN. Patients are excluded if being unable to give informed consent, have visual limitations, hard of hearing in combination with living as a single person, did not have command of the Dutch language, were planned 
for a hospital admission within 3 months and/or suffer from chronically obstructive pulmonary disease, Parkinson's disease, extracorporeal dialysis, (pre)dementia or another disease with a expectedly shortened life span.

\subsection{Study design}

A prospective, randomised controlled trial is conducted with a follow up period of 12 months. Cardiologists and HFN select patients with HF, whereas the research nurses contact the patient in case of eligibility. After given informed consent, patients are randomised by a dedicated software system (SPSS 15.0) either to the control group, receiving usual care according the European guidelines or to the intervention group, receiving the Health Buddy ${ }^{\circledR}$. Before start of the intervention (TO) patients fill out a questionnaire. Patient's baseline characteristics are retrieved from the medical chart. Follow up questionnaires are released after 3, 6, 9 and 12 months (Figure 1).

\subsection{Study hypotheses}

The hypotheses are tested that the admission rate for HF is lower in the intervention group than in the control group and that TM is cost-effective compared with usual care.

\subsection{Primary objective}

The primary objectives are to study the effectiveness of the Health Buddy ${ }^{\circledR}$ in terms of hospital admissions for HF and cost effectiveness, as expressed in costs per quality adjusted life years (QALY's). Also quality of care is studied, comprising mortality, planned and unplanned HF related contacts with caregivers.

\subsection{Secondary objectives}

Secondary objectives are:

1. to study outcomes in terms of therapy adherence, level of disease specific knowledge and quality of life;

2. to demonstrate patient determinants affecting the outcomes of the Health Buddy ${ }^{\circledR}$ in terms of care consumption, level of knowledge and adherence. 


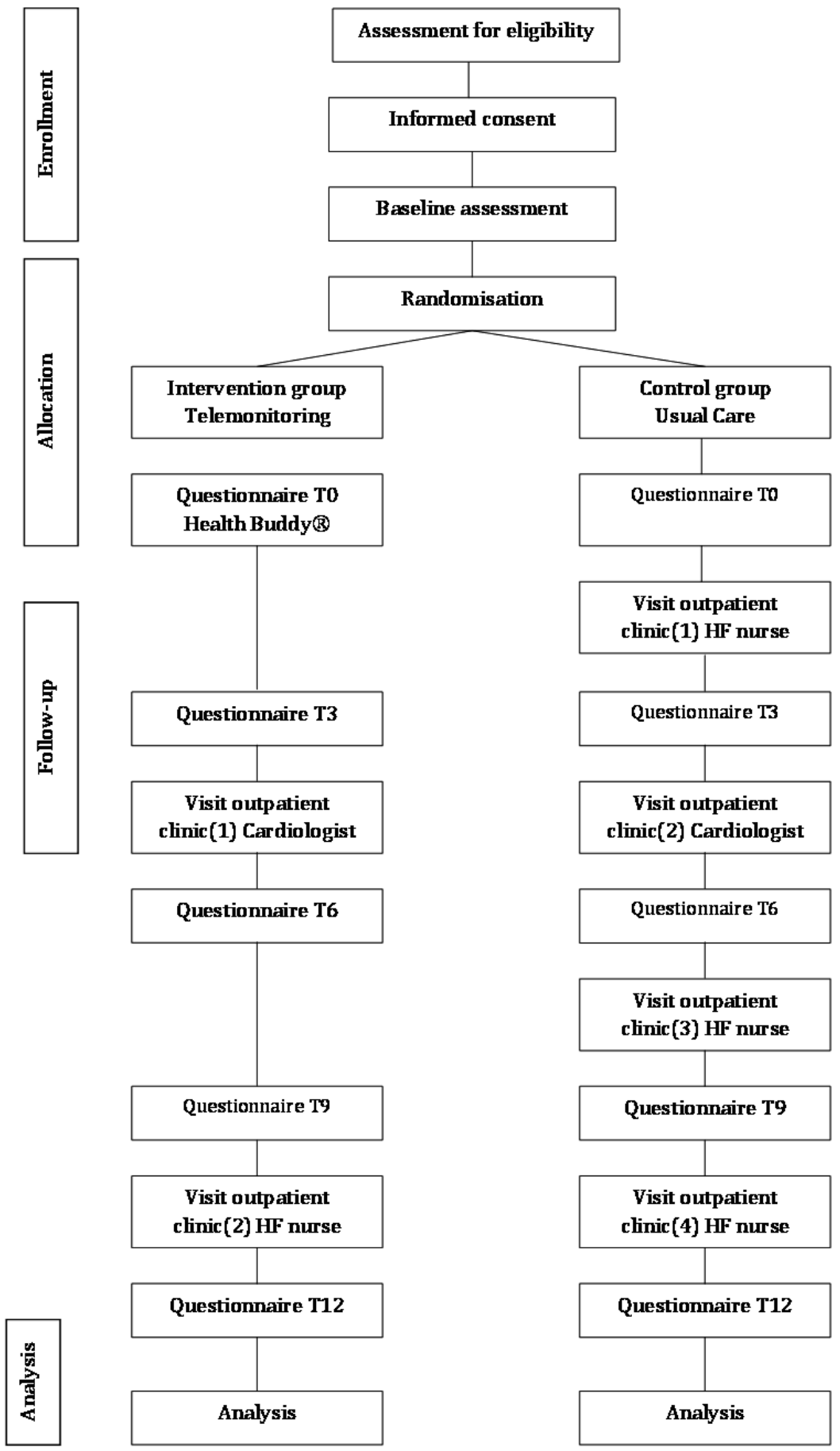

Figure 1 Consort flowchart 


\section{Intervention}

\subsection{The Health Buddy ${ }^{\circledR}$}

The Health Buddy ${ }^{\circledR}$ is an easy-to-use device with a liquid crystal display screen and four buttons to answer questions provided in daily dialogues. The responses to the dialogues are sent to a protected server and successively to the caregivers' i-Care desktop (Figure 2).

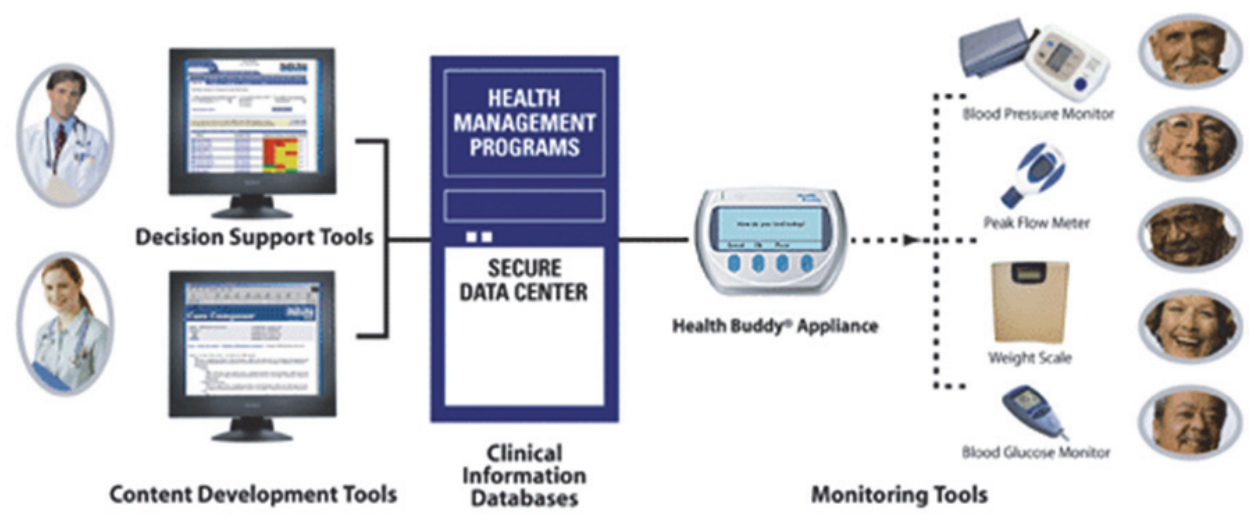

Figure 2 The Health Buddy ${ }^{\circledast}$ system

Patients' responses to the dialogues are transferred into risk profiles (low, medium or high) and ordered according to risk level. Consequently, care providers are able to quickly select high-risk patients and anticipate to their problem. The involved care providers consist of specialized HFNs, a nurse assistant and a supervising cardiologist. The HFNs are highly educated in chronic heart failure at the level of an advanced medical student, and are very experienced regarding HF care. The nurse assistant is a caregiver at a lower educational nursing level being instructed before and coached by a HFN during the study.

The original English content of the Health Buddy ${ }^{\circledR}$ was translated into Dutch by the distributing company (Sananet) and adapted to the Dutch health care situation and European guidelines [1] by a cardiologist (A.G.) and a HF nurse practitioner (J.B.). Sananet was responsible for the final layout whereas the health care providers were finally responsible for the content.

\subsection{Content of the program}

The content of the Health Buddy ${ }^{\circledR}$ covers scheduled dialogues about three domains: symptoms, knowledge and behaviour respectively. The total amount of dialogues 
counts 145 different combinations, yet the combination of dialogues changes day by day. The questions are answered by selecting one of the four keys. If the answer is correct, this is confirmed by the system, whereas in case of an incorrect response, the right answer is provided. In this way knowledge increases both by correcting and by repetition of dialogues.

In case of repeated mistakes after 3 months, the nurse assistant will contact the patient and explain the misunderstood issues. Patients at high risk for symptoms will always be approached by a HFN since the start of the program.

\subsection{The tailor-made aspects of the content}

Primarily the goal of the foregoing feasibility study was to study whether patients were able to handle a TM system, and secondly that the provided information was sufficient for care providers to monitor patients at a distance. Focused interviews with patients and HFNs showed a high satisfaction with the system, but a need was felt for more flexibility of the content, regarding the emphasis of monitoring in relation to knowledge and behaviour or to symptoms [9]. Because no such differentiated TM contents were available, self-designed combinations of dialogues were used for that purpose. The first step to tailor the content was the assessment of distinguishing characteristics in $\mathrm{HF}$ patients, regarding symptoms, level of disease specific knowledge and behaviour [10, 11]. Out of a combination of these characteristics four programs are constructed. The main difference between the programs is more or less emphasis on symptoms or education. The duration of the programs differs from 30 to 180 days (Table 1 ).

Table 1 Tailor-made programs

\begin{tabular}{lccc}
\hline & Symptoms & Education / Adherence & Days \\
\hline Program 1 & + & + & 90 \\
Program 2 & + & $+/-$ & 30 \\
Program 3 & - & + & 90 \\
Program 4 & - & - & 180 \\
\hline
\end{tabular}

+ strongly focused on; +/- moderate focused on; -less focused on.

Program1: contains a high level of monitoring symptoms and a high level of education: at the start all patients are allocated at this program;

Program 2: contains a high level of monitoring symptoms and a lower level of education: patients allocated at this program are indicated for intensive monitoring because of severe heart failure or many complaints. Their disease specific education level allows a less intensive education program;

Program 3: contains a low level of monitoring symptoms and a high level of education: patients with few complaints and a low disease specific education level are allocated to this program;

Program 4: contains a low level of monitoring symptoms and a low level of education: patients with few complaints and a high level of disease specific education are allocated to this program. 
During the first 90 days all patients receive the same program. At the last day of each program a calculation is made about the number of high risk labels in the last 30 days. The result of this calculation indicates the allocation to the next program (Figure 3).

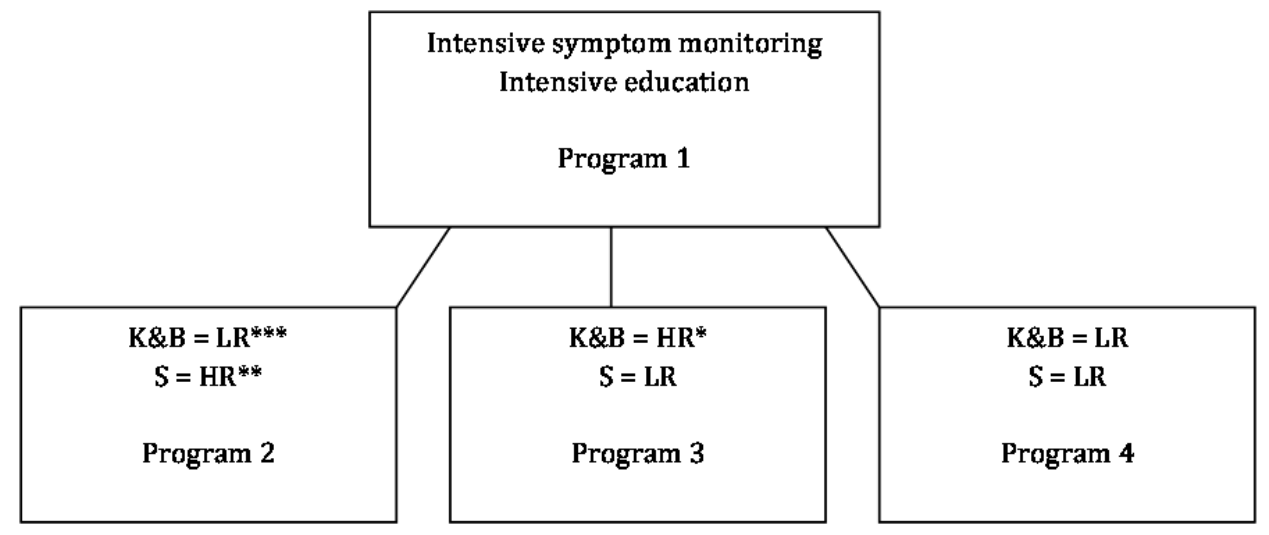

Figure 3 Program overview

$\mathrm{K} \& \mathrm{~B}=$ Knowledge $\&$ Behaviour, $\mathrm{S}=$ symptoms, $\mathrm{HR}=$ high risk, $\mathrm{LR}=$ low risk

* $\mathrm{K} \& \mathrm{~B}=\mathrm{HR}$ : an amount equal or more then 4 high risk alerts on knowledge or behaviour, or the sum of both during the last 30 days;

** $\mathrm{S}=\mathrm{HR}$ : an amount of 4 high risk alerts on symptoms during the last 30 days, or 2 high risk alerts on symptoms during the last 15 days, or 1 high risk alert on symptoms during the last 7 days;

$* * * \mathrm{~K} \& \mathrm{~B}=\mathrm{LR}$ (or) $\mathrm{S}=\mathrm{LR}$ : none or less $\mathrm{HR}$ alerts as described in $\mathrm{K} \& \mathrm{~B}=\mathrm{HR}$ or $\mathrm{S}=\mathrm{HR}$.

Always the decision is made about allocation to a next level program as described in Figure 3, except for two situations. The first situation is after a HF admission: then always allocation to program 2 is done for the duration of 30 days, independent of the preceding program before admission. The second exception regards patients waiting for heart transplantation; they always are allocated to program 2.

Another way to tailor the program, additional to the before mentioned programs, is the possibility to switch off parts of the content. This can be used in case specific information is not applicable for a certain patient, such as information about nitroglycerine, beta-blocker, ACE-inhibitors, ARB antagonists, potassium saving diuretics and digitalis.

\subsection{Procedure}

Patients complete the daily dialogs on a self-selected moment. The pilot study showed that depending on the answers, the time to complete the dialogues varies between 3 and 10 minutes. The Health Buddy ${ }^{\circledR}$ gives an option to review the dialogues at the end of the session. 
The HFN and nurse assistant check the dialogues on a daily basis except for the weekends. The mean handling time per patient was previously found to be $2 \mathrm{~min}$. and 20 sec. per day including both checking the dialogues and the related actions [9].

Patients, spouse or family member in the intervention as well as in the control group receive verbal and written information according to the European Guidelines [1]. Patients are instructed about signs and symptoms of HF, self management as actively seeking help in case of progressive dyspnoea, weight gain and oedema, importance of medical and non-medical therapy compliance, salt and fluid restriction, importance of physical activity and other, more patient tailored, information. Instructions were given for seeking help outside the office hours. The information supplied by the TM system is additional to the usual care information.

For the intervention group 2 face-to-face contacts per year were scheduled consisting of 1 to the cardiologist and another 1 to the HFN. Telephone contacts with the HFN or nurse assistant in response to a Health Buddy ${ }^{\circledR}$ alert, were considered as planned contacts. Patients assigned to the control group were planned to have 4 visits, including 1 to the cardiologist and 3 to the HFN (Figure 1). Unscheduled contacts with a care provider were allowed at any time for both patient groups. In two of the participating centres, depending on patients' mobility, contacts with the HFN took place either in the outpatient clinic or by a home visit.

\section{Study measures}

\subsection{Instrumentation}

All patients are asked to fill out an extensive questionnaire at baseline $\left(T_{0}\right)$, after 3,6 and 9 months and after the follow-up period of one year $\left(T_{12}\right)$. Information is gathered about prescription of medication, medical history and socio-demographics. Measurement of quality of life occurs by means of Kansas City Cardiomyopathy Questionnaire (KCCQ) [12] and the EQ 5D [13]; disease specific knowledge by the Dutch Heart Failure Knowledge Score (DHFKSc) [14] and self management by the European Heart failure Self Care Behaviour Scale (EHFSCB) [15]. Adherence for pharmacological and nonpharmacological prescriptions and depression are measured by respectively the Heart Failure Compliance Questionaire (HFCQ) [16] and the Hospital Anxiety and Depression Scale (HADS) [17]. Dyspnea and tiredness are assessed by the Borg scale [18], selfefficacy by the Barnason Efficacy Expectation Scale [19] and personal individual characteristics by the DS-14 [20]. Care consumption and mortality are based on hospital registration, costs by hospital registration and a cost-diary filled out by the patients. Comorbidity is assessed by the Charlson index [21] (Table 2). 
Table 2 Measurements table

\begin{tabular}{ll}
\hline & Assessment \\
\hline Cardiovascular hospitalisation / death & 12 months \\
Co morbidity & 12 months \\
Self Care & Baseline, 3, 6, 9, 12 months \\
Compliance & Baseline, 3, 6, 9, 12 months \\
Dyspnea / tiredeness & Baseline, 3, 6, 9, 12 months \\
Depression & Baseline, 3, 6, 12 months \\
Self efficacy & Baseline, 3, 6, 12 months \\
Disease specific Quality of life & Baseline, 3, 6, 12 months \\
Quality of live (costs) & Baseline, 3, 6, 12 months \\
Disease specific knowledge & Baseline, 3, 6, 9, 12 months \\
Personal individual characteristics & Baseline \\
Classification of heart failure & Baseline, 12 months \\
Costs & Baseline, 3, 6, 9, 12 months \\
\hline
\end{tabular}

\subsection{Power}

A sample size of 188 patients in both arms was calculated, based on a minimum reduction of $38 \%$ and a maximum reduction of $48 \%$ for hospitalisation for heart failure [ 9 , $22,23]$, using an alpha of 0.05 and a power of 0.80 . To compensate for non-evaluable patients, we planned to enrol $10 \%$ more patients for both groups. Therefore, a total of 390 patients will enrol into the study.

\subsection{Statistical analysis}

Data will be analysed according to the intention-to-treat principle, using SPSS statistical software (SPSS 15.0). Stratified data analysis per centre will be performed. The primary objective, number of admissions for heart failure will be evaluated by the Kaplan Meier survival analysis. Categorical variables will be presented as the observed number and percentage, whereas the continuous variables will be reported as the mean standard deviation. Differences for continuous variables will be tested with the independent $t$ test. Further multivariate techniques will be used to adjust for possible differences in baseline characteristics and scores. Comparison of observations between the groups, considering the different locations will be analysed by the MAN(C)OVA test for repeated measures. The $P$-value of $<0.05$ will be considered as statistically significant.

\subsection{Clinical endpoint}

An independent panel, consisting of an independent HF cardiologist (chairman), geriatrist and nephrologist, is compiled to adjudicate whether hospitalisation and / or death 
is related to $\mathrm{HF}$ in terms of this protocol. The committee is blinded to study arm assignment, and members independently review each case in order to classify a HF related admission or death. The independent opinions are reconciled at a panel meeting. In case of lacking unanimity, the case is discussed during the meeting with the aim to develop consensus. By unremitting non-unanimity the endpoint will be established by the chairman.

\section{Acknowledgments}

This study is being conducted within the Department of Integrated Care and the Department of Cardiology of the Maastricht University Medical Centre, the departments of Cardiology of the Orbis Medical Centre of Sittard and Atrium medical Centre of Heerlen in cooperation with the Department of Health Care and Nursing sciences, and the School for Public Health and Primary Care (CAPHRI) at Maastricht University.

\section{Funding}

The study is carried out by unrestricted grants from the Government of the Province Limburg, Rescar Foundation, Annadal Foundation, pharmaceutical industry Astra Zeneca, department of Integrated Care of the Maastricht University Medical Centre, the administration of the University Maastricht and of the Maastricht University Medical Centre. 


\section{References}

1. Dickstein K. et al., 2008. ESC Guidelines for the diagnosis and treatment of acute and chronic heart failure. The European Journal of Heart Failure 933-989. http://www.escardio.org/guidelines-surveys/escguidelines/GuidelinesDocuments/guidelines-HF-EJHF.pdf

2. Coleman K, Austin BT, Brach, C, Wagner H. Evidence on the chronic care model in the new millennium. Health Affairs 2009; 28(1): 75-85.

3. McAlister FA, Stewart S, Ferrua S, McMurray J. Multidisciplinary Strategies for the Management of Heart Failure Patients at High Risk for Admission: A Systematic Review of Randomized Trials. Journal of the American College of Cardiology 2004; 44 (4).

4. Yu DSF, Thompson DR, Lee DTF. Disease management programmes for older people with heart failure: crucial characteristics which improve post-discharge outcomes. The European Heart Journal 2006; 27: 596-612.

5. Sloan RS, Pressler SJ. Cognitive deficits is heart failure: Re-cognition of vulnerability as a strange new world. Journal of Cardiovascular Nursing 2009; 24(3): 241-8.

6. Braunstein JBAG, Anderson GF, Gerstenblith G, Weller W, Niefeld M, Herbert R, Wu AW. Noncardiac comorbidity increases preventable hospitalizations and mortality among medicare beneficiaries with chronic heart failure. Journal of the American College of Cardiology 2003; 42(7).

7. Strömberg A. The crucial role of patient education in heart failure. European Journal of Heart Failure 2005; 7: 363-369.

8. Alverson DA, Holtz B, D'lorio J, DeVany M, Simmons S, Poropatich RK. One Size Doesn't Fit All: Bringing Telehealth Services to Special Populations. Telemedicine and e-Health 2008; 14(9): 957-963.

9. Boyne JJ, Vrijhoef HJM, de Wit R, Kragten J, Platteel P, de Weerd GJ, Oude Hengel H, Gorgels APM. Telemonitoring in patients with heart failure: a feasibility study (TEHAF). European Journal of Cardiovascular Nursing 2008; 7(S1): 20-21.

10. Van der Wal MHL, Jaarsma T, Moser DK, Veeger NJGM, Wiek H, van Gilst WH, Van Veldhuisen, DJ. Compliance in heart failure patients: the importance of knowledge and beliefs. European Heart Journal 2006; 27(4): 434-440.

11. Miller-Davis C, Marden S, Kline Leidy N. The New York Heart Association Classes and functional status: What are we really measuring? Heart Lung 2006; 35: 217-224.

12. Green CP, Porter CB, Bresnahan DR, Spertus JA. Development and evaluation of the Kansas City Cardiomyopathy Questionnaire: a new health status measure for heart failure. Journal of the American College of Cardiology 2000; 35(5): 1245-55.

13. Brooks R, Rabin R, de Charro F. The measurement and valuation of health status using EQ-5D: a European perspective. Kluwer Academic Publishers 2003;ISBN 1-4020-1214-4

14. Van der Wal MHL, Jaarsma T, Moser DK, Veldhuisen van DJ. Development and testing of the Dutch Heart Failure Knowledge Scale. European Journal of Cardiovascular Nursing 2005; 4(4); 273-7.

15. Jaarsma T, Strömberg A, Märtenson J. Development and testing of the EuropeanHeart Failure Self-Care Behaviour Scale. European Journal of Heart Failure 2003; 5(3): 363-70.

16. Evangelista LS, Berg J, Dracup K. Relationship between psychosocial variables and c compliance in patients with heart failure. Heart \& Lung 2001; 30(4): 294-301.

17. Zigmond AS, Snaith RP. The hospital anxiety and depression scale. Acta Psychiatrica Scandinavica 1982; 67(6): 361-370.

18. Borg GA. Psychophysical bases of perceived exertion. Medical Science of Sports Exercise 1982; 14: 37781.

19. Barnason S, Zimmerman L. Nieveen J. Schmaderer M. Development of a self-efficacy instrument for coronary artery bypass graft (CABG) patients. Journal of Nursing Measurement 2002; 10(2): 23-133.

20. Denollet, J. DS14: Standard Assessment of Negative Affectivity, Social Inhibition, and Type D Personality. Psychosomatic Medicine 2005; 67: 89-97.

21. D'Hoore W, Bouckaert A, Tilquin C. Practical Considerations on the Use of the Charlson Comorbidity Index with Administrative Data Bases. Clinical Epidemiology 2009; 49 (12): 1429-1433. 
22. Benatar D, Bondmass M, Ghitelman J, Avitall B. Outcomes of Chronic Heart Failure: Archives of Internal Medicine 2003; 163: 347-352.

23. Macropoulos LR, Knoop JD. CHF hospital admissions reduced by $57 \%$ ( 0.234 PPPY) in medicare population and 48\% (0.299 PPPY) in commercial population using advanced home monitoring program in large patient population. Journal of Cardiac Failure 2003; 9(5): S1-103. 



\section{CHAPTER 3}

Adherence among telemonitored patients with heart failure to pharmacological and non-pharmacological recommendations (preliminary results)

Bram L.T. Ramaekers, Josiane J.J. Janssen-Boyne, Anton P.M. Gorgels,

Hubertus J.M. Vrijhoef

Adapted from: Telemedicine and e-Health volume 15 (6) July / August 2009 


\section{Abstract}

Objective: Adherence among HF patients is regarded as an important proxy for outcomes such as hospitalisations, morbidity, mortality and costs. In many health care systems these outcomes are in need for improvement. By applying telemonitoring, this study aimed to assess its short-term impact on patients' disease specific knowledge, adherence and depression.

Materials and Methods: As part of a larger trial, this study reports preliminary findings amongst 101 patients from three Dutch hospitals. Patients were randomised to receive care using telemonitoring or standard care. Data concerning patients' disease specific knowledge, adherence to pharmacological and non-pharmacological recommendations and depression were collected by postal questionnaires. In this study, data collected before randomization and three months afterwards were analysed.

Results: Disease specific knowledge improved significantly in two of the three hospitals $(P<0.001$ and $P=0.040)$. Adherence in terms of fluid restrictions $(P=0.012)$, daily weighing $(P<0.001)$, physical exercising $(P=0.034)$ and alcohol restrictions $(P=$ 0.040 ) improved significantly in the telemonitoring group. Additional, in contrast with the hypothesized increase of depression, the use of telemonitoring resulted in a substantial (not significant) decrease in depression using multivariate regression analyses.

Conclusion: The improved adherence rates within the three month study period underscores the potential of telemonitoring to enhance self-management among HF patients and consequently its potential impact on outcomes. Longer-term results will enable to reach solid conclusions concerning the relation between telemonitoring and patients' adherence. 


\section{Introduction}

As the prevalence of heart failure (HF) is epidemically rising, also the costs related to the care for these patients are dramatically increasing $[1,2]$. In developed countries, it is estimated that HF consumes $1-2 \%$ of the total healthcare budget, and these costs are expected to rise unless the number of hospitalisations falls [1]. If this epidemic of HF continuous, considering the already limited resources and manpower in healthcare, the demand for care will exceed its supply. Therefore, healthcare systems are encouraged to develop innovative strategies to deal with the economic burden of HF as well as improving the quality of care to enhance medical outcomes and patients' quality of life. The impact HF possesses on patients is significant; as a result of the high number of hospitalisations, depression, anxiety and symptoms like dyspnoea, oedema and low exercise tolerance, their quality of life decreases considerably [3, 4].

To guide healthcare in the direction to solve these shortcomings, the implementation of enhanced communication systems possibly is an adequate strategy. In this direction, telemonitoring could be a useful tool. Even though research concerning telemonitoring for patients with HF is still in its infancy, the available evidence is promising [5, $6]$. The Health Buddy ${ }^{\circledR}$ system is such a promising telemonitoring device, which provides daily dialogs to chronically ill patients $[7,8]$. These dialogs make frequently monitoring of patients possible and accordingly enable healthcare providers to detect highrisk cases in an early stage. Consequently, anticipating on high risk cases could prevent deteriorations in patients' health status and thus prevent (re)hospitalisations. Further, the Health Buddy ${ }^{\circledR}$ system also aims to educate and counsel patients to change their health behaviour towards the disease and to increase their self-management ability.

In the scope of behaviour change, there is much to gain since adherence to medical regimes is still a serious problem in chronic diseases in general and also within patients diagnosed with HF $[9,10]$. The potential of telemonitoring to improve patients' adherence to medical regimes should not be undervalued. By improving adherence, telemonitoring is expected to have an impact on the rate of disease progression and mortality, whilst improving the quality of life $[10,11]$. Furthermore, improved patients' adherence (especially with drug therapy) is beneficial to the healthcare system, because drug therapy is one of the most cost-effective interventions. By preventing relatively expensive hospitalisations (50\% of HF hospitalisations are associated with poor medication and dietary adherence [14], telemonitoring has the potential to reduce total healthcare costs $[1,11-14]$.

Against this background, the aim of this study is to analyse to what extent telemonitoring, i.e. the Health Buddy ${ }^{\circledR}$ system, has impact on the adherence among HF patients within a period of three months. In the first three months the Health Buddy ${ }^{\circledR}$ offers an intensive educational program to all patients, focused on monitoring and recognizing symptoms, disease specific knowledge and patients' adherence. Adherence, in this study, is related to eight health behaviours: taking the prescribed medication, appoint- 
ment keeping, keeping diet (specifically this includes sodium restrictions, fluid restrictions and daily weighing), performing physical exercise, smoking cessation, and minimizing the intake of alcohol. In addition to patients' adherence, also the effect of telemonitoring on disease specific knowledge is analysed, as increasing disease specific knowledge is essential to increase patients' adherence [10]. Besides disease specific knowledge also a huge amount of other variables are assumed to affect adherence to pharmacological regimes. This includes depression, which is associated with nonadherence [15]. An earlier non-controlled study in the Netherlands, reported that the use of the Health Buddy ${ }^{\circledR}$ system was associated with increased feelings of depression [8]. Hence, the impact of telemonitoring on feelings of depression and their possible role on adherence is also analysed.

Safety concerns were the main reasons to analyse the preliminary results of this study. Therefore possible adverse effects of telemonitoring (i.e. the role of depression) are monitored and although the acceptability of telemonitoring devices among HF patients in general is not considered as a problem $[6,8]$, this should also be evaluated on the short term.

\section{Materials and Methods}

The included patients originally participate in a one year lasting RCT, which considers the cost-effectiveness of telemonitoring using the Health Buddy ${ }^{\circledR}$ system [16]. In this paper, preliminary data of 101 patients enrolled during the first 3 months of the trial, were analysed.

The intervention group consisted of 56 patients using telemonitoring on a daily basis. These patients received a Health Buddy ${ }^{\circledR}$ device in their home environment; the Health Buddy ${ }^{\circledR}$ device is an easy to use device with a big screen and four buttons to answer the questions provided in the daily dialogs. By means of the dialogs, the Health Buddy ${ }^{\circledR}$ system aims to monitor these patients and to increase their disease specific knowledge. Additionally, by educating and counselling HF patients, the Health Buddy ${ }^{\circledR}$ system aims to improve patients' adherence to pharmacological and non-pharmacological recommendations.

The gathered information (using the telemonitoring device) is sent to a protected server and subsequently to the caregivers' i-Care desktop. Subsequently, the data are transferred into risk profiles (low, medium or high), depending on patients' response to the dialogues. This is done for three categories (symptoms, health behaviour/life style and disease specific knowledge). Consequently, care providers are enabled to quickly select high-risk patients and anticipate on this. The clinical care provided to patients in the intervention group is to a high extend identical among the three participating hospitals, since use was made of national guidelines for the treatment of HF [17]. 
The control group consisted of 45 patients receiving usual care without the Health Bud$\mathrm{dy}^{\circledR}$ system. Also in the control group, clinical care was highly standardized among the three participating hospitals. All patients receive information about their disease and are accompanied by a specialized nurse. However, despite these standardized procedures, there remain some differences between the three hospitals (i.e. in providing information and in the follow-up), these differences may induce inter-hospital variation in the control group.

Main data were collected using the Dutch Heart Failure Knowledge Scale (ranging from 0-15)[18], the Heart Failure Compliance Scale (ranging from 0\%-100\%) [19] and the Hospital Anxiety and Depression Scale (depression scale ranges from 0-21) [20]. Considering the data gathered using the Heart Failure Compliance Scale, patients' adherence is considered sufficient if the score is $\geq 75 \%$ [19]. Furthermore, data were collected at two points in time, a pre-measurement before randomization (T0) and three months after randomization (T3). Data-analysis took place by means of descriptive statistics, chi-square tests and multivariate regression analyses, which are performed using SPSS 12.0.1 with an apprehended $\alpha$ of 0.05. Furthermore, multivariate regression models were checked for possible significant interaction terms and covariates. In addition, to correct for possible demographic differences and variations induced by the differences in care provided by the three hospitals (inter-hospital variation), also the hospital that is responsible for the treatment of patients (Heerlen, Maastricht or Sittard) is considered in all analyses.

\section{Results}

The mean age of patients is 72.7 ( $s d=9.5$ ) years in the intervention group and 70.4 ( $s d$ $=10.5$ ) years in the control group. A majority of patients $(51.5 \%)$ is treated in Maastricht and for more than a third of the patients is primary school the highest completed education. Amongst respondents, the majority is male (Table 1). After performing Chisquare tests, no significant differences were found in the basic characteristics, which indicate that the control group and intervention group are comparable. 
Table 1 Characteristics of the population $(\mathrm{N}=101)$

\begin{tabular}{|c|c|c|c|c|c|c|}
\hline \multirow[t]{2}{*}{ Characteristic } & \multicolumn{2}{|c|}{ Intervention group } & \multicolumn{2}{|c|}{ Control group } & \multicolumn{2}{|c|}{ Total } \\
\hline & $\mathrm{n}$ & $\%$ & $\mathrm{n}$ & $\%$ & $\mathrm{n}$ & $\%$ \\
\hline \multicolumn{7}{|l|}{ Hospital } \\
\hline Maastricht & 28.0 & 50.0 & 24.0 & 53.3 & 52.0 & 51.5 \\
\hline Heerlen & 16.0 & 28.6 & 11.0 & 24.4 & 27.0 & 26.7 \\
\hline Sittard & 12.0 & 21.4 & 10.0 & 22.2 & 22.0 & 21.8 \\
\hline \multicolumn{7}{|l|}{ Sex } \\
\hline Male & 34.0 & 60.7 & 28.0 & 62.2 & 62.0 & 61.4 \\
\hline Female & 22.0 & 39.3 & 17.0 & 37.8 & 39.0 & 38.6 \\
\hline \multicolumn{7}{|l|}{ Highest completed education } \\
\hline None & 1.0 & 1.8 & 0.0 & 0.0 & 1.0 & 1.0 \\
\hline Primary school & 25.0 & 44.6 & 13.0 & 28.9 & 38.0 & 37.6 \\
\hline Middle secondary school & 9.0 & 16.1 & 11.0 & 24.4 & 20.0 & 19.8 \\
\hline Higher secondary school & 2.0 & 3.6 & 3.0 & 6.7 & 5.0 & 5.0 \\
\hline Lower professional school & 12.0 & 21.4 & 10.0 & 22.2 & 22.0 & 21.8 \\
\hline Middle professional school & 3.0 & 5.4 & 5.0 & 11.1 & 8.0 & 7.9 \\
\hline Higher professional school or University & 4.0 & 7.1 & 3.0 & 6.7 & 7.0 & 6.9 \\
\hline
\end{tabular}

\section{Disease Specific Knowledge}

Disease specific knowledge measured at T0 is high (average score of 12.5 on a $0-15$ scale), over time disease specific knowledge increased in the whole intervention group (all three hospitals). In the analyses an interaction term emerged, which indicated that the effect of telemonitoring on the disease specific knowledge differs among the three participating hospitals. Therefore, disease specific knowledge is considered per hospital. The disease specific knowledge increased significantly in two (Maastricht and Heerlen) of the three participating hospitals (Table 2).

Table 2 Disease specific knowledge and results of the multivariate regression analyses $(\mathrm{N}=101)^{\mathrm{a}}$

\begin{tabular}{|c|c|c|c|c|c|c|c|c|c|}
\hline \multirow[t]{2}{*}{ Knowledge } & \multicolumn{3}{|c|}{ Intervention group } & \multicolumn{3}{|c|}{ Control group } & \multirow[t]{2}{*}{ Difference $^{b}$} & \multirow[t]{2}{*}{$\beta^{c}$} & \multirow{2}{*}{$\begin{array}{c}\text { Significance } \\
\text { (p-value) }\end{array}$} \\
\hline & TO & T3 & $\Delta$ & TO & T3 & $\Delta$ & & & \\
\hline Maastricht & 12.9 & 13.6 & 0.6 & 11.6 & 11.4 & -0.2 & 0.8 & 1.349 & 0.000 \\
\hline Heerlen & 12.1 & 13.1 & 1.0 & 12.8 & 13.5 & 0.7 & 0.3 & -0.031 & 0.944 \\
\hline Sittard & 13.2 & 13.4 & 0.3 & 13.6 & 12.7 & -0.9 & 1.2 & 0.976 & 0.040 \\
\hline
\end{tabular}

${ }^{\mathrm{a}} \mathrm{TO}$ is the pre-measured score, T3 is the score after 3 months and $\Delta$ is the difference between those two measurements. For the multivariate regression analyses, knowledge at T3 was considered as dependent variable.

${ }^{\mathrm{b}}$ This variable is the result of: $\Delta$ intervention group $-\Delta$ control group

${ }^{c}$ The $\beta$ value expresses the difference in adherence between the intervention- and the control group 


\section{Adherence}

Both patient groups indicated at T0 average adherence rates for appointment keeping, taking prescribed medication, smoking cessation and alcohol restrictions of $89 \%$ or higher. Medium adherence rates among patients were measured for daily weighing, sodium and fluid restrictions (averages between $70.0 \%$ and $75.0 \%$ ) and low rates for physical exercising (on average $<65.0 \%$ ).

In the multivariate regression analyses concerning patients' health behaviours, no significant interaction terms or covariates emerged. Additionally, at T3 high scores without variance were reported for medication adherence (mean $=100 \%$ ). Consequently, it was not possible to perform a regression analyses for this constant variable.

The Health Buddy ${ }^{\circledR}$ system significantly affected four health behaviours; patients who were using the Health Buddy ${ }^{\circledR}$ system indicated on average a higher score for adhering to their fluid restriction, adhering to weighing recommendations, following the exercising recommendations and adhering to their alcohol restrictions (Table 3).

Table 3 Self-reported adherence and results of the multivariate regression analyses $(N=101)^{a}$

\begin{tabular}{|c|c|c|c|c|c|c|c|c|c|}
\hline \multirow{2}{*}{$\begin{array}{l}\text { Adherence by } \\
\text { health behavior }\end{array}$} & \multicolumn{3}{|c|}{ Intervention group } & \multicolumn{3}{|c|}{ Control group } & \multirow{2}{*}{$\begin{array}{c}\text { Difference }^{\mathrm{b}} \\
(\%)\end{array}$} & \multirow[t]{2}{*}{$\beta^{c}$} & \multirow{2}{*}{$\begin{array}{c}\text { Significance } \\
\text { (p-value) }\end{array}$} \\
\hline & $\begin{array}{l}\text { T0 } \\
\text { (\%) }\end{array}$ & $\begin{array}{l}\mathrm{T} 3 \\
(\%)\end{array}$ & $\begin{array}{c}\Delta \\
(\%)\end{array}$ & $\begin{array}{l}\text { T0 } \\
(\%)\end{array}$ & $\begin{array}{l}\mathrm{T} 3 \\
(\%)\end{array}$ & $\begin{array}{c}\Delta \\
(\%)\end{array}$ & & & \\
\hline Appointment & 96.0 & 93.3 & -2.7 & 95.6 & 97.2 & 1.6 & -4.3 & -3.965 & 0.264 \\
\hline Medication $^{d}$ & 99.6 & 100.0 & 0.4 & 99.4 & 100.0 & 0.6 & -0.2 & n.a. & n.a. \\
\hline Sodium & 75.9 & 78.6 & 2.7 & 73.3 & 74.4 & 1.1 & 1.6 & 2.617 & 0.359 \\
\hline Fluid & 79.0 & 87.1 & 8.1 & 68.9 & 71.1 & 2.2 & 5.9 & 10.296 & 0.012 \\
\hline Weighing & 75.0 & 91.7 & 16.7 & 69.6 & 67.4 & -2.2 & 18.9 & 20.803 & 0.000 \\
\hline Exercise & 64.7 & 72.3 & 7.6 & 58.0 & 57.2 & -0.8 & 8.4 & 10.331 & 0.034 \\
\hline Smoking $^{\mathrm{e}}$ & 95.5 & 95.1 & -0.4 & 93.3 & 94.4 & 1.1 & 1.6 & -1.349 & 0.342 \\
\hline Alcohol & 91.5 & 96.9 & 5.4 & 89.4 & 89.4 & 0.0 & 5.4 & 6.681 & 0.040 \\
\hline
\end{tabular}

${ }^{\mathrm{a}}$ TO is the pre-measured score, T3 is the score after 3 months and $\Delta$ is the difference between those two measurements. For the multivariate regression analyses, T3 scores for health behaviors were considered as dependent variables.

${ }^{\mathrm{b}}$ This variable is the result of: $\Delta$ intervention group $-\Delta$ control group

${ }^{c}$ The $\beta$ value expresses the difference in adherence between the intervention- and the control group

${ }^{d}$ It is not possible to perform a regression analyses for this constant variable

${ }^{\mathrm{e}}$ This percentage also includes patients who did not smoke before participating in the study

\section{Depression}

In the multivariate regression analyses concerning depression, no significant differences emerged. However, when comparing the mean depression scores for the control group and the intervention group over time, a decreased depression score was found in the intervention group (Table 4). 
Table 4 Average self-reported depression and results of the multivariate regression analyses $(\mathrm{N}=101)^{\mathrm{a}}$

\begin{tabular}{|c|c|c|c|c|c|c|c|c|c|}
\hline \multirow[t]{2}{*}{ Depression } & \multicolumn{3}{|c|}{ Intervention group } & \multicolumn{3}{|c|}{ Control group } & \multirow[t]{2}{*}{ Difference $^{b}$} & \multirow[t]{2}{*}{$\beta^{c}$} & \multirow{2}{*}{$\begin{array}{c}\text { Significance } \\
\text { (p-value) }\end{array}$} \\
\hline & TO & T3 & $\Delta$ & TO & T3 & $\Delta$ & & & \\
\hline Depression & 6.5 & 5.4 & -1.1 & 6.5 & 6.4 & $0.0^{d}$ & -1.1 & -0.825 & 0.118 \\
\hline
\end{tabular}

${ }^{\mathrm{a}}$ T0 is the pre-measured score, T3 is the score after 3 months and $\Delta$ is the difference between those two measurements. For the multivariate regression analyses, T3 scores for health behaviors were considered as dependent variables.

${ }^{\mathrm{b}}$ This variable is the result of: $\Delta$ intervention group $-\Delta$ control group

${ }^{c}$ The $\beta$ value expresses the difference in adherence between the intervention- and the control group

${ }^{d}$ This value is 0.0 because of rounding

\section{Discussion}

In the preliminary results of this study it is found that the Health Buddy ${ }^{\circledR}$ system is accountable firstly, for an increase in disease specific knowledge within HF patients treated in two of the three participating hospitals. Since knowledge of patients in the third hospital increased considerable in both, the intervention group and the control group, no significant difference between the two groups was found here.

Secondly, the Health Buddy ${ }^{\circledR}$ system might be cited for the increased adherence rates in case of adhering to fluid restrictions, daily weighing, physical exercising and recommendations concerning alcohol consumption. These effects are established within a period of three months, which is rather impressive considering the life style changes needed to achieve these improvements in patients' adherence over such a short follow-up period. Although it needs to be seen if these patients are able to maintain these life style changes over a longer period of time, the improvements in knowledge scores gain trust in the impact of telemonitoring.

With regard to the relation between the Health Buddy ${ }^{\circledR}$ system and depression a noticeable result is found. In contrast with the hypothesized increase of depression, a decreased depression is measured in the intervention group. Although, the difference was not statistical significant, it is substantial and over a longer follow-up period potentially significant.

\section{Limitations of the study}

Questionnaires used to assess patients' adherence in this study are based on selfreported values. It is suggested that this is a subjective way of measuring adherence and therefore has often higher outcomes than objective ways of measuring adherence [21]. People often have the tendency to present themselves in the best light since they consider this as socially more desirable (i.e. response bias) [22, 23]. However, selfreported adherence is mostly a good predictor for future adherence [24]. Therefore, effects of response bias in this study should not be exaggerated. 
Data are checked for the assumptions of linear regression (normality, linearity, and equality of variance). Although the visual evaluation of the normality plots is good, because of outliers the assumption concerning normality of residuals is not always met. This is likely a consequence of the relative small sample size and it implicates that some $p$-values and confidence intervals reported in the result section might be biased. However, this does not bias the direction of the reported effects nor the reported $\beta$ 's.

\section{Related Studies}

Currently, literature concerning the effectiveness of telemonitoring for HF is quite limited [5]. Moreover, consequences of telemonitoring for patients' adherence remain infrequently reported in the available studies and therefore solid evidence on this topic is lacking. However, as a result of the increasing number of RCT's and as information and communication technologies become normalized into medical practice, the evidence body is expected to enlarge considerably next decade [6].

A small study $(\mathrm{N}=20)$ with one-year follow-up analyses the relation between telemonitoring and patients' adherence [25]. The control group in the study received care as usual and the intervention group received care, using telemonitoring. This randomised pilot study, suggested that telemonitoring improves HF patients' adherence in terms of daily weighing, measuring pulse and blood pressure [25]. Further, two studies $\left(\mathrm{N}=52\right.$ and $\mathrm{N}=108$ ) with a pretest-posttest design, using the Health Buddy ${ }^{\circledR}$ system as intervention, also showed a trend which suggests telemonitoring has the potential to improve patients' adherence $[8,26]$. However, with regard to the limited patient sample and the used research design, it is not certain whether these effects are caused only by telemonitoring.

Studies using different interventions to improve patients' adherence to pharmacological and non-pharmacological recommendations among HF patients do exist. The Health Buddy ${ }^{\circledR}$ system tries to improve patients' adherence to pharmacological and non-pharmacological recommendations by educating and counselling them. In a review by Van der Wal et al. [10], looking at interventions focusing on education and counselling with HF patients, it was found that "education and counselling might have an important role in improving adherence". Also, in a recent multicentre randomised trial ( $N=1023,17$ centres) with a follow-up of 18 months, it seems that nurse-led education and counselling significantly improves adherence rates of non-pharmaceutical behaviours in HF patients [27].

Further, another large scale multicentre randomised trial ( $N=1518,51$ centres) with a mean follow-up period of 16 months, reported positive effects of education and counselling on patients' adherence. Authors reported an improved diet and medication adherence among HF patients assigned to the intervention group [28]. 


\section{Implications for Practice}

In addition to other tools, telemonitoring can contribute to an increased adherence to non-pharmacological recommendations among HF patients on the short term. Moreover, telemonitoring seems to have a pleasant side effect, that is an increased feeling of safety perceived by HF patients [8]. Based on this, healthcare providers should consider involving telemonitoring to their arsenal of treatment possibilities, on the conditions that patients have a positive attitude towards telemonitoring and that there is a need for it. To realize this, health insurance companies should facilitate telemonitoring, to ensure that the delivery of telemonitoring is not only on temporary basis, as it currently is in most cases. For the suppliers of telemonitoring, there are directions given in this article for the further development of their product. In this process, suppliers should cooperate with researchers to determine objectively whether the product is actually improved in terms of better patient outcomes and cost-effectiveness.

Implementing telemonitoring in clinical practice incorporates more than adding a treatment option; it requires redesigning the care process. It is likely that this will also affect the positions of stakeholders. Considering that telemonitoring potentially prevents hospitalisations and the external funding of the participating hospitals being based on the number of hospitalisations and length of stay, their participation in this study can be considered as positively remarkable.

\section{Implications for Further Research}

Mostly, objectives in telemonitoring research are to determine outcomes in terms of patients' quality of life, number of hospitalisations, morbidity, mortality and/or costs. Ultimately those outcomes are what matters most in policy making. However, improved medical outcomes are often driven by better adherence and with regard to the diversity of telemonitoring interventions and HF patients, research concerning process indicators such as patients' adherence, possibly increases insights why certain telemonitoring interventions are more (cost-) effective than others. Which is crucial to decisions concentrating on the strategy how to apply telemonitoring to HF populations [5]. Implementing telemonitoring in clinical practice requires rearranging the care process. In addition to the outcomes like quality of life, hospitalisations morbidity, mortality and costs, adherence should therefore be studied in telemonitoring research and as patients' adherence often deteriorates over time [11], preferably it should be studied over a longer time span. Furthermore, to measure patients' adherence, valid and reliable measures should be developed and used [10]. Especially in medication adherence, self-reported data may be biased.

When using telemonitoring systems it could be an effective strategy to anticipate on the characteristics of patients. Especially in changing the behaviour of patients (what most telemonitoring systems are intending to do) this could be effective. It is not recommended to change the personal characteristics of patients, because it is majorly 
heritable and hard to change [29]. However, it could be used to predict outcomes and anticipate on this. For example, if someone scores high on a depression scale this person is less inclined to follow the medical regimes than someone who scores low for this scale [23]. Therefore, telemonitoring systems should be adjusted to the needs of certain vulnerable subgroups in the population (e.g. depressive subgroups or subgroups with low social support).

These (vulnerable) subgroups possibly help to explain differences in adherence behaviour and/or in the effectiveness of telemonitoring systems, therefore they should be revealed. Some authors report that paying more attention to factors such as depression may result in a decreased number of hospitalisations [30].

\section{Conclusions}

It can be concluded that telemonitoring devices such as the Health Buddy ${ }^{\circledR}$ system have the potential to increase the disease specific knowledge in HF patients. Further, also the possibility of telemonitoring to improve adherence to non-pharmacological recommendations such as fluid restrictions, daily weighing, physical exercising and alcohol restrictions is demonstrated in this study. However, telemonitoring might be less effective for certain subgroups in the population and the effects of telemonitoring on adherence in HF patients should be monitored over a longer time span than three months and in a larger sample to reach more solid conclusions, which is expected in the further course of the RCT used in this article. Nevertheless, the reported improvements in patients' adherence within a time span of three months, underscores the potential of telemonitoring to improve self-management among HF patients; which may improve patients' health status and quality of life, reduce healthcare utilization (e.g. the number of hospitalisations and the number of appointments) and accordingly yield cost savings. Therefore, telemonitoring is a promising method to improve adherence in HF patients and to cope with the burden of HF on both the patients and the healthcare system. 


\section{References}

1. Berry C, Murdoch D, R. , McMurray J, J. V. Economics of chronic heart failure. European journal of Heart Failure 2001; 3(3): 283-91.

2. Whellan DJ. Heart failure disease management: implementation and outcomes. Cardiology in Review 2005; 13(5): 231-9.

3. Lainscak M, Keber I. Patient's view of heart failure: from the understanding to the quality of life. European Journal of Cardiovascular Nursing 2003; 2(4): 275-81.

4. McMurray JJV, Petrie MC, Murdoch DR, Davie AP. Clinical epidemiology of heart failure: public and private health burden. European Heart Journal 1998; 19 Suppl P: P9-16.

5. Chaudhry SI, Phillips CO, Stewart SS, Riegel B, Mattera JA, Jerant AF, et al. Telemonitoring for patients with chronic heart failure: a systematic review. Journal of Cardiac Failure 2007; 13(1): 56-62.

6. Clark RA, Inglis SC, McAlister FA, Cleland JGF, Stewart S. Telemonitoring or structured telephone support programmes for patients with chronic heart failure: systematic review and meta-analysis. British Medical Journal 2007; (5) 334(7600): 942.

7. Boyne J, Vrijhoef HJM, Wit R, Kragten J, Platteel P, Weerd GJ, et al. Telemonitoring in patients with heart failure: A feasibility study (TEHAF). European Journal of Cardiovascular Nursing 2008; 7: S20-S1.

8. Vrijhoef HJM, Boyne J, Engering W, Gorgels APM. Telebegeleiding bij hartfalen: haalbaarheidsonderzoek van de Health Buddy ${ }^{\circledR}$ [Telemonitoring in heart failure: feasibility study of the Health Buddy ${ }^{\circledR}$. Maastricht: azM/UM; 2005.

9. Evangelista LS, Doering LV, Dracup K, Westlake C, Hamilton M, Fonarow GC. Compliance behaviors of elderly patients with advanced heart failure. Journal of Cardiovascular Nursing 2003; 18(3): 197-206-quiz 7-8.

10. Van der Wal MHL, Jaarsma T, Veldhuisen DJ. Non-compliance in patients with heart failure; how can we manage it? European Journal of Heart Failure 2005; 7: 5-17.

11. Evangelista LS, Dracup K. A closer look at compliance research in heart failure patients in the last decade. Progress in Cardiovascular Nursing 2000; 15(3): 97-103.

12. Lee WC, Chavez YE, Baker T, Luce BR. Economic burden of heart failure: a summary of recent literature. Heart \& lung 2004; 33(6): 362-71.

13. Giordano A, Scalvini S, Zanelli E, Corrà U, Longobardi GL, Ricci VA, et al. Multicenter randomised trial on home-based telemanagement to prevent hospital readmission of patients with chronic heart failure. International Journal of Cardiology 2009; 131(2): 192-199.

14. Heidenreich PA, Ruggerio CM, Massie BM. Effect of a home monitoring system on hospitalization and resource use for patients with heart failure. American Heart Journal 1999; 138(4): 663-40.

15. Van der Wal MHL, Jaarsma T. Adherence in heart failure in the elderly: Problem and possible solutions. International Journal of Cardiology 2008; 125(2): 203-8.

16. Vrijhoef H. Telemonitoring in patients with heart failure (TEHAF 2). 2008 [cited 02-12-2008]; Available from: http://clinicaltrials.gov/ct2/show/NCT00502255

17. Nederlandse Vereniging voor Cardiologie [Dutch Association of Cardiology]. Multidisciplinaire richtlijn chronisch hartfalen [Multidisciplinary guideline chronic heart failure]. 2002 [cited 05-12-2008]; Available from: http://www.cbo.nl/product/richtlijnen/folder20021023121843/rl_hartfalen_2002.pdf

18. Van der Wal MHL, Jaarsma T, Moser DK, van Veldhuisen DJ. Development and testing of the Dutch Heart Failure Knowledge Scale. European Journal of Cardiovascular Nursing 2005; 4(4): 273-7.

19. Evangelista LS, Berg J, Dracup K. Relationship between psychosocial variables and compliance in patients with heart failure. Heart \& Lung 2001; 30(4): 294-301.

20. Croon EM, Nieuwenhuijsen K, Hugenholtz NIR, Dijk FJH. Drie vragenlijsten voor diagnostiek van depressie en angststoornissen [Three questionnaires to diagnose depression and anxiety]. 2005 [cited 02-04-2008]; Available from: http://www.psychischenwerk.nl/datafiles/Drie\%20vragenlijsten\%20voor\%20diagnostiek.pdf

21. Jaarsma T, Abu-Saad HH, Dracup K, Halfens R. Self-care Behaviour of Patients with Heart Failure. Scandinavian Journal of Caring Sciences 2000; 14: 112-9. 
22. Polit DF, Beck CT. Nursing Research: principles and methods. 7 ed. Philadelphia: Lippincott Company; 2003.

23. Van der Wal MHL. Compliance in heart failure patients; who cares? [Thesis]. Groningen: Rijksuniversiteit Groningen; 2007.

24. Brink-Muinen A, Dulmen AM. Factoren gerelateerd aan farmacotherapietrouw van chronisch zieken: Resultaten van studies uitgevoerd in Nederland sinds 1990 [Factors related to adherence of chronic ill patients: results of studies performed since 1990 in the Netherlands]. Utrecht: NIVEL; 2004.

25. De Lusignan S, Wells S, Johnson P, Meredith K, Leatham E. Compliance and effectiveness of 1 year's home telemonitoring. The report of a pilot study of patients with chronic heart failure. The European journal of Heart Failure 2001; 3(6): 723-30.

26. Bigelow JH, Cretin S, Solomon M, Wu S-Y, O'Connell M. Patient Compliance With and Attitudes Towards Health Buddy ${ }^{\circledR}$. 2000 [cited 17-03-2008]; Available from: http://stinet.dtic.mil/oai/oai?verb=getRecord\&metadataPrefix=html\&identifier=ADA381865

27. Van der Wal MHL, Jaarsma T. Nurse-led intervention can improve adherence to non-pharmacological treatment in heart failure patients (Data from the $\mathrm{COACH}$ study). European Journal of Cardiovascular Nursing 2008; 7: S41.

28. Gesica Investigators. Randomised trial of telephone intervention in chronic heart failure: DIAL trial. British Medical Journal 2005; 331(7514): 425-30.

29. Ranchor AV. Wat zijn mogelijke gezondheidsgevolgen van persoonlijkheidskenmerken? [What are possible health consequences resulting from personality characteristics?]. Nationaal Kompas Volksgezondheid 2007 [cited 02-04-2008]; Available from: http://www.rivm.nl/vtv/object_document/o5621n18953.html

30. MacMahon KMA, Lip GYH. Psychological Factors in Heart Failure: A Review of the Literature. Archives of Internal Medicine 2002; 162: 509-16. 



\section{CHAPTER 4}

\section{Effects of tailored telemonitoring on heart}

failure patients' knowledge, self-care, self-efficacy and adherence:

\section{A randomised controlled trial}

Josiane J.J. Boyne, Hubertus J.M. Vrijhoef, Marieke Spreeuwenberg, Gerjan De Weerd, Johannes Kragten, Anton P.M. Gorgels

Published online 29 April 2013 European Journal of Cardiovascular Nursing DOI: $10.1177 / 1474515113487464$ 


\section{Abstract}

Background: The education of patients with heart failure (HF) is an essential part of disease management. The perspectives of an increasing number of patients and a shortage of professionals force healthcare to explore new strategies in supporting patients to be better informed and more active.

Methods: Three hundred and eighty-two patients with HF (age 71, SD 11.2 years) were randomly assigned to either a telemonitoring or a usual care group. Patients received four postal questionnaires to assess their levels of self-reported knowledge, selfcare, self-efficacy and adherence. Generalized estimating equations analysis was performed to assess the effects of telemonitoring during the 1-year follow-up. Corrections for baseline were performed if needed.

Results: Baseline differences between groups were found for self-care $(p=0.001)$ and self-efficacy $(p=0.024)$. Knowledge of patients in the telemonitoring group significantly improved with 0.9 point on a 15 -points scale $(p<0.001)$. Their self-care abilities improved with 1.5 point on a 12-item scale whereas no changes were found in patients receiving usual care $(p<0.001)$. Self-efficacy of patients in the intervention group improved significantly after 6 months yet was not significantly different after 3 months and 1 year. For patients in the intervention group adherence improved for daily weighing $(p<0.001)$ during the whole follow-up and for fluid intake $(p=0.019)$ after 3 months and after 12 months $(p=0.086)$. Adherence for activity recommendations improved $(p=0.023)$ after 3 months and importance of medication adherence increased after 6 $(p=0.012)$ and 12 months ( $p=0.037)$. No effects were found regarding appointments, diet, smoking and use of alcohol.

Conclusions: Tailored telemonitoring was found to educate patients with $\mathrm{HF}$ and to improve their self-care abilities and sense of self-efficacy.

Keywords: Heart failure, telemonitoring, knowledge, self-care, adherence, self-efficacy 


\section{Introduction}

Chronic heart failure (HF) causes a burden for patients, their environment and healthcare resources $[1,2]$. Deterioration of HF is often the result of patients' therapy non-adherence [3]. Paradoxically, HF deterioration demands optimizing therapy and therapy adherence, yet the increased complexity of the treatment regimen is expected to result in a decrease in patient compliance [4]. HF symptoms are mostly caused by hemodynamic imbalance, and optimizing hemodynamic by pharmacologic and nonpharmacologic therapy requires patients' cooperation and participation [5], which may be expressed as self-care abilities. Self-care management refers to decision making in response to signs and symptoms. In HF, self-care management requires that patients recognize a change (such as increasing oedema), evaluate the change and decide to take action, implement a treatment strategy and evaluate the response to the treatment implemented. The difficulty patients have in detecting and interpreting their symptoms has led to interest in remote monitoring and devices to monitor fluid accumulation, which could improve outcomes [6].

To achieve good medical outcomes, on-going and repeated education of patients with HF is needed $[7,8]$. The telemonitoring system in the current study provides repetitive tailor-made disease specific information and self-care support. The hypothesis is that repeated, tailored and dosed information will improve patients' disease-specific knowledge level and enhance self-care, leading to increased self-efficacy and better adherence. In published telemonitoring studies, little is reported on the effects of knowledge and self-care [9-11], self-efficacy [11] or therapy adherence [12-15]. Moreover, when reporting about adherence it is mostly focused on medication, blood pressure, body weight and use of the system, rather than on compliance for salt restriction, physical activity or appointments with caregivers. In addition, the studies are mostly small or pilot studies without a control group. Although non-compliance is recognized in patients with HF, it remains unclear which intervention is successful in improving patients' compliance to non-pharmacologic therapy and evidence-based interventions to improve compliance in patients with HF are scarce [16]. Therefore, the aim of this prospective randomised multicentre telemonitoring study is to analyse the effects of telemonitoring on disease specific knowledge, self-efficacy, self-care and adherence.

\section{Methods}

\section{Population}

Three hundred and eighty two consecutive patients with HF who were classified by the New York Heart Association (NYHA) with class II-IV HF visiting the outpatient clinic of one of three hospitals in the South of the Netherlands were included in the study com- 
paring telemonitoring with usual care (TEHAF) [17]. HF was defined as at least one episode of fluid retention requiring diuretics, either with an echocardiographic left ventricular ejection fraction $\leq 40 \%$ or a preserved ejection fraction with diastolic dysfunction. Further inclusion criteria for patients were age $\geq 18$ years, the ability to provide informed consent and that they were being treated by a HF nurse together with a cardiologist. Patients were excluded if operating the Health-Buddy ${ }^{\circledR}$ (the telemonitoring device) was physically or cognitively impracticable, if suffering from Chronic Obstructive Pulmonal Disease Gold-classification 3 or 4 , if receiving haemodialysis or in case of a disease with an expectedly shortened life span [17]. In contrast to other studies, a prior admission for HF [18-20] was not a prerequisite for inclusion.

\section{Study design}

Between October 2007 and December 2008, 382 patients were assigned to a study arm [Figure 1] using a computer-generated randomization procedure. Patients of the usual care group received oral and written information, had an easy access to the HF nurse and four planned outpatient clinic visits during follow-up. Patients of the telemonitoring group received identical information but only two planned outpatient clinics.

The telemonitoring device (Health Buddy ${ }^{\circledR}$ ) has a liquid crystal display and four keys connected to a landline phone. Patients received daily pre-set dialogues and questions about their symptoms, knowledge and behaviour, which had to be answered by touching one of the keys. Subsequently the answers were sent via a protected server to the nurses' desktop. During this process responses were transferred into risk profiles (low, medium, high) [17], allowing the nurse to quickly identify high-risk patients. Positive answers for symptoms were transferred into a high-risk alert and triggered immediate action by the HF nurse. In case patients gave an incorrect answer-not necessarily a high risk-to a knowledge or behaviour issue, the device automatically provided the correct answer. This was visible in the display, aiming an increase of patients' disease specific knowledge and behaviour. A HF nurse and a nurse assistant led the process: the nurse assistant took care of educational and general high-risk alerts, such as persistent lack of adherence or symptoms of depression [17]. High-risk alerts for knowledge or behaviour indicate a lack of knowledge or behaviour, being a risk factor for deterioration. For example, if a patient did not know that increasing weight is a risk factor (knowledge) or did not frequently weigh themselves (behaviour), there is a risk of deterioration. In such cases the nurse-assistant contacted the patient to identify and discuss the underlying problem. In case of depression, patients were contacted and evaluated for related support. To tailor the program content and meet with personal specific needs on treatment or education, we created four sets of dialogues with variable emphasis on symptoms, knowledge and behaviour [17]. At the start of the study all patients received the same initial set of dialogues, being evenly balanced for symptoms and education. After 3 months the first evaluation of symptoms and education level occurred, followed 
by allocation to the best fitting next program, either an educational or an intensive symptom-monitoring program. This evaluation was based on the number of high-risk alerts during the last 30 days before the end of a program. At any moment during the study re-allocation to another program was possible, aiming to maintain with the best fitting dialogues set [17]. Following an admission for HF, patients were always reallocated to an intensive symptom monitoring set of dialogues. Monitoring of vital signs was not part of the system.

\section{Data collection and instruments}

This study evaluated the level of disease-specific know-ledge, self-care, self-efficacy and adherence to therapy. Data were collected by four postal questionnaires. Knowledge on HF and the regimen was measured with the Dutch Heart Failure Knowledge Scale, which consists of 15 multiple-choice items (0-15). This scale is a reliable and valid instrument to measure knowledge on HF in general, symptom recognition and HF treatment. Higher scores indicate more knowledge [21]. Self-care behaviour was measured with the 12-item European Heart Failure Self-Care Behaviour Scale (EHFSCB), which is a reliable and valid scale to measure self-care behaviour. The items are rated on a 5-point scale between 1 (completely agree) and 5 (completely disagree), with lower scores indicating that the patient performs more self-care behaviour [22].

The 15-item Barnason Efficacy Expectation Scale assessed self-efficacy. Items are rated from on a 5-point scale between 0 (completely disagree) to 4 (completely agree) [23], with higher scores indicating patients had more confidence. To assess compliance, the Heart Failure Compliance Scale was used [24]. In this questionnaire, the following six health behaviours were identified; appointment-keeping, medication, sodium restriction, fluid restriction, daily weighing and exercise. Patients were firstly asked to state how important the health behaviour was by using a 5-point scale ranging from 0 (not at all important) to 4 (highly important). Finally, compliance was measured on a 5point Likert scale (0, never; 1 , seldom; 2 , half of the time; 3 , mostly; and 4, always). Higher scores indicate better adherence. 


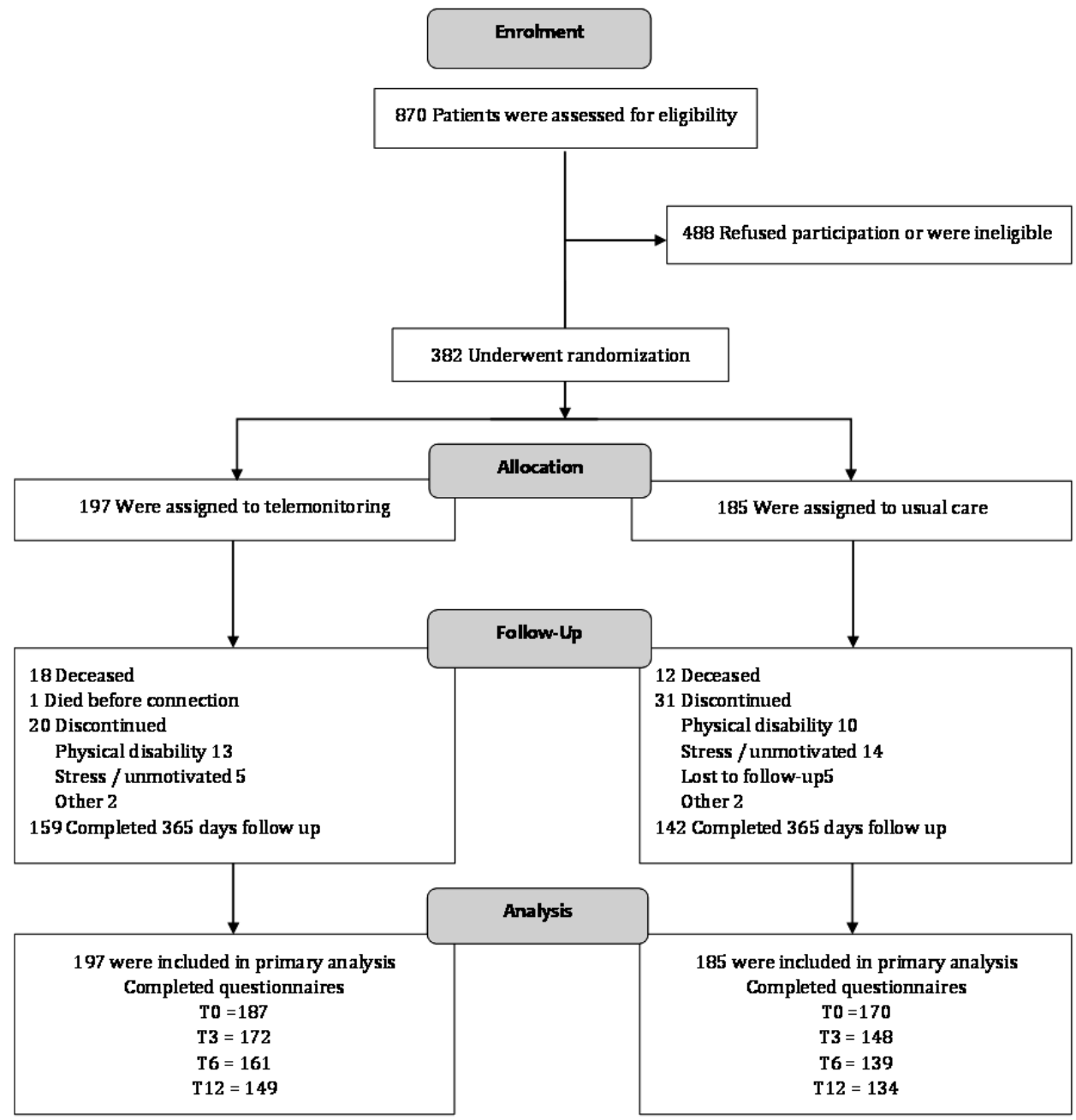

Figure 1 CONSORT flow diagram

\section{Sample size}

Sample size calculation was based on admissions for HF. Usual-care 1-year follow-up admission rate was estimated at $25 \%$. To detect a reduction of $25 \%$ to $12.5 \%$ in $\mathrm{HF}$ hospitalisations with a two-sided $95 \%$ significance, a power of 0.80 and $10 \%$ loss-tofollow-up, a sample size of 195 patients per group was needed.

\section{Data analysis}

Demographic interval and ratio variables were investigated for normality of distribution with the Shapiro-Wilk test. If normally distributed, means and standard deviations are 
given, otherwise score ranges are provided. Categorical variables are presented as frequencies and percentages. Univariate statistics on differences of baseline variables were calculated by the Student t-test if normally distributed or if not by the MannWhitney test.

The effects on knowledge, self-care, self-efficacy and adherence in time (baseline, T3, T6, T12) were assessed with generalized estimating equations analysis (GEE). GEE was used to correct for the dependency of the observations in time and for the difference of the time periods between the follow-up measurements. The method of GEE is often used to analyse longitudinal and other correlated response data. GEE takes into account the correlational nature of repeated measures data within subjects and securing minimal loss of patients due to incomplete data. Data imputation is not executed because when using GEE to analyse a longitudinal dataset, imputation of missing data has no value above non-imputation [25].

A structured covariance matrix was used in the GEE analysis. As independent variables three dummy variables for time, group (usual care versus intervention) and interaction effects between group and the dummy variables of time were included. The analyses were corrected for baseline differences. Differences were considered statistically significant when $p$-values were smaller than 0.05 . SPSS version 18 was used. Data analysis was based on the intention to treat principle.

\section{Results}

\section{Baseline characteristics}

Of the 382 patients included, 197 were allocated to the intervention group and 185 to the usual-care group. Mean age was 71 (32-93) and $45 \%$ were $\geq 75$ years old; $59 \%$ were male and $64 \%$ lived with a partner; $57 \%$ were in NYHA-functional class II, $40 \%$ in class III and $3 \%$ in class IV. Mean left ventricular ejection fraction was $0.38 ; 61 \%$ were $\leq 0.45$ and $50 \%$ had ischemic heart disease. Study arms were well balanced regarding baseline characteristics. Use of HF medication was high (Table 1). Follow-up was incomplete in $81(21 \%)$ cases -43 in the usual-care and 38 in the intervention-arm-due to death, increasing physical impairment, stress or losing motivation. 
CHAPTER 4

Table 1 Baseline characteristics

\begin{tabular}{|c|c|c|c|c|}
\hline Variable & $\mathbf{N}$ & Intervention (197) & Control (185) & $p$-value \\
\hline Age & 382 & $71.0 \pm 11.9$ & $71.9 \pm 10.5$ & 0.621 \\
\hline Range $^{*}$ & & $32-72-91$ & $37-74-93$ & \\
\hline$\geq 75$ & & $88(44.7)$ & $85(46.5)$ & 0.199 \\
\hline Gender & 382 & & & 0.747 \\
\hline Male & & $115(58.4)$ & $111(60.0)$ & \\
\hline Female & & $82(41.6)$ & $74(40.0)$ & \\
\hline Married / partner & 379 & $122(62.6)$ & $123(66.8)$ & 0.265 \\
\hline Education / no (\%) & 363 & 190 & 173 & 0.589 \\
\hline Primary school & & $63(33)$ & $59(34)$ & \\
\hline Second.sch. /Low vocational training & & $91(48)$ & $71(41)$ & \\
\hline Middle Vocational training & & $19(10)$ & $23(13)$ & \\
\hline High vocational / university & & $17(9)$ & $20(12)$ & \\
\hline History of HF (months) & 382 & $32( \pm 38)$ & $29( \pm 38)$ & 0.413 \\
\hline NYHA-classification / no (\%) & 382 & & & 0.404 \\
\hline NYHA II & 219 & $110(28.8)$ & $109(28.5)$ & \\
\hline NYHA III & 153 & $79(20.7)$ & $74(19.4)$ & \\
\hline NYHA IV & 10 & $8(2.1)$ & $2(0.5)$ & \\
\hline Blood pressure & 382 & & & \\
\hline Systolic & & $125 \pm 21.9$ & $128 \pm 24.0$ & 0.156 \\
\hline Diastolic & & $72 \pm 12.5$ & $74 \pm 12.2$ & 0.193 \\
\hline Heart rate & 382 & $77 \pm 15.1$ & $75 \pm 13.8$ & 0.252 \\
\hline \multicolumn{5}{|l|}{ Medication } \\
\hline Diuretics & 380 & $170(86.3)$ & $163(88.1)$ & 0.783 \\
\hline ACE inhibitors & 378 & 113 (57.9) & $104(56.8)$ & 0.826 \\
\hline ATII-antagonists & 373 & $67(34.7)$ & $56(31.1)$ & 0.459 \\
\hline Bèta-blockers & 379 & $161(82.6)$ & $149(81.0)$ & 0.689 \\
\hline Digoxin & 372 & $46(23.8)$ & $45(25.1)$ & 0.770 \\
\hline Nitrates & 376 & $64(33.2)$ & $72(39.3)$ & 0.212 \\
\hline Statins & 377 & $111(57.5)$ & $107(58.2)$ & 0.900 \\
\hline Coumarins & 377 & 119 (61.0) & $95(52.2)$ & 0.084 \\
\hline ASA & 373 & $60(31.1)$ & $71(39.4)$ & 0.091 \\
\hline Charlson index & 382 & $2.6( \pm 1.5)$ & $2.4( \pm 1.4)$ & 0.358 \\
\hline
\end{tabular}

Values are presented as number (\%) or mean \pm SD

*Not normally distributed: minimum-median-maximum 


\section{Effect on disease specific knowledge}

The mean knowledge score on baseline was comparable for both groups with rates of $12.6( \pm 1.7)$ and $12.3( \pm 1.8)$ respectively for the telemonitoring and usual care group $(p=0.09)$. Over time, the level of knowledge increased for both groups. However, after 12 months the telemonitoring group improved with 0.9 and the usual care group with 0.3 points. This resulted in a statistically significant difference, in favour of the telemonitoring group, which was already visible after 3 months $(p<0.001)$ (Table 2$)$.

Table 2 Effects on level of disease specific knowledge

\begin{tabular}{llcccc}
\hline & & Baseline & T3 & T6 & T12 \\
\hline intervention & mean & 12.6 & 13.3 & 13.2 & 13.5 \\
& SD & 1.7 & 1.1 & 1.2 & 1.2 \\
& mean & 12.3 & 12.5 & 12.4 & 12.6 \\
& SD & 1.8 & 1.8 & 1.9 & 1.8 \\
& & & & & .901 \\
& B & .313 & .832 & .753 & .000 \\
\hline
\end{tabular}

* difference between mean of intervention and care as usual group

\section{Effect on self-care}

At baseline a statistically significant difference $(p=0.001)$ in favour of the telemonitoring-group was measured with a mean score of 18.9 ( \pm 5.3 ) against $20.9( \pm 6.1$ ) for the usual care group. Lower scores indicate better results. Mean scores of the intervention group increased to $17.4( \pm 4.5)$ whereas the control group remained at the same level of 20.8 ( \pm 5.8$)$. When uncorrected for baseline difference, this resulted in a significant difference during whole follow-up $(p<0.001)$ remaining statistically different after correction for baseline values $(p<0.001)$ (Table 3$)$.

Table 3 Effects on self-care abilities

\begin{tabular}{llcccc}
\hline & & Baseline & T3 & T6 & T12 \\
\hline Intervention & mean & 18.9 & 17.4 & 17.1 & 17.4 \\
& SD & 5.3 & 6.1 & 4.4 & 4.5 \\
& mean & 20.9 & 20.0 & 20.0 & 20.8 \\
Uncorrected* & SD & 6.1 & 5.1 & 5.7 & 5.8 \\
& B & & & & -3.277 \\
Corrected* & P-value & -2.005 & -2.639 & -2.767 & $<0,001$ \\
& B** & 0.001 & $<0,001$ & $<0,001$ & -2.154 \\
& P-value & - & -1.598 & -1.592 & $<0.001$ \\
\hline
\end{tabular}

* Uncorrected or corrected for baseline value

** Difference between mean of intervention and care as usual group 


\section{Effect on self-efficacy}

Baseline self-efficacy score showed a statistical significant difference between the two groups, with a mean score of $53.2( \pm 7.1)$ for the telemonitoring and $51.1( \pm 9.6)$ for the usual care group $(p=0.024)$.

Scores increased to $54.9( \pm 6.5)$ and $52.3( \pm 8.9)$ respectively, after 12 months. When uncorrected for baseline values, the results remained significantly different during follow-up ( $p=0.010)$. However, after correction for the baseline score, this statistical significant difference disappeared $(p=0.192)$, except for the scores after 6 months $(p=0.002)$ (Table 4).

Table 4 Effects on self-efficacy

\begin{tabular}{llcccc}
\hline & & Baseline & T3 & T6 & T12 \\
\hline Intervention & mean & 53.2 & 54.1 & 55.6 & 54.9 \\
& SD & 7.1 & 7.8 & 5.1 & 6.5 \\
Care as usual & mean & 51.2 & 51.9 & 51.7 & 52.3 \\
& SD & 9.6 & 8.7 & 8.8 & 8.9 \\
Uncorrected* & $\beta^{* *}$ & & & & 2.398 \\
& P-value & 2.030 & 2.436 & 3.649 & 0.010 \\
Corrected* & $\beta^{* *}$ & 0.024 & 0.008 & 0.000 & 1.181 \\
& P-value & - & 1.342 & 2.492 & 0.192 \\
\hline
\end{tabular}

* Correction for baseline value

** Difference between mean of intervention and care as usual group

\section{Effect on adherence}

Effects on self-reported adherence are assessed for importance and estimation of adherence regarding eight domains. Importance refers to how patients consider the necessity to adhere, whereas estimation indicates the execution of adherence. On baseline only importance of daily weighing and fluid intake were significantly different, persisting during follow-up. On baseline, no differences for estimation of adherence were found for any domain.

Respondents from the telemonitoring arm were significantly affected regarding four health behaviours resulting in a better score for fluid restriction, adherence to weighing, importance of medication and activity recommendations; the latter, however, only at 3 months after inclusion. Regarding the item weighing and fluid restriction, importance had a lower score than estimation of weighing and fluid restriction. Importance of medication adherence increased significantly after 6 and 12 months and estimation improved to $100 \%$ after 1 year, yet without a statistical significant difference between groups. No differences were found for appointments, diet, smoking and use of alcohol (Table 5). 
Table 5 Effects on adherence

\begin{tabular}{|c|c|c|c|c|c|c|c|c|}
\hline & \multicolumn{2}{|c|}{ Baseline } & \multicolumn{2}{|c|}{ T3 } & \multicolumn{2}{|c|}{ T6 } & \multicolumn{2}{|c|}{ T12 } \\
\hline & $\mathrm{IMP}^{\mathrm{a}}$ & $\mathrm{EST}^{\mathrm{a}}$ & IMP & EST & IMP & EST & IMP & EST \\
\hline \multicolumn{9}{|l|}{ Appointments } \\
\hline Telemonitoring & 83.3 & 97.3 & 81.5 & 96.0 & 82.5 & 97.1 & 84.3 & 97.2 \\
\hline UC & 82.1 & 96.5 & 81.8 & 95.6 & 84.3 & 97.3 & 84.1 & 97.3 \\
\hline P-value & 0.604 & 0.478 & 0.912 & 0.840 & 0.482 & 0.866 & 0.955 & 0.981 \\
\hline \multicolumn{9}{|l|}{ Medication } \\
\hline Telemonitoring & 88.3 & 98.9 & 90.4 & 99.8 & 93.5 & 99.8 & 93.5 & 100 \\
\hline UC & 88.7 & 99.6 & 87.8 & 99.7 & 88.0 & 98.9 & 89.8 & 98.7 \\
\hline P-value & 0.837 & 0.161 & 0.226 & 0.504 & 0.012 & 0.235 & 0.037 & 0.107 \\
\hline \multicolumn{9}{|l|}{ Weighing } \\
\hline Telemonitoring & 65.4 & 77.0 & 73.5 & 88.9 & 76.0 & 88.6 & 75.4 & 87.2 \\
\hline UC & 58.6 & 73.2 & 59.8 & 73.2 & 63.2 & 70.9 & 61.3 & 72.8 \\
\hline P-value & 0.031 & 0.238 & 0.000 & 0.000 & 0.000 & 0.000 & 0.000 & 0.000 \\
\hline \multicolumn{9}{|l|}{ Diet } \\
\hline Telemonitoring & 68.9 & 77.2 & 72.6 & 80.4 & 74.2 & 80.5 & 73.8 & 81.7 \\
\hline UC & 69.1 & 77.2 & 68.3 & 79.8 & 67.3 & 78.6 & 69.9 & 80.9 \\
\hline P-value & 0.940 & 0.996 & 0.116 & 0.801 & 0.012 & 0.403 & 0.174 & 0.724 \\
\hline \multicolumn{9}{|l|}{ Fluid } \\
\hline Telemonitoring & 68.5 & 77.3 & 73.7 & 83.1 & 75.9 & 84.4 & 76.5 & 84.8 \\
\hline UC & 62.1 & 76.6 & 64.5 & 77 & 66.4 & 75.7 & 68.6 & 81 \\
\hline P-value & 0.027 & 0.812 & 0.001 & 0.019 & 0.000 & 0.000 & 0.003 & 0.086 \\
\hline \multicolumn{9}{|l|}{ Activities } \\
\hline Telemonitoring & 60.3 & 62.1 & 66.4 & 69.1 & 65.4 & 67.9 & 63.8 & 65.8 \\
\hline UC & 62.8 & 58.8 & 64.8 & 61.9 & 65.8 & 65.4 & 62.8 & 64.1 \\
\hline P-value & 0.329 & 0.296 & 0.549 & 0.023 & 0.877 & 0.409 & 0.732 & 0.61 \\
\hline \multicolumn{9}{|l|}{ Smoking } \\
\hline Telemonitoring & 82.1 & 91.3 & 83.3 & 91.4 & 83.1 & 91.1 & 84.3 & 92.2 \\
\hline UC & 80.2 & 92.0 & 81.6 & 91 & 81.8 & 90.9 & 83.7 & 92.4 \\
\hline P-value & 0.581 & 0.783 & 0.610 & 0.889 & 0.708 & 0.932 & 0.845 & 0.918 \\
\hline \multicolumn{9}{|l|}{ Alcohol } \\
\hline Telemonitoring & 61.5 & 90.6 & 65.7 & 92.5 & 65.8 & 92.3 & 63.9 & 90.3 \\
\hline UC & 60.6 & 93.5 & 62.9 & 93.2 & 62.1 & 91.9 & 61.2 & 92.5 \\
\hline P-value & 0.809 & 0.152 & 0.423 & 0.710 & 0.327 & 0.842 & 0.487 & 0.311 \\
\hline
\end{tabular}

${ }^{a}$ IMP=importance, EST=estimation 


\section{Adherence of using the telemonitoring system}

The overall daily compliance (expressed as the percentage responses to the total number of daily dialogues over all patients) to the intervention was 90\% (median 92.3, interquartile population range, 84.7-94.9), uncorrected for days in hospital or other absence reasons. During the first 3 months compliance was 93\%, and when repeating the same sets of dialogues compliance was $95 \%$. Daily compliance was $87 \%$ when allocated to the program with emphasis on symptoms; allocation to an educational program showed a daily compliance of $88 \%$.

\section{Discussion}

This study compared self-management skills enhanced by means of tailored telemonitoring or by care as usual. Patients were optimally motivated and supported by the research assistant to reflect on all questions within the questionnaires; however, all results were strictly patient reported without supervision or control. The qualitative nature of the questionnaires may be the most appropriate to justify the views of individuals; however, they are less suitable for testing research. The study population was a typical HF population and in spite of the random assignment to one of the study arms, significant differences were present on baseline for self-care and self-efficacy, probably based on co-incidence. Self-care has been defined as an active cognitive process undertaken by a patient to maintain health or manage illness and disease [26]. Self-care may be particularly difficult for elderly patients with HF because of age-related changes such as the loss of hearing and visual capacity, and impaired functional status [27]. Factors as lack of education, unavailable support, co-morbidities and multiple symptoms may fortify these changes and negatively affect self-care abilities. Self-care is not synonymous with treatment adherence or compliance but instead subsumes treatment adherence as one component of self-care [6]. It was found that in the telemonitoring group, disease-specific knowledge, self-care and self-efficacy improved significantly. Interestingly, self-efficacy improved quickly in telemonitored patients and stayed on the high level whereas in the usual care arm improvement evolved slowly. This implicates that telemonitoring needs a short time track to reach a high level of confidence, in contrast with usual care requiring a longer time.

Influencing adherence is complicated, and may be hampered by different barriers on patient, provider or system level [28]. Adherence can be defined as 'the extent to which a persons' behaviour (in terms of taking medication, following diet or executing life style changes) coincides with the 'clinical prescription' [4]. Fewer than half of patients with HF report weighing themselves daily, [29] and only 5\% report weight gain as a worsening symptom [16]. Moreover, the majority of patients showed a delay time of 3-7 days before seeking treatment [16]. This may be due to the poor correlation be- 
tween increased body weight and other signs and symptoms, such as dyspnoea or oedema [30]. In this study an increased adherence was found for daily weighing and persisting fluid restriction. No adherence changes were found for appointments, diet, smoking and use of alcohol. Regarding weighing, at baseline, we found approximately $75 \%$ adherence for daily weighing in both groups, which was relatively high compared to the daily weighing compliance of $12-75 \%$ published by Van der Wal [16]. Compared to the usual care group, both importance and estimation improved significantly in the telemonitoring group. After 1 year, weighing adherence was importantly higher in the telemonitoring group reaching a level of $87 \%$. In the telemonitoring group it was paradoxically found that patients scored importance of weighing considerably lower than estimation. Supposedly patients weighed themselves because the system asked for it, rather than because of an awareness of the importance of weighing. If correct, this implies a problem once patients are no longer monitored by the system, demanding persisting support not only for daily weighing but also for self-care in case of weight gain.

Regarding use of medication a significant improvement was found for importance, yet no effect on estimation was found. The latter probably is caused by the already high baseline adherence of $98 \%$, leaving no room for improvement. Other studies report compliance rates of about $70 \%$ [16]. In comparison, our findings differ, suggesting a very high adherence to medication. An explanation of the possible overestimation in our study may be the design of self-reporting on adherence and the occurrence of socially acceptable answers.

Execution of physical activity was positively influenced by telemonitoring especially after 3 months, yet also the usual care group showed improved activity level albeit after a longer time. Compared with other studies reporting activity adherence of about $55 \%$ [16], both groups in our study scored higher (around 63\%). Regarding salt restricted diet, use of alcohol and smoking no differences were found between groups, suggesting no influence of telemonitoring regarding these aspects. Regarding smoking and diet, adherence at baseline level was low, leaving extensive room for improvement, yet no effects were found. For both groups, adherence rates for these aspects were comparable with other studies [16]. This underscores the difficulty in changing these types of lifestyle aspects. Obviously, barriers exist, apparently not impressionable by a telemonitoring system. A study by Artinian et al. followed 18 patients for 3 months of whom nine were using telemonitoring [9]. No results were reported about knowledge or self-efficacy. They found no difference for quality of life and self-management between the groups, yet a significant improvement for quality of life as well as for selfmanagement within groups. Although 3 months may be considered a short time to improve self-management, they succeeded to make improvements in both groups, suggesting no additional effect of telemonitoring. In contrast to Artinian, we followed patients for 1 year and continued to see improvements over the whole study period with a significant difference between groups even after 3 months. Regarding medica- 
tion adherence, both studies were comparable as both showed high medication adherence and no differences between groups. What was remarkable in Artinian's study was that almost half of the participants did not enjoy their experience with telemonitoring; in contrast in our study the patients appreciated it. Notwithstanding the fact we did not measure patient experience, we translate the high daily compliance into willingness to use and the enjoyment of using the telemonitoring system.

Health literacy is associated with higher HF knowledge and self-care confidence. Knowledge is important for adequate self-care and health-related responsibilities, which in their turn influence the hospitalisation rate of patients [31]. To meet patients' needs, we tailored the content by developing four different sets of dialogues with different emphasis on symptoms or education [17]. Balk et al. [10] studied 214 patients with a mean age of 66 years and a mean follow-up time of 288 days. No effects were demonstrated for quality of life or for self-care, the latter being in contrast with our study. Knowledge about HF, however, increased for both groups with a statistical difference in favour of the telemonitoring group, which was comparable with our results. The difference in mean age (66 versus 72 years in our study) suggests that age is neither a facilitator nor a barrier to improve self-care by telemonitoring. In contrast to our study with the focus on education and patient-reported signs and symptoms, Balk et al. combined education and monitoring of vital signs. Given the absence of effect on hospitalisations and length of stay in hospital, addition of vital signs monitoring apparently did not influence the studied variables and has no value above the patient-reported signs and symptoms in the current study. Another study performed by Seto et al. [32] following 100 patients for 12 months reported improved quality of life and self-care maintenance, yet no difference in self-care management. Their intervention consisted of weekly telephone contact, gathering information mainly on vital signs and a weekly transmission of an ECG. In contrast to our study their focus was on vital signs monitoring, ignoring education and support of self-care. It is therefore not surprising that no effects could be found for self-care management and confidence.

Analysis of the first 100 patients after the first 3 months follow-up in our study [33] showed a difference for patients' knowledge of HF between the three participating institutions, probably caused by divergent methods of healthcare practice. This difference disappeared in the final analysis ( $p=0.707$ ) (data not shown). From this it is assumed that differences of nursing procedures do not affect the results, which supports the generalizability of the concept.

To achieve improvement of patient empowerment skills, optimal use of the telemonitoring system is a prerequisite. Given the conceivable lack of adherence regarding daily use of the system [34], a tailor-made approach is a likely solution. In this respect an important condition is that the information communicated meets the patients' needs; needless information will be boring and result in neglect of the system. The high percentage of daily system adherence $(90 \%)$ confirms the success of our approach (i.e. tailoring the dialogues into four different programs). Education is a precursor of self- 
care behaviour and in our study we found increased levels for both. This improvement is exceptional, while patients in our control group are intensively followed by a HF nurse and provided with a high standard of HF care.

Statistical differences were found for knowledge and self-care, temporary effects for self-efficacy and improvement of compliance regarding some aspects. The improved knowledge and self-care on one hand and the reduced number of contacts with the HF nurse on the other hand [34] suggest the clinical relevance of this concept of telemonitoring, as educational aspects improved while nurses spent less time.

Telemonitoring has to be considered as additional to usual care; however, the statistical results and clinical relevance of this study [35] suggest that telemonitoring could substitute for tasks such as education and support, improving cost effectiveness of HF care.

\section{Limitations}

This study uses a quantitative questionnaire design, which is a limitation of this study. Quantitative methods presume to approach the research problems in an objective way. The use of standard questions by researchers can lead to "structural bias" and false representation, where the data actually reflect the view of the researcher instead of the participating subject. Pre-set answers will not necessarily reflect how people really feel about a subject and in some cases might just be the closest match to preconceived hypotheses. As a consequence, the results of a quantitative questionnaire design may be statistically significant but are often practically insignificant and their clinical relevance may be unclear.

Notwithstanding the application of valid and reliable instruments to measure knowledge, self-care, self-efficacy and adherence, all scores are patient reported. This possibly may have affected data about compliance while patients may have given socially acceptable answers.

Study participation mostly refers to motivated patients and motivation is known to be important for self-care [36], although patients using telemonitoring still demonstrate more self-care showing its positive effect. Nevertheless, participating patients may be somewhat different from the general population, raising questions about the generalization of these findings.

\section{Conclusion}

The combination of personal education by a nurse during face-to-face contact and education using this specific telemonitoring design was found to improve patients' knowledge and self-care abilities. Influencing adherence is shown to be difficult for most aspects, yet succeeded for fluid restriction and daily weighing. However, it re- 
mains unclear whether daily weighing persists when telemonitoring stops. The earlier reported reduced number of contacts with the HF nurse combined with improved patient capabilities suggests that telemonitoring is complementary, and may substitute for healthcare professionals regarding the performance of educational tasks.

Further development of a tailor-made approach and corresponding research is needed to explore the optimal fit of telemonitoring, the healthcare professional and the individual patient.

\section{Implications for practice}

Telemonitoring can be used to substitute educational nursing tasks and to support patients in their HF related self-care abilities. 


\section{References}

1. McMurray JJ, Stewart S. The burden of heart failure. European Heart Journal Supplements 2002; 4 (supplementD): D50-D58.

2. Bonneux L, Barendregt JJ, Meeter K, Bonsel GJ, Vandermaas PJ. Estimating Clinical Morbidity Due to Ischemic-Heart-Disease and Congestive-Heart-Failure-the Future Rise of Heart-Failure. American Journal of Public Health 1994; 84: 20-28.

3. Wal van der MHL, Jaarsma T, Moser DK, Veeger NJGM, Gilst van WH, Veldhuisen van DJ. Compliance in heart failure patients: the importance of knowledge and beliefs. European Heart Journal 2006; 27: 434440.

4. Sackett DL, Haynes RB. Compliance with therapeutic regimens. Baltimore: The Johns Hopkins University Press, 1976.

5. Monane M, Bohn RL, Gurwitz JH, Glynn RJ, Avorn J. Noncompliance with congestive heart failure therapy in the elderly. Archives of Internal Medicine 1994; 154: 433-7.

6. Riegel B, Moser DK, Anker SD, Appel LJ, Dunbar SB, Grady KL, Gurvitz MZ, Havranek EP, Lee CS, Lindenfeld JA, Peterson PN, Pressler SJ, Schocken DD, Whellan DJ. Promoting Self-Care in Persons With Heart Failure: A Scientific Statement From the American Heart Association. Circulation 2009; 120: 1141-1163.

7. Ni H, Nauma D, Burgess D, Wise K. Factors influencing knowledge of and adherence to self-care among patients with heart failure. Archives of Internal Medicine 1999; 159: 1613-19.

8. Boyde M, Tuckett A, Peters R, Thompson D, Turner C, Stewart S. Learning for heart failure patients (The L-HF patient study). Journal of Clinical Nursing 2009; 8(14): 2030-9.

9. Artinian NT, Harden JK, Kronenberg MW, Vander Wal JS, Daher E, Stephens Q, Bazzi RI. Pilot study of a webbased compliance monitoring device for patients with congestive heart failure. Heart \& Lung 2003; 32: 226-233.

10. Balk AHMM, Davidse W, van Dommelen P, Klaassen E, Caliskan K, van der Burg P, et al. Tele-guidance of chronic heart failure patients enhances knowledge about the disease. European Journal of Heart Failure 2008; 10 (11): 1136-42.

11. Dansky KH, Vasey J \& Bowles K. Use of telehealth by older adults to manage heart failure. Research in Gerontological Nursing 2008; 1: 25-32.

12. Antonicelli R, Mazzanti I, Abbatecola AM, Parati G. Impact of home patient telemonitoring on use of $\beta$ blockers in congestive heart failure. Drugs Aging 2008; 27(10): 801-5.

13. DeBusk RF, Miller NH, Parker KM, Bandura A, Kraemer HC, Cher DJ, West JA, Fowler MB, Greenwald G. Care management for low-risk patients with heart failure: a randomized, controlled trial. Annuals of Internal Medicine 2004; 141: 606-613.

14. Laramee AS, Levinsky SK, Sargent J, Ross R, Callas P. Case management in a heterogeneous congestive heart failure population: a randomized controlled trial. Archives of Internal Medicine 2003; 163: 809-817.

15. de Lusignan S, Wells S, Johnson P, Meredith K, Leatham E. Compliance and effectiveness of 1 year's home telemonitoring. The report of a pilot study of patients with chronic heart failure. The European Journal of Heart Failure 2001; 3: 723-730.

16. Wal van der MHL, Jaarsma T, Veldhuisen van DJ. Non-compliance in patients with heart failure; how can we manage it? The European Journal of Heart Failure 2005; 7: 5-17.

17. Boyne JJJ, Vrijhoef HJM, De Wit R, Gorgels APM. Telemonitoring in patients with heart failure, the TEHAF study: Study protocol of an ongoing prospective randomised trial. International Journal of Nursing Studies 2011; 48: 94-99.

18. Weintraub A, Gregory D, Patel AR, Levine D, Venesy D, Perry K, Delano C, Konstam M. A Multicenter Randomized Controlled Evaluation of Automated Home Monitoring and Telephonic Disease Management in Patients Recently Hospitalized for Congestive Heart Failure: The SPAN-CHF II Trial. Journal of Cardiac Failure 2010; 16: 285-292.

19. Benatar D, Bondmass M, Ghitelman J, Avitall B. Outcomes of Chronic Heart Failure. Archives of Internal Medicine 2003; 163: 347-352. 
20. Cleland J, Louis A, Rigby A, Janssens U, Balk A, TEN-HMS Investigators. Noninvasive Home Telemonitoring for Patients with Heart Failure at High Risk of Recurrent Admission and Death: The Trans-European Network-Home-Care Management System (TEN-HMS) study. Journal of American College of Cardiology 2005; 45: 1654-1664.

21. Van der Wal MHL, Jaarsma T, Moser DK, Veldhuisen van DJ. Development and testing of the Dutch Heart Failure Knowledge Scale. European Journal of Cardiovascular Nursing 2005; 4(4): 273-7.

22. Jaarsma T, Strömberg A, Märtenson J. . Development and testing of the European Heart Failure Self-Care Behaviour Scale. European Journal of Heart Failure 2003; 5(3): 363-70.

23. Barnason S, Zimmerman L, Nieveen J, Schmaderer M. Development of a self-efficacy instrument for coronary artery bypass graft (CABG) patients. Journal of Nursing Measurement 2002; 10(2): 123-133.

24. Evangelista LS, Berg J, Dracup K. . Relationship between psychosocial variables and compliance in patients with heart failure. Heart \& Lung 2001; 30(4): 294-301.

25. Twisk J, De Vente W. Attrition in longitudinal studies: How to deal with missing data. Journal of clinical Epidemiology 2002; 55: 329-337.

26. Riegel B, Carlson B, Glaser D. Development and testing of a clinical tool measuring self-management of heart failure. Heart Lung 2000; 29: 4-12.

27. Sweitzer N, Stevenson LW. Hospitalization for heart failure in the elderly. American Journal of Geriatric Cardiology 1999; 8: 276-81.

28. McEntee ML, Cuomo LR, Dennison CR. Patient-, Provider-, and System-Level Barriers to Heart Failure Care. Journal of Cardiovascular Nursing 2009; 24(4)

29. Wright SP, Walsh H, Ingley KM, Muncaster SA, Gamble GD, Pearl A, Whalley GA, Sharpe N, Doughty RN. Uptake of self-management strategies in a heart failure management programme. The European Journal of Heart Failure 2003; 5: 371-380.

30. Webel AR, Frazier SK, Moser DK, Lennie TA. Daily variability in dyspnea, edema and body weight in heart failure patients. Journal of Cardiovascular Nursing 2007; 6: 60-65.

31. Dennison CR, McEntee ML, Samuel L, Johnson BJ, Rotman S, Kielty A, Russell SD. Adequate health literacy is associated with higher heart failure knowledge and self-care confidence in hospitalized patients. Journal of Cardiovascular Nursing 2011; 26(5): 359-67.

32. Seto E, Leonard KJ, Cafazzo JA, Barnsley J, Masino C, Ross HJ. Mobile Phone-Based Telemonitoring for Heart Failure Management: A Randomized Controlled Trial. Journal of Medical Internet Research 2012; 14(1): e3.

33. Ramaekers BL, Janssen-Boyne JJ, Gorgels AP, Vrijhoef HJ. Adherence among telemonitored patients with heart failure to pharmacological and nonpharmacological recommendations. Journal of Telemedicine and eHealth 2009; 15(6): 517-24.

34. Chaudry S, Mattera J, Curtis J, Spertus J, Herrin J, Lin Z, Philips C, Hodshon B, Cooper L, Krumholz H. Telemonitoring in Patients with Heart Failure. New England Journal of Medicine 2010; 363: 2301-23.

35. Boyne JJ, Vrijhoef HJ, Crijns HJ, De Weerd GJ, Kragten J, Gorgels AP. Tailored telemonitoring in patients with heart failure: results of a multicentre randomized controlled trial. The European Journal of Heart Failure 2012; 14(7): 791-801. 


\section{CHAPTER 5}

\section{Tailored telemonitoring in patients with heart}

failure:

Results of a multicenter randomised controlled trial

Josiane J.J.Boyne, Hubertus J.M.Vrijhoef, Harry J.G.M.Crijns, Gerjan De Weerd, Johannes Kragten, Anton P.M. Gorgels

The European journal of heart failure 2012; 14(7): 791-801. 


\section{Abstract}

Aims: Recent increases in heart failure tend to overload the healthcare system. Consequently, there is a need for innovative strategies to reduce heart failure hospitalisations.

Methods and results: A multicentre randomised controlled trial was carried out to test the hypothesis that telemonitoring reduces heart failure hospitalisations during 1year follow-up. The mean age of the 382 participating patients was 71.5 (32-93) years; the mean left ventricular ejection fraction was 0.38 , and in $61 \%$ it was $\leq 0.45 \%$. Mean time to first heart failure-related hospitalisation was 161 days for the intervention group and 139 days for the usual-care group; hospitalisations occurred in 18 (9.1\%) compared with 25 (13.5\%) patients, with a total number of 24 and 43 hospitalisations, respectively [Kaplan-Meier $\mathrm{P}=0.151$, hazard ratio $(\mathrm{HR}) 0.65,95 \%$ confidence interval (CI) 0.35-1.17].

Subgroup analysis of the primary endpoint showed benefits for three subgroups: duration of heart failure, having a pacemaker, and co-habiting. The combined endpoint of heart failure admission and all-cause mortality was similar for both groups (KaplanMeier $\mathrm{P}=0.641, \mathrm{HR} 0.89,95 \% \mathrm{Cl} 0.69-1.83$ ). No differences were found regarding secondary endpoints, except for the reduced number of face-to-face contacts with the heart failure nurse (Mann-Whitney $\mathrm{P}=0.001)$. Mortality was $18(9.1 \%)$ in the intervention group and $12(6.5 \%)$ in the usual-care group (Mann-Whitney $P=0.34$, Cox regression analysis $\mathrm{P}=0.82$ ).

Conclusion: No significant differences were found regarding the primary endpoint, possibly caused by a relative under powering of the population combined with welltreated study groups. However, telemonitoring tends to reduce heart failure (re)admissions and significantly decreases contacts with specialized nurses. Further research with pre-specified groups, as found in the subgroup analysis, is needed.

Trial registration: NCT00502255.

Keywords: Heart failure † Telemonitoring † Tailored care + RCT + Education 


\section{Introduction}

The prevalence of heart failure is rising due to improved survival after acute cardiac events and ageing of the population [1, 2]. Multidisciplinary nurse-led heart failure clinics are able to reduce the frequent admissions seen in this condition $[3,4]$. Such disease management systems comprise many elements, being described in eight domains, among other methods of communication [5]. Telemonitoring is a promising development of the latter [3], which however, may fail if used in isolation [6] or if focusing on vital signs only $[7,8]$. The Health-Buddy ${ }^{\circledR}$ is a telemonitoring system which is patient driven, collecting and providing tailored patient- and disease-specific information. Pilot data showed that adherence to treatment is improved by involving patients in the process and stimulating self-care [9]. We performed a randomised study comparing this novel approach to telemonitoring with usual care, both within an existing comprehensive disease management system. We hypothesized that telemonitoring reduces heart failure hospitalisations compared with usual care.

\section{Methods}

\section{Trial design}

As described previously [10], the TElemonitoring in HeArt Failure (TEHAF) study is a prospective open label, multicentre, randomised controlled trial with blinded endpoint evaluation, conducted at three hospitals in The Netherlands. Investigators and study personnel (except for data entry officers) were unaware of the treatment group results until database closure. The study is registered at Clinicaltrials.gov (NCT00502255). Approval was obtained from the Medical Ethical Committee of the participating centres, according to the Declaration of Helsinki [11]. Written informed consent was obtained before randomisation.

\section{Study population}

From October 2007 to December 2008, consecutive patients with heart failure in New York Heart Association (NYHA) class II-IV were included. Heart failure was defined as at least one episode of fluid retention requiring diuretics, either with an echocardiographic left ventricular ejection fraction $\leq 40 \%$ or a preserved ejection fraction with diastolic dysfunction. Further inclusion criteria were age $\geq 18$ years, capable of providing informed consent, and being treated by a heart failure nurse together with a cardiologist. Patients were excluded if operating the Health-Buddy ${ }^{\circledR}$ system was physically or cognitively impracticable or when their expected life span was 1 year. A prior admission for heart failure $[8,12,13]$ was not a prerequisite for inclusion. 


\section{Patient recruitment and randomization procedure}

We screened 870 consecutive patients during their planned visit to our heart failure clinics; 488 patients refused to participate or were ineligible. Thus 382 , recruited at the heart failure outpatient clinic, were enrolled and assigned to a study arm, using a computer-generated randomisation procedure, with stratification per centre.

\section{Intervention and usual care}

The patients in the intervention arm received a device, with a liquid crystal display and four keys, connected to a landline phone. Automatic transfer of vital signs was not part of the system. Heart rate and blood pressure for both groups were collected during regular face-to-face contacts. Daily pre-set dialogues were communicated about symptoms, knowledge, and behaviour, being answered by touching one of the keys and sent to a server and to the nurses' desktop. Incorrect answers to a knowledge or behaviour issue were automatically corrected by the device and were visible in the display. Responses were also transferred into risk profiles (low, medium, high) [10]. Positive answers for symptoms triggered immediate responses by the heart failure nurse. A heart failure nurse and a nurse assistant led the process.

The nurse assistant took care of educational and general high risks, such as persistent lack of adherence or symptoms of depression [10]. In Table 1 we present the four sets of dialogues with variable emphasis on symptoms or knowledge and behaviour, created to meet specific needs on treatment or education. All patients started with the initial set of dialogues, which was evenly balanced for symptoms and education. After 3 months the dialogues were adjusted to the best fitting set for the current individual profile. Re-allocation to any of the other sets was possible at any time [10]. Following an admission for heart failure, re-allocation occurred to dialogues emphasizing symptom monitoring. Nurse-led usual care was given according to the latest European Society of Cardiology (ESC) guidelines [14], including oral and written educational information, and psychosocial support as needed. In the intervention group, two of four follow-up visits were skipped. Baseline characteristics were gathered the first visit after enrolment. General and disease-specific information was also collected using a questionnaire. Follow-up was 1 year. Hospitalisations were identified during follow-up visits and by reviewing medical records. Research nurses not involved in the patient care collected data on hospitalisation and mortality. 
Table 1 Tailor-made programs

\begin{tabular}{lccc}
\hline & Symptoms & Education / Adherence & Days \\
\hline Program 1 & + & + & 90 \\
Program 2 & + & $+/-$ & 30 \\
Program 3 & - & + & 90 \\
Program 4 & - & - & 180 \\
\hline
\end{tabular}

+ strongly focused on; +/-moderate focused on; -less focused on.

Program 1: contains a high level of monitoring symptoms and a high level of education: at the start all patients are allocated at this program;

Program 2: contains a high level of monitoring symptoms and a lower level of education: patients allocated at this program are indicated for intensive monitoring because of severe heart failure or many complaints. Their disease specific education level allows a less intensive education program;

Program 3: contains a low level of monitoring symptoms and a high level of education: patients with few complaints and a low disease specific education level are allocated to this program;

Program 4: contains a low level of monitoring symptoms and a low level of education: patients with few complaints and a high level of disease specific education are allocated to this program.

\section{Outcomes}

The primary outcome was time to first heart failure hospitalisation, i.e. at least one overnight stay for a new episode or progression of fluid retention, with insufficient response to adjustment of oral medication, needing in-hospital intravenous treatment. Secondary outcomes included the combined endpoint of heart failure admission and all cause death, the number of re-admissions for heart failure, all hospitalisations, and days in hospital for heart failure, cardiovascular (i.e. related to treatment or diagnostics of cardiac disease, or heart failure therapy related) and other-cause hospitalisations (i.e. not related to heart failure or cardiovascular), mortality, and number of visits to the heart failure clinic. An independent expert committee, blinded to study arm assignment, adjudicated heart failure-related hospitalisations and deaths. Occasional differences in judgment were reconciled at a panel meeting and settled by the chairman in the case of non-unanimity.

\section{Statistical analysis}

The primary endpoint was summarized by treatment group and tested by the KaplanMeier time to event function. The 1-year admission rate within the usual-care arm was estimated at $25 \%$ [15]. To detect a $50 \%$ reduction from $25 \%$ to $12.5 \%$ in heart failure hospitalisations with a two-sided $95 \%$ significance, a power of 0.80 , and $10 \%$ loss to follow-up, a sample size of 195 patients per group was needed. All analyses were performed on an intention-to-treat basis. 
Interval and ratio variables were investigated for normality of distribution with the Shapiro-Wilk test. If normally distributed, means and standard deviations are given, otherwise score ranges are provided. Continuous variables are presented as median and interquartile ranges. Categorical variables are presented as frequencies and percentages. Univariate statistics on differences in baseline variables were calculated by the Student t-test if normally distributed, or, if not, by the Mann-Whitney test. Differences between categories in baseline factors were checked with log-likelihood $X^{2}$. Secondary endpoints were calculated with the Mann -Whitney test, combined endpoint with the Kaplan-Meier, and mortality with the Cox regression analysis. All data analyses were performed using SPSS-pc version 16.0.

Subgroup analysis of the primary endpoint with $95 \%$ confidence intervals $(\mathrm{Cl})$ was performed using a Cox proportional hazards model.

\section{Results}

Of the 382 patients included, 197 were allocated to the intervention group and 185 to the usual-care group. Mean age was 71.5 (32-93) years and $46 \%$ were $\geq 75$ years old, $59 \%$ were male, $65 \%$ lived with a partner, and $57 \%$ were in functional class II, $40 \%$ in class III, and $3 \%$ in class IV. Admission for heart failure during 30 days before inclusion occurred in $6.8 \%$ of the population and in $16.5 \%$ within the 12 weeks before inclusion, without differences between groups. Mean left ventricular ejection fraction was 0.38 , and in $61 \%$ it was $\leq 0.45 \%$; $50 \%$ had ischemic heart disease. Study arms were balanced regarding baseline characteristics, except for predominance of atrial fibrillation in the intervention group ( $p=0.007)$.

Use of heart failure medication was high, as shown in Table 2. As seen in Figure 1, follow-up was incomplete in $81(21 \%)-43$ in the usual-care and 38 in the intervention arm-due to death, increasing physical impairment, stress, or losing motivation. 
Table 2 Baseline characteristics

\begin{tabular}{|c|c|c|c|c|c|}
\hline Variable & $\mathbf{N}$ & Intervention (197) & Control (185) & Total (382) & $p$-value \\
\hline Age & 382 & $71.0 \pm 11.9$ & $71.9 \pm 10.5$ & $71 \pm 11$ & 0.621 \\
\hline Range* & & $32-72-91$ & $37-74-93$ & & \\
\hline Median & 382 & $72(63-81)$ & $74(65-80)$ & $73(64-80)$ & \\
\hline$\geq 75$ & & $88(45)$ & $85(46)$ & $173(45)$ & 0.199 \\
\hline Gender & 382 & & & & 0.747 \\
\hline Male & & $115(58)$ & $111(60)$ & $226(59)$ & \\
\hline Female & & $82(42)$ & $74(40)$ & $156(41)$ & \\
\hline Married / partner & 379 & $122(62)$ & $123(66)$ & $245(64)$ & 0.265 \\
\hline Education & 363 & & & & 0.589 \\
\hline Primary school & & $63(33)$ & $59(34)$ & $122(34)$ & \\
\hline Second.sch. /Low vocational training & & $91(48)$ & $71(41)$ & $162(45)$ & \\
\hline Middle Vocational training & & $19(10)$ & $23(13)$ & $42(12)$ & \\
\hline High vocational / university & & $17(9)$ & $20(11)$ & $37(10)$ & \\
\hline History of HF (months) ${ }^{+}$ & 382 & $19(6-41)$ & $17(6-40)$ & $18(6-40)$ & 0.413 \\
\hline HF history $<18$ months & & $98(26)$ & $98(26)$ & $196(51)$ & \\
\hline Range $^{*}$ & & $1-18-240$ & $1-15-293$ & & \\
\hline NYHA-classification / no (\%) & 382 & & & & 0.404 \\
\hline NYHA II & & $110(56)$ & 109 (59) & $219(57)$ & \\
\hline NYHA III & & $79(40)$ & $74(40)$ & $153(40)$ & \\
\hline NYHA IV & & $8(4)$ & $2(1)$ & $10(3)$ & \\
\hline Blood pressure $^{+}$ & 382 & & & & \\
\hline Systolic & & $120(110-140)$ & $125(110-140)$ & $123(110-140)$ & 0.156 \\
\hline Diastolic & & $72 \pm 12.5$ & $74 \pm 12.2$ & $73(12)$ & 0.193 \\
\hline Heart rate ${ }^{+}$ & 382 & $75(68-85)$ & $72(68-85)$ & $74(65-85)$ & 0.252 \\
\hline LBBB & 382 & $20(10.2)$ & $22(11.9)$ & $42(11)$ & 0.587 \\
\hline Heart rhythm at baseline & 382 & & & & \\
\hline Sinus rhythm & & $96(48.7)$ & $113(61.1)$ & $209(55)$ & 0.015 \\
\hline Atrial fibrillation & & $62(31.5)$ & 35 (18.9) & $97(25)$ & 0.007 \\
\hline Pacemaker rhythm & & $36(18.3)$ & 35 (18.9) & $71(18)$ & 0.817 \\
\hline Other & & $3(1.5)$ & $2(1.1)$ & $5(1)$ & n.a. \\
\hline \multicolumn{6}{|l|}{ Echocardiography } \\
\hline Ejection fraction $^{+}$ & 374 & $36(28-50)$ & $35(26-42)$ & $36(28-48)$ & 0.751 \\
\hline median ejection fraction & & 36 & 35 & 36 & \\
\hline Mitral regurgitation & 375 & $122(64)$ & $121(67)$ & $243(65)$ & 0.345 \\
\hline Tricuspid regurgitation & 375 & $102(54)$ & $86(47)$ & $188(50)$ & 0.381 \\
\hline Ischemia & 382 & $99(50.3)$ & $91(49.2)$ & $190(50)$ & 0.835 \\
\hline
\end{tabular}


CHAPTER 5

\begin{tabular}{|c|c|c|c|c|c|}
\hline Variable & $\mathbf{N}$ & Intervention (197) & Control (185) & Total (382) & $p$-value \\
\hline Pacemaker & & 59 (29.9) & $53(28.6)$ & $112(29)$ & 0.147 \\
\hline DDD & & $15(25)$ & $19(36)$ & $34(30)$ & \\
\hline Biventricular & & $2(3)$ & $7(13)$ & $9(8)$ & \\
\hline$I C D$ & & $14(24)$ & $11(21)$ & $25(22)$ & \\
\hline Biventricular ICD & & $24(41)$ & $14(26)$ & $38(34)$ & \\
\hline Other & & $4(7$ & $2(4)$ & $6(6)$ & \\
\hline \multicolumn{6}{|l|}{ Blood samples (mmol/L) } \\
\hline Sodium & 382 & $140.1 \pm 2.9$ & $140.2 \pm 2.9$ & $140.1 \pm 2.9)$ & 0.779 \\
\hline Potassium & 382 & $4.36 \pm 0.5$ & $4.37 \pm 0.5$ & $4.27 \pm 0.5$ & 0.873 \\
\hline Urea & 382 & $11.18 \pm 6.2$ & $10.76 \pm 5.6$ & $10.9 \pm 5.9$ & 0.485 \\
\hline Creatinine (micromol/L) & 382 & $128 \pm 53.9$ & $125 \pm 55.3$ & $127 \pm 54.5$ & 0.466 \\
\hline Pro-BNP ${ }^{* *}$ & 145 & $313 \pm 506$ & $417 \pm 561$ & $365 \pm 560$ & 0.953 \\
\hline NT Pro-BNP ${ }^{* * *}$ & 131 & $2837 \pm 5293$ & $3229 \pm 6003$ & $3033 \pm 5648$ & 0.730 \\
\hline Haemoglobin & 382 & $8.2 \pm 1.1$ & $8.2 \pm 1.2$ & $8.1 \pm 1.1$ & 0.950 \\
\hline \multicolumn{6}{|l|}{ Medication } \\
\hline Diuretics & 380 & $170(86)$ & $163(88)$ & $333(87)$ & 0.783 \\
\hline ACE inhibitors & 378 & $113(58)$ & $104(57)$ & $217(57)$ & 0.826 \\
\hline ATII-antagonists & 373 & $67(35)$ & $56(31)$ & $123(33)$ & 0.459 \\
\hline Bèta-blockers & 379 & $161(82)$ & $149(81)$ & $310(82)$ & 0.689 \\
\hline Digoxin & 372 & $46(24)$ & $45(25)$ & $91(24)$ & 0.770 \\
\hline Nitrates & 376 & $64(33)$ & $72(39)$ & $136(36)$ & 0.212 \\
\hline Statins & 377 & $111(57)$ & $107(58)$ & $218(57)$ & 0.900 \\
\hline Coumarins & 377 & $119(61)$ & $95(52)$ & $214(57)$ & 0.084 \\
\hline ASA & 373 & $60(31)$ & $71(39)$ & $131(35)$ & 0.091 \\
\hline Charlson index十 & 382 & $2(2-3)$ & $2(1-3)$ & $2(1-3)$ & 0.358 \\
\hline $\begin{array}{l}\text { Values are presented as number } \\
{ }^{*} \text { Not normally distributed: minir } \\
\text { + } \text { Median (Interquartile } 25-75 \text { ) } \\
{ }^{* *} \mathrm{pmol} / \mathrm{L} \text { ref. value }<35 \mathrm{pmol} / \mathrm{L} \\
{ }^{* * *} \mathrm{pg} / \mathrm{ml} \text { ref.value }<450 \mathrm{pg} / \mathrm{ml}\end{array}$ & $\begin{array}{l}\text { mean } \\
\text { edian- }\end{array}$ & $\begin{array}{l}\text { SD } \\
\text { maximum }\end{array}$ & & & \\
\hline
\end{tabular}




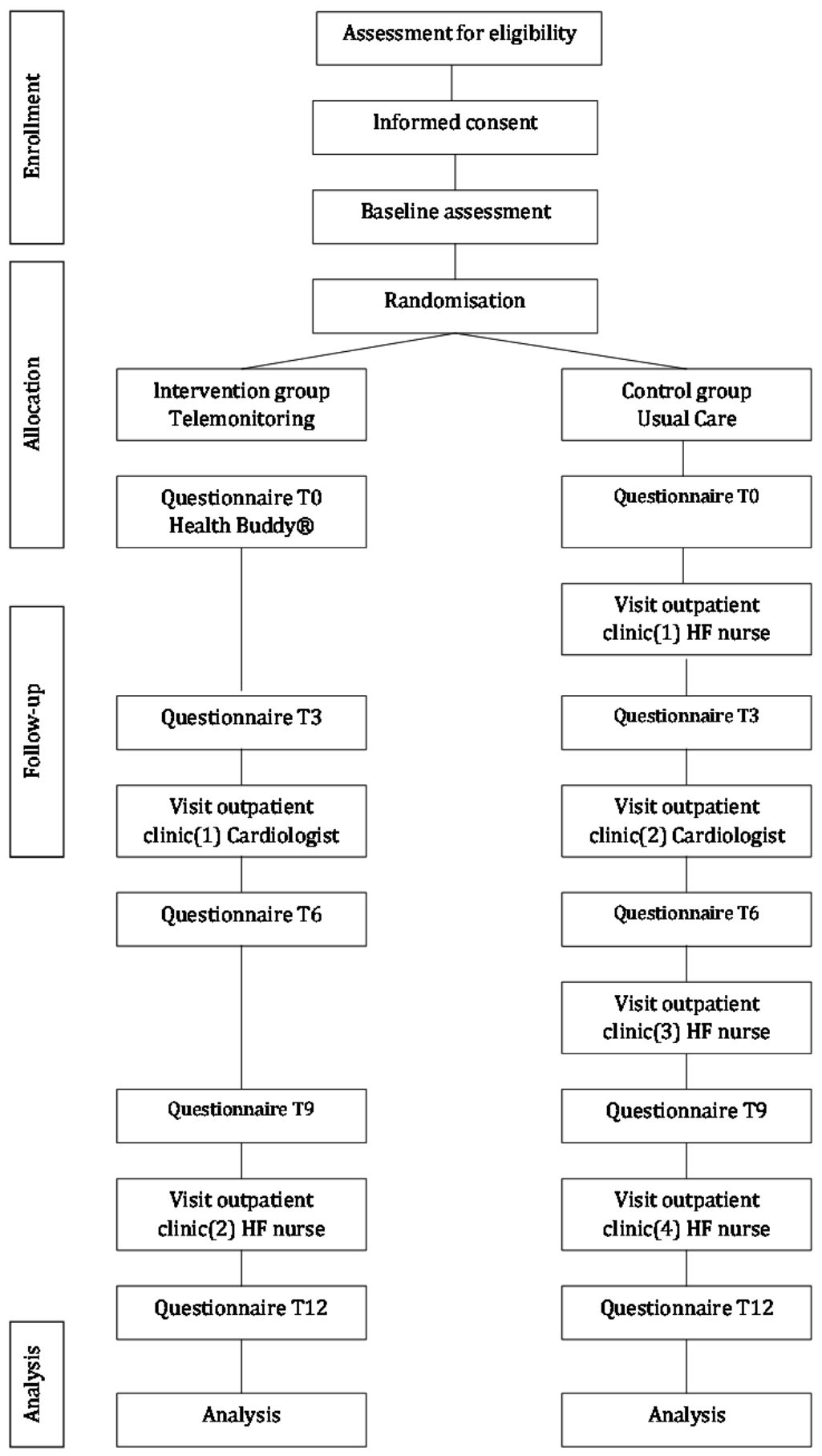

Figure 1 Consort diagram 


\section{Remote monitoring compliance, program allocation and contacts with the heart failure nurse.}

After the basal set of dialogues during the first 3 months patients were allocated to the best fitting sets: $17(9 \%)$ were re-allocated to the same set, $29(15 \%)$ to sets emphasizing symptoms, $64(23 \%)$ to the education set, and $89(45 \%)$ to a maintenance program.

Sixteen patients $(8 \%)$ died, dropped out, or did not finish the first set for other reasons.

The overall daily compliance (expressed as the percentage of responses to the total number of daily dialogues for all patients) with the intervention was 90\% (median 92.3, interquartile population range, 84.7-94.9), uncorrected for days in hospital or other reasons for absence. During the first 3 months compliance was $93 \%$ and, when repeating the same sets, compliance was $95 \%$. Daily compliance for the sets with emphasis on symptoms and education was $87 \%$ and $88 \%$, respectively, and for the maintenance set it was $87 \%$.

Planned and unplanned face-to-face contacts with the heart failure nurse showed a yearly average of 1.36 (range $0-11$ ) in the intervention group against $1.74(0-8)$ in the usual-care group (Mann-Whitney $p=0.001$ ). The number of telephone contacts with the nurse was the same in both groups.

\section{Primary endpoint}

In Figure 2A a trend is presented to a reduced time to first heart failure admission: for the intervention group mean time to first admission was 161 days (range 344, median 170) and for the usual-care group 139 days (range 296, median 126). In the intervention group 18 (9.1\%) patients had 24 admissions for heart failure compared with 25 (13.5\%) patients with 43 admissions in the usual-care group [difference 4.4 percentage points, Kaplan-Meier $p=0.151$ hazard ratio (HR) 0.65, 95\% Cl 0.35-1.17].

\section{Secondary endpoints}

The combined endpoint of heart failure admission and all-cause mortality was similar in the intervention and usual-care group (Kaplan-Meier $p=0.641$, HR 0.89, 95\% Cl 0.691.83 ) as shown in Figure 2B. No difference was found for subgroups. Total number of days in hospital was 1128 vs. 866, respectively (Mann-Whitney $p=0.338$ ), and the number of days of admission for heart failure was 253 (22\%) and 330 days (38\%) for the intervention and usual-care group, respectively (Mann-Whitney $p=0.156$ ). Table 3 shows the number of days of admission for cardiovascular reasons not due to heart failure, 155 (14\%) in 26 patients vs. 101 (12\%) in 18 patients for the intervention and usual care group, respectively (Mann-Whitney $p=0.284$ ). Days of admission for other causes were $720(64 \%)$ in 48 patients and 435 (50\%) in 35 patients for the intervention 
and usual-care group, respectively (Mann-Whitney $p=0.205$ ). Re-admissions for heart failure occurred in 5 patients and in 11 patients, respectively (Mann-Whitney $p=$ $0.097)$. The mean duration per heart failure admission was $9.9(0-36)$ days and 8.0 (039) days for the intervention and usual-care group, respectively; the duration of nonheart failure admissions was 8.8 (0-112) vs. 7.7 (0-69) days.

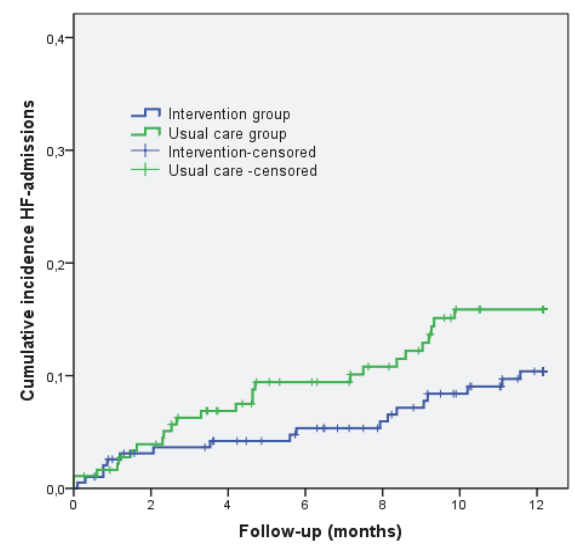

Figure 2a Primary endpoint: time to first heart failure admission

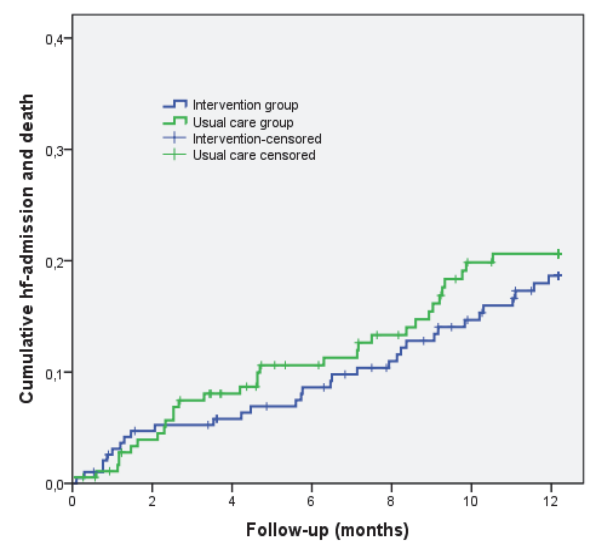

Figure $\mathbf{2 b}$ Combined endpoint of heart failure admissions and all cause death 
Table 3 Overview of the secondary endpoints, hospitalisation and contacts with caregivers.

\begin{tabular}{|c|c|c|c|c|c|c|c|c|c|}
\hline & \multicolumn{3}{|c|}{ All patients } & \multicolumn{3}{|c|}{ Heart failure $<18$ months } & \multicolumn{3}{|c|}{ Heart failure $>18$ months } \\
\hline & $\begin{array}{l}\text { Intervention } \\
(\mathrm{N}=197)\end{array}$ & $\begin{array}{l}\text { Usual care } \\
(\mathrm{N}=185)\end{array}$ & $\rho$-value & $\begin{array}{c}\text { Intervention } \\
(n=98)\end{array}$ & $\begin{array}{l}\text { Usual care } \\
(n=98)\end{array}$ & p-value & $\begin{array}{c}\text { Intervention } \\
(\mathrm{n}=99)\end{array}$ & $\begin{array}{l}\text { Usual care } \\
(n=87)\end{array}$ & p-value \\
\hline Primary endpoint & $18(9.1)^{\ddagger}$ & $25(13.5)$ & 0.15 & & & & & & \\
\hline \multicolumn{10}{|l|}{ Secondary endpoints } \\
\hline \multicolumn{10}{|l|}{ Patients with heart failure admissions } \\
\hline 1 admission & $13(6.5)$ & $14(7.6)$ & & 3 & 6 & & 10 & 8 & \\
\hline 2 admissions & $4(2.0)$ & $7(3.8)$ & & - & 2 & & 4 & 5 & \\
\hline$>2$ admissions & $1(0.5)$ & $4(2.2)$ & & - & 3 & & 1 & 1 & \\
\hline Patients admitted for heart failure & $18(9.1)$ & $25(13.5)$ & 0.15 & $3(3.1)$ & $11(11.2)$ & 0.03 & $15(15.2)$ & $14(16.1)$ & 0.87 \\
\hline All admissions for heart failure & 24 & 43 & 0.18 & 3 & 19 & 0.01 & 21 & 24 & 0.53 \\
\hline Total heart failure hospital days & 253 & 330 & 0.18 & 29 & 176 & 0.02 & 224 & 154 & 0.95 \\
\hline Patients with cardiovascular admissions ${ }^{\dagger}$ & $26(13.2)$ & $18(9.7)$ & 0.29 & 15 & 12 & 0.53 & 11 & 6 & 0.32 \\
\hline 1 admission & $24(12.2)$ & $15(8.1)$ & & 14 & 11 & & 10 & 4 & \\
\hline 2 admissions & $2(1.0)$ & $1(0.5)$ & & 1 & 1 & & 1 & - & \\
\hline$>2$ admissions & & $2(1.1)$ & & - & - & & - & 2 & \\
\hline Total cardiovascular hospital days & 155 & 101 & 0.28 & 123 & 67 & 0.44 & 32 & 34 & 0.36 \\
\hline Patients with other cause admissions & $49(24.8)$ & $35(18.9)$ & 0.16 & 27 & 19 & 0.13 & 21 & 16 & 0.63 \\
\hline 1 admission & $35(17.1)$ & $30(16.2)$ & & 21 & 18 & & 14 & 12 & \\
\hline 2 admissions & $11(5.6)$ & $3(1.6)$ & & 4 & _- & & 7 & 3 & \\
\hline$>2$ admissions & $2(1.0)$ & $2(1.1)$ & & 1 & 1 & & - & 1 & \\
\hline Total other cause hospital days & 720 & 435 & 0.21 & 228 & 251 & 0.29 & 492 & 184 & 0.50 \\
\hline Contacts with cardiologist & $448 \pm 2.29^{\dagger}$ & $444 \pm 2.40$ & 0.77 & $250 \pm 2.55$ & $235 \pm 2.40$ & 0.50 & $198 \pm 2.02$ & $209 \pm 2.40$ & 0.29 \\
\hline Contacts with heart failure nurse & $267 \pm 1.36$ & $321 \pm 1.74$ & $<0.01$ & $109 \pm 1.11$ & $163 \pm 1.66$ & $<0.01$ & $158 \pm 1.61$ & $158 \pm 1.82$ & 0.08 \\
\hline Mortality & $18(9.1)$ & $12(6.5)$ & 0.34 & $8(8.2)$ & $7(7.1)$ & 0.79 & $10(10.1)$ & $5(5.7)$ & 0.28 \\
\hline Combined endpoint & 32 & 32 & 0,64 & 11 & 15 & 0,37 & 21 & 17 & 0,96 \\
\hline Total amount of days in study & 64911 & 59204 & & 32152 & 31524 & & 32759 & 27680 & \\
\hline Mean days in study (per patiënt) & 330 & 320 & & 328 & 322 & & 331 & 318 & \\
\hline
\end{tabular}

p-value: Mann-Whitney test

${ }^{\dagger}$ Cardiovascular or heart failure therapy related

$\neq$ (percentage)

tMean number of contacts

\section{Subgroup analysis of the primary endpoint}

Cox regression analysis showed an important interaction between group assignment and heart failure duration, $p=0.007$, odds ratio $(\mathrm{OR})=0.983,95 \% \mathrm{Cl} 0.970-0.995$ adjusted for the baseline variables ischemia, blood urea, haemoglobin level, heart rate, NYHA class, and systolic blood pressure, as shown in Table 4. Subgroup analyses showed that the variables heart failure duration $\leq 18$ months (HR $0.26,95 \% \mathrm{Cl} 0.07$ - 
$0.94, p=0.026)$, having a pacemaker (HR 0.37, 95\% Cl 0.15-0.93, $p=0.030$ ), and cohabiting ( $\mathrm{HR} 0.42,95 \% \mathrm{Cl} 0.17-1.01, p=0.040$ ) were positive for the telemonitoring arm, as illustrated in Figure 3. If heart failure duration was $\leq 18$ months, patients had significantly fewer admissions for heart failure (Mann-Whitney $p=0.026$ ) (Figure 2C). Moreover, no patients were re-admitted in the intervention group, compared with 5 patients with 11 readmissions in the usual care group (Mann-Whitney $p=0.024$ ).

Table 4 Univariate and Cox regression analysis of the primary endpoint

\begin{tabular}{|c|c|c|c|c|}
\hline & $P$-value & Hazard & Lower & Upper \\
\hline \multicolumn{5}{|l|}{ Univariate analysis } \\
\hline Group (intervention / usual care) & 0.155 & 0.65 & 0.35 & 1.18 \\
\hline \multicolumn{5}{|l|}{ Cox regression analysis } \\
\hline Group (intervention / usual care) & $<0.001$ & 4,96 & 2.022 & 12.181 \\
\hline Group * History of HF & .007 & 0,98 & .970 & .995 \\
\hline NYHA 2 & .020 & & & \\
\hline NYHA 3 vs 2 & .006 & 0,00 & $<0.001$ & .183 \\
\hline NYHA 4 vs 2 & .216 & 0,00 & $<0.001$ & 49.205 \\
\hline BP systolic & $<0.001$ & 0,94 & .909 & .968 \\
\hline History of HF & .001 & 1,02 & 1.007 & 1.024 \\
\hline Ischemia & .022 & 2,14 & 1.113 & 4.098 \\
\hline Urea & .001 & 1,08 & 1.031 & 1.122 \\
\hline Haemoglobin & .004 & 0,64 & .474 & .867 \\
\hline Heart Rate & $<0.001$ & 1,05 & 1.023 & 1.068 \\
\hline NYHA $2 *$ BP-sys & .011 & & & \\
\hline NYHA 3 vs $2 *$ BP-sys & .004 & 1,06 & 1.018 & 1.095 \\
\hline NYHA 4 vs $2 *$ BP-sys & .094 & 1,08 & .987 & 1.183 \\
\hline
\end{tabular}

Hazard $=$ Cox Regression Effect

Table 4 Cox regression analysis was performed to demonstrate the influence of baseline characteristics on admissions for heart failure. This table demonstrates the interaction between HF-history and group allocation. 
CHAPTER 5

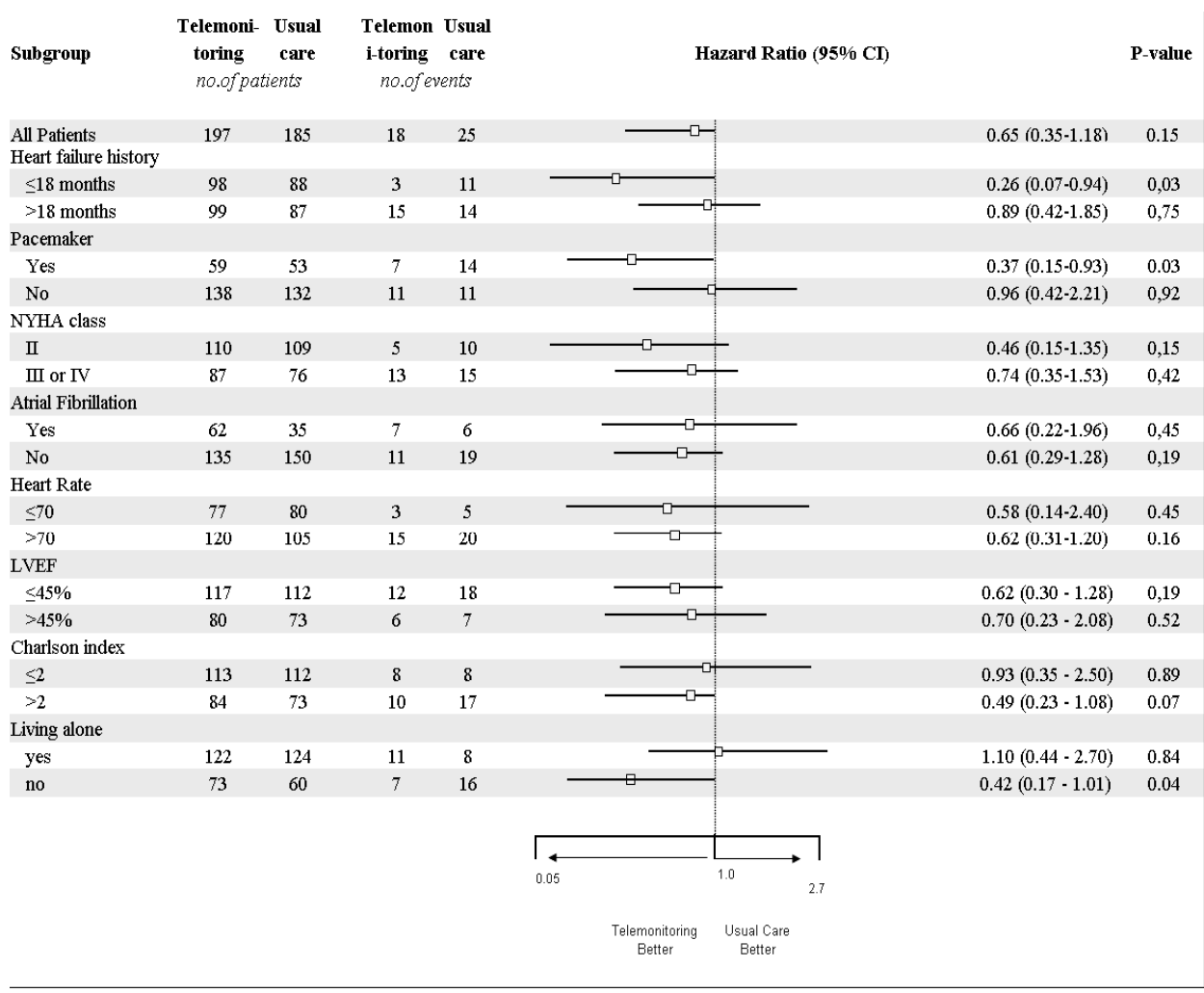

Figure 3 Subgroup Analysis of time to first admission for heart failure

NYHA denotes New York Heart Association. Data on living alone were missing for 3 patients

Figure 3 Hazard ratio and 95\% confidence interval for different subgroups of patients

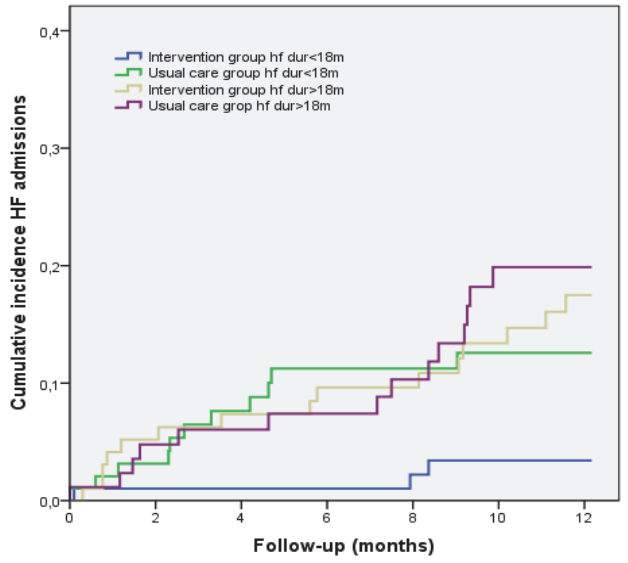

Figure $2 \mathrm{c}$ time to first heart failure admission for patients with a heart failure duration $<18$ months and $>18$ months 


\section{Mortality}

Eighteen patients (9.1\%) died in the intervention group and $12(6.5 \%)$ in the usual-care group (Mann-Whitney $p=0.34$ ), due to cardiovascular disease in $11(61 \%)$ compared with 7 (58\%), respectively (Mann-Whitney $p=0.92$ ). After adjustment for age, NYHA classification, and urea, using Cox regression analysis no statistical difference was found $(p=0.82)$. Mortality was evenly distributed over time.

\section{Discussion}

This is the first randomised controlled clinical trial in a heart failure population evaluating a tailored telemonitoring approach aimed at identifying early symptoms and enhancing self-care and treatment adherence through increasing disease-specific knowledge. Nevertheless, due to practical restrictions, tailoring of the telemonitoring was not as advanced as the authors intended; they still talk about "tailoring", while this is a remarkable differentiating feature compared with other telemonitoring systems.

It is concluded that this study resulted in a neutral effect, possibly caused by under powering of the population on one hand and using medically well-treated study groups on the other hand. The latter has limited the room for improvement. Power analysis was based on a $25 \%$ admission rate for heart failure [15]. However, this reference population included discharged patients after an admission for heart failure, whereas our patients were recruited at the outpatient clinic, with only $6.8 \%$ of patients admitted for heart failure during the 30 days before study enrolment. With respect to the patients in the usual-care group, they mostly were in NYHA class II (57\%), medically well treated with $90 \%$ on angiotensin-converting enzyme (ACE) inhibitors and $82 \%$ on betablockers, and undergoing an intensive follow-up at the heart failure outpatient clinic.

Regarding the primary endpoint, a reduced number of hospitalisations for heart failure in contrast to a non-significant increased mortality was found in the intervention group. The higher mortality rate may have influenced the reduction of heart failure admissions. Therefore, a composite endpoint of heart failure admissions and mortality for all causes would have been stronger. Nevertheless, combining heart failure admissions and mortality also resulted in a neutral outcome for the whole study groups, and for the subgroups (data not shown). Using the distinction between telemonitoring and structured telephone support (STS) as described by Inglis et al. [16], the TEHAF study belongs to the STS group; however, studies, comparable with our study, with intensified management, were excluded from their systematic review. Inglis et al. found a significantly reduced number of hospitalisations for heart failure $(p=0.0001)$, and allcause hospitalisations $(p=0.02)$, and a non-significant trend for all-cause mortality $(p=$ 0.08 ). In contrast to these findings, we only found a trend to reduced heart failure hospitalisations and also a high daily adherence to the intervention. 
The very well treated usual care group, leaving little opportunity for improvement, may have declared the absence of a significant effect on heart failure hospitalisations and mortality. Follow-up included visits at the outpatient clinic and/or home visits. No distinction was made between these follow-up modalities, although home visits were mostly to more seriously ill patients with a high care consumption, which may have negatively influenced the results. Inglis et al. [16] reported two studies with an improved knowledge level, which was comparable with our results, yet a discussion of these results is beyond the scope of this article.

Daily use of the system is a critical factor for success of therapy; therefore, efforts have to be made to increase adherence to the daily system. Notwithstanding the similarity in terms of being categorized as STS, there were some important differences between the TELE-HF and TEHAF studies, which may have influenced daily system adherence by patients as well as by caregivers. One important difference was the tailoring of information to patients' needs and physical stability. For example, patients whose condition was stable received only a few symptomatic questions, whereas questioning about symptoms was intensified in cases of physical instability. Tailoring of information has the potential to involve patients and corresponds most to face to face contacts, giving patients the feeling of being taken seriously and leading to increased patient commitment. Telemonitoring may be considered as a decision-making aid. Decision aids prepare people to be involved in the decision-making process. The ultimate goal of decision aids is to improve decision making in order to reach a high quality decision [17]. A strategy of applying individualized questions on symptoms at the time of enrolment has been used before [18], resulting in $98.5 \%$ compliance. In addition to the system used in the TELE-HF study, our system delivers education and supports selfmanagement. Curiosity about new information may have triggered an improved daily use of the system by patients. Our impression is that almost the same not-applicable questions are boring and may lead to non-adherence to the system. In addition, the system used in this study collected patient information by requiring them to press a button on an appliance, after patients had been read a question on the display, whereas patients in the TELE-HF study had to make a daily toll-free call which may have been experienced as an obstacle to compliance. In contrast to the TELE-HF, no reminders were needed to activate caregivers to review patient information, while reviewing remote information was embedded in the daily organisation of nursing care.

Subgroup analysis showed greater effects in patients with a heart failure duration, 18 months, having a pacemaker, and patients not living alone. The effectiveness regarding heart failure duration may be due to a greater willingness to adopt an appropriate lifestyle and to cope effectively with heart failure. Moreover this category mostly has less severe heart failure, and is easier to treat at a distance. Also co-habiting patients seem to benefit more from telemonitoring, possibly caused by encouragement by the partner to use the system. On the other hand, a patient's responsibility for the partner might have been a motive for adherence to the system. 
The TEMA-HF [19] study included 160 patients in eight centres, with a mean age of 76 years, and a follow-up time of 6 months. Using a telemonitoring system automatically transferring body weight, blood pressure, and heart rate, a reduced mortality rate ( $p=$ $0.001)$, number of re-admissions for heart failure $(p=0.056)$, and number of days to follow-up ( $p=0.02$ ) was found. Moreover, the system was used as a communicationfacilitating tool between the heart failure clinic and general practitioners (GPs). Patients were recruited during hospitalisation and patients of both groups visited the outpatient clinic 2 weeks after discharge. In addition to this, patients of the telemonitoring group visited the cardiologist after 3 and 6 months, while patients of the usual-care group were followed by their GP. Yet it is unclear whether or not patients in the usual-care group had planned appointments that may have resulted in suboptimal care. This is in contrast to our study where the intervention was superposed on optimal care in both groups, with all patients treated at the heart failure clinic or visited at home. The possible suboptimal care of the usual-care group in the TEMA-HF study may have enhanced the differences between the groups, whereas the optimal treatment for both groups in our study may have mitigated the differences. No between-group differences for medication were found at baseline in the TEMA-HF study, whereas a significant difference was found to the disadvantage of the usual-care group regarding the use of diuretics, ACE inhibitors, and beta-blockers at the end of the study. This indicates undertreatment of patients in the usual care group. The combination of suboptimal care and under-treatment in the usual-care group of the TEMA-HF study, in contrast to the wellorganised care and optimal medication treatment in our study groups, may explain the difference in effects on mortality. Also, patients in the TEMA-HF study were recruited during hospitalisation, whereas patients of the TEHAF study were mostly stable as they were recruited at a regular visit to the outpatient clinic. Patients discharged for heart failure are at risk of being re-admitted for heart failure [20,21], in contrast to stable patients followed at a heart failure clinic. Accordingly, the most benefit to gain in terms of heart failure (re)admissions can be found in recently discharged patients. This discrepancy in study populations may explain the difference in the reduced number of heart failure admissions between the studies. However, sub analysis in our study found differences between groups depending on their heart failure duration, whereas the TEMA-HF study described no subgroup analysis. It would be interesting to know whether the results of the TEMA-HF study could be attributed to the automated data transfer only, to the improved communication between caregivers, or to both. However, the introduction of a telemonitoring application to improve communication between caregivers is new and challenging, and the positive results and experiences create opportunities where cooperation between caregivers is needed. Another method of remote monitoring is the use of an implantable diagnostic tool to measure intrathoracic impedance. Van Veldhuizen et al. [22] reported on a clinical trial comparing one study group with access to all device-based diagnostic information with a group without this information available. The primary endpoint was heart failure hospitalisations and all- 
cause mortality. A total of 168 participated in the intervention and 167 in the control arm. Patient characteristics were comparable with those of our study regarding NYHA classification, medication prescription, and type of heart failure, yet differed in terms of left ventricular ejection fraction ( $25 \%$ vs. $35 \%$ ), mean age (64 vs. 72 years), and gender (male $86 \%$ vs. $59 \%$ ). A remarkable feature of the DOT-HF study is the high number of admissions for heart failure (96) as well as for other cardiovascular reasons (189), which is in contrast to our study, whereas mortality was comparable. The high number of hospitalisations in the treatment arm was unexpected, as using intrathoracic impedance previously has been shown to reduce hospital admissions [23-25]. Although early signs and symptoms are reported to be unspecific [26], impedance monitoring also did not succeed in preventing admissions for heart failure (HR 1.79). Remarkable and rather distressing is the high number of patients in the study arm admitted with signs and symptoms of heart failure yet without an Optivol alert, indicating signs and symptoms to be more reliable than impedance monitoring. The large number of outpatient unplanned visits in the DOT-HF study is also in contrast to our study that showed a significant reduction in face-to-face contacts with the nurse. Of note in the DOT-HF study is the contrast between the high number of alerts requiring physical examination on the one hand, and the number of patients admitted without Optivol alerts on the other hand. Those findings suggest that monitoring intrathoracic impedance is unreliable at the moment and is not ready (yet) for implementation in daily practice. The authors conclude that further studies are needed to examine the place of this feature; a suggestion may be to collect patient data regarding signs and symptoms, while the current study has proven that evaluation is useful both to guide patients at a distance resulting in fewer heart failure hospitalisations and contacts with caregivers, in contrast to the DOT-HF study underestimating signs and symptoms. The combination of data collection of impedance and symptoms may provide more insight into the relationship between both which probably will improve the usefulness of this feature. Angermann et al. [27] described their experiences with the INH study with an intervention existing of a combination of different actions such as intensive telephone contacts between the specialist nurse and the patient with structured monitoring of symptoms, medication, mood, and well-being; up-titration of medication; availability of blood pressure and weight; and the need for adjusted specialist care. The study population consisted of patients with systolic heart failure; 352 in the intervention (HNC) and 363 in the control (UC) arm. No difference was found regarding the primary endpoint of time to death or rehospitalisation; however, patients in the HNC arm were more frequently re-admitted, whereas in the UC arm more patients died, which was in contrast to our study.

They also found surrogates for improved well-being in the HNC group, yet it is not clear which part of the intervention is responsible for that finding. The high number (37\%) of questions related to non-cardiac problems was remarkable, again demonstrating the complexity of care for heart failure patients. In their discussion, Angermann et al. state that comprehensive care models have to integrate specific surveillance for the 
complex facets of heart failure and physical problems of multimorbidity and old age, and we agree with this. However, it has to be determined whether for patients frequently needing more attention for non-cardiac problems a generalist nurse preferably should supervise them rather than a specialized nurse. The number of non-cardiac problems probably is even higher in the group of patients suffering from heart failure with preserved systolic function, while those patients mostly are older; because only patients with systolic heart failure were included, information about the effect on this important heart failure category is missing. Involving patients with diastolic heart failure would probably have strengthened their findings. Regarding the high number of patients who withdrew from the intervention it would be interesting to know why they withdrew, yet unfortunately the authors gave no explanation of this finding.

The $21 \%$ of patients not completing the 1-year follow-up was comparable with a recently published study [6] and is expected, given their limited general condition and older age. The dropout rate was higher in the usual-care group, mainly due to loss of interest and loss to follow-up.

Similar to the HOME-HF study [28], a reduction in face-to-face contacts was found. While our contacts concern the heart failure nurse, it remains unclear which contacts were reduced in the HOME-HF-study as the authors were referring to secondary outpatient visits.

No significant difference was found for mortality, suggesting there was no negative effect of the intervention and of the reduced number of face-to-face contacts. This finding and the decreased number of heart failure admissions suggest the intervention to be cost-effective.

Regarding the different programs used in this study, their specific value cannot be commented on, as this was not part of the study.

\section{Limitations}

This study was slightly underpowered due to a power calculation based on a recently admitted heart failure population whereas our population was recruited from regular outpatient visits. A combined endpoint of heart failure hospitalisations and mortality would have been appropriate. No subgroups were pre-specified, therefore the results of the subgroup analysis have to be considered as hypothesis generating, in future research. There was a slightly unequal distribution over the study arms, although this had no effect on baseline characteristics and clinical descriptors. All-comer outpatients with stable heart failure were enrolled, resulting in a heterogeneous mix of differences in hospitalisation rates, heart failure severity, stages of heart failure, and comorbidities. However, the study groups were well balanced concerning these items. In addition, recruitment of a real-life population strengthens the external validity of our findings. 
Not all participants completed the full follow-up, mostly due to age and the disease severity typical for the study population.

\section{Conclusion}

No significant differences were found regarding the primary endpoint, most probably caused by a relative under-powering of the population combined with well-treated study groups. However, telemonitoring tends to reduce heart failure (re)admissions and significantly decreases contacts with specialized nurses. Further research is required to investigate telemonitoring in pre-specified subgroups, and the match between the system and the patient.

These data about stable clinic patients may provide information for power analysis in future studies. 


\section{References}

1. Mosterd A, Hoes A. Clinical epidemiology of heart failure. Heart 2007; 93: 1137-1146.

2. Bonneux L, Barendregt J, Meeter K, Bonsel G, Vandermaas P. Estimating clinical morbidity due to ischemic-heart-disease and congestive-heart-failure-the future rise of heart-failure. American Journal of Public Health 1994; 84: 20-28.

3. Rich M, Beckham V, Wittenberg C, Leven C, Freedland K, Carney R. A multidisciplinary intervention to prevent the readmission of elderly patients with congestive heart failure. New England Journal of Medicine 1995; 333: 1190-1195.

4. Phillips C, Wright S, Kern D, Singa R, Shepperd S, Rubin H. Comprehensive discharge planning with postdischarge support for older patients with congestive heart failure: a meta-analysis. Journal of American Medical Association 2004; 291: 1358-1367.

5. Krumholz H, Currie P, Riegel B, Philips C, Peterson E, Smith R. A taxonomy for disease management: a scientific statement from the American Heart Association Disease Management Toxonomy Writing group. Circulation 2006; 114: 1432-144.

6. Chaudhry S, Mattera J, Curtis J, Spertus J, Herrin J, Lin Z, Philips C, Hodshon B, Cooper L, Krumholz H. Telemonitoring in patients with heart failure. New England Journal of Medicine 2010; 363: 2301-2309.

7. Mortara P, Pinna G, Johnson P, Ponikowski P, Tavazzi L, Sleight P. Home telemonitoring in heart failure patients: the HHH study (Home or Hospital in Heart Failure). The European Journal of Heart Failure 2009; 11: 312-318.

8. Cleland J, Louis A, Rigby A, Janssens U, Balk A, TEN-HMS Investigators. Noninvasive home telemonitoring for patients with heart failure at high risk of recurrent admission and death: the Trans-European Network-Home-Care Management System (TEN-HMS) study. Journal of American College of Cardiology 2005; 45: 1654-1664.

9. Vrijhoef HJ, Janssen-Boyne JJ, Kragten J, De Weerd GJ, Frederix M, Gorgels AP. The Health Buddy ${ }^{\circledR}$ telemonitoring system for patients with heart failure. The European Journal of Heart Failure 2006; 5 : Suppl174.

10. Boyne JJ, Vrijhoef HJ, De Wit R, Gorgels AP. Telemonitoring in patients with heart failure, the TEHAF study: study protocol of an ongoing prospective randomised trial. International Journal of Nursing Studies 2011; 48: 94-99.

11. World Medical Association. Declaration of Helsinki: ethical principle for medical research involving human subjects. 59th WMA General Assembly, Seoul 2008; www.wma.net/e/policy/b3.htm

12. Weintraub A, Gregory D, Patel AR, Levine D, Venesy D, Perry K, Delano C, Konstam M. A Multicenter randomized controlled evaluation of automated home monitoring and telephonic disease management in patients recently hospitalized for congestive heart failure: the SPAN-CHF II trial. Journal of Cardiac Failure 2010; 16: 285-292.

13. Benatar D, Bondmass M, Ghitelman J, Avitall B. Outcomes of chronic heart failure. Archives of Internal Medicine 2003; 163: 347-352.

14. Nieminen M, Böhm M, Cowie M, Drexler H, Filippatos G, Jondeau G, Hasin Y, Lopez-Sendon J, et al. ESC Committee for Practice Guideline (CPG). Executive summary of the guidelines on the diagnosis and treatment of acute heart failure: the Task Force on Acute Heart Failure of the European Society of Cardiology. The European Heart Journal 2005; 26: 384-416.

15. Cleland JG, Swedberg K, Follath F, Komajda M, Cohen-Solal A, Aguilar JC, Dietz R, Gavazzi A, Hobbs R, Korewicki J, Madeira HC, Moiseyev VS, Preda I, van Gilst WH, Widimsky J, Freemantle N, Eastaugh J, Mason J; Study Group on Diagnosis of the Working Group on Heart Failure of the European Society of Cardiology. The Euro Heart Failure survey programme-a survey on the quality of care among patients with heart failure in Europe. Part 1: patient characteristics and diagnosis. The European Heart Journal 2003; 24: 442-463. 
16. Inglis SC, Clark RA, McAlister FA, Stewart S, Cleland JG. Which components of heart failure programmes are effective? A systematic review and meta-analysis of the outcomes of structured telephone support or telemonitoring as the primary component of chronic heart failure management in 8323 patients: Abridged Cochrane Review. The European Journal of Heart Failure 2011: 9: 1028-1040.

17. Stacey D, Carol L, Bennett CL, Barry MJ, Col NF, Eden KB, Holmes-Rovner M, Llewellyn-Thomas H, Lyddiatt A, Légaré $F$, Thomson R. Decision aids for people facing health treatment or screening decisions. Cochrane Database Systematic Review 2003; 3: CD001431.

18. Goldberg L, Piette J, Walsh M, Frank T, Jaski B, Smith A, Rodriguez R, Mancini D, Hopton L, Oray E, Loh E. Randomized trial of a daily electronic home monitoring system in patients with advanced heart failure: the Weight Monitoring in Heart Failure (WHARF) trial. American Heart Journal 2003; 146: 705-712.

19. Dendale P, De Keulenaer G, Troisfontaines P, Weytjens C, Mullens W, Elegeert I, Ector B, Houbrechts M, Willekens $\mathrm{K}$, Hansen $\mathrm{D}$. Effect of a telemonitoring facilitated collaboration between general practitioner and heart failure clinic on mortality and rehospitalization rates in severe heart failure: the TEMA-HF 1 (TElemonitoring in the MAnagement of Heart Failure) study. The European Journal of Heart Failure 2012; 14: 333-340.

20. Stewart S, Maclntyre K, McCleod ME, Bailey AE, Capewell S, McMurray JJ. Trends in heart failure hospitalisations in Scotland, 1990-1996: an epidemic that has reached its peak? European Heart Journal 2001; 22: 209-217.

21. Mosterd A, Reitsma JB, Grobbee DE. ACE inhibition and hospitalization rates for heart failure in The Netherlands, 1980-1998. The end of an epidemic? Heart 2002; 87: 75-76.

22. Van Veldhuisen DJ, Braunschweig F, Conraads V, Ford I, Cowie M, Jondeau G, Kautzner,J, Aguilera R, Lunati M, Yu CM, Gerritse B, Borggrefe M. Intrathoracic impedance monitoring, audible patient alerts, and outcome in patients with heart failure. Circulation 2011; 124: 1719-1726.

23. Yu CM, Wang L, Chau E, Chan RH, Kong SL, Tang MO, Christensen J, Stadler RW, Lau CP. Intrathoracic impedance monitoring in patients with heart failure: correlation with fluid status and feasibility of early warning preceding hospitalization. Circulation 2005; 112: 841-848.

24. Vollmann D, Nägele H, Schauerte P, Wiegand U, Butter C, Zanotto G, Quesada A, Guthmann A, Hill MRS, Lamp B; European InSync Sentry Observational Study Investigators. Clinical utility of intrathoracic impedance monitoring to alert patients with an implanted device of deteriorating chronic heart failure. European Heart Journal 2007; 28: 1835-1840.

25. Packer M, Abraham WT, Mehra MR, Yancy CW, Lawless CE, Mitchell JE, Smart FW, Bijou R, O'Connor CM, Massie BM, Pina IL, Greenberg BH, Young JB, Fishbein DP, Hauptman PJ, Bourge RC, Strobeck JE, Murali S, Schocken D, Teerlink JR, Levy WC, Trupp RJ, Silver MA; PREDICT Study Investigators and Coordinators. Utility of impedance cardiography for the identification of short-term risk of clinical decompensation in stable patients with chronic heart failure. Journal of the American College of Cardiology 2006; 47: 22452252.

26. Stevenson LW, Perloff JK. The limited reliability of physical signs for estimating hemodynamics in chronic heart failure. Journal of American Medical Association 1989; 261: 884-888.

27. Angerman C, Störk S, Götz G, Faller H, Jahns R, Frantz S, Loeffler M, Ertl G. Mode of action and effects of standardized collaborative disease management on mortality and morbidity in patients with systolic heart failure: the interdisciplinary network for heart failure (INH) study. Circulation Heart Failure Journal 2012; 5: 25-35.

28. Dar O, Riley J, Chapman C, Dubrey S, Morris S, Rosen S, Roughton M, Cowie M. A randomized trial of home telemonitoring in a typical elderly heart failure population in NorthWest London: results of the Home-HF study. The European Journal of Heart Failure 2009; 11: 319-325 


\section{CHAPTER 6}

Cost-effectiveness analysis of telemonitoring versus usual care in patients with heart failure (the TEHAF-study)

Josiane J.J. Boyne, Antoinette D.I. Van Asselt, Anton P.M. Gorgels, Lotte M.G. Steuten, Hubertus J.M. Vrijhoef, on behalf of the TEHAF investigators

Journal of Telemedicine and Telecare: $2013 ; 19(5): 242-248$ 


\section{Summary}

We examined the incremental cost-effectiveness of telemonitoring (TM) versus usual care (UC) in patients with congestive heart failure (CHF). In one university and two general hospitals, 382 patients were randomised to usual care or telemonitoring and followed for 1 year. Hospital-related and home costs were estimated, based on resource use multiplied by the appropriate unit prices. Effectiveness was expressed as QALYs gained. Information was gathered, using 3 monthly costs diaries and questionnaires. The mean age of the patients was 71 years (range 32-93), 59\% were male and $64 \%$ lived with a partner. Health related quality of life improved by 0.07 points for the usual care and 0.1 points for the telemonitoring group, but the difference between groups was not significant. There were no significant differences in annual costs per patient between groups. At a threshold of $€ 50,000$ the probability of telemonitoring being cost-effective was $48 \%$. The cost effectiveness analysis showed a high level of decision uncertainty, probably caused by the divergence between the participating institutions. It is therefore premature to draw an unambiguous conclusion regarding cost-effectiveness for the whole group. 


\section{Introduction}

The prevalence of congestive heart failure (CHF) will rise in ageing populations and so will the related health care costs for these patients [1, 2]. The prevalence of CHF is $1-2 \%$ in industrialised countries and increases with age [3]. Expenditure on CHF consumes 1$2 \%$ of the total healthcare budget in industrialised countries [4, 5]. The danger is that the demand for care will exceed available resources. Telemonitoring (TM) is a promising method for managing CHF, [6] but it has not yet been widely adopted Studies regarding cost reductions are not convincing, mainly due to inconsistent methodology [7, 8]. One study and two reviews suggested a tendency to lower costs, yet none reached definitive conclusions about costs [9-11]. We conducted the Telemonitoring in Heart Failure (TEHAF) study, to assess the effects on hospital admissions, quality of life, adherence, self-care, self-efficacy, disease specific knowledge and depression. Although the overall result, using time to first CHF hospitalisation as the endpoint, did not show a benefit, post-hoc analysis showed a significant decrease in CHF hospitalisations in the subgroup of patients with CHF duration less than 18 months (without a significant difference in mortality rate) and in face-to-face contacts with the heart failure nurse (heart-failure nurse) [11]. The aim of the present study was to investigate the incremental cost-effectiveness of TM versus usual care (UC) in patients with CHF and also in the subgroups of patients with CHF duration shorter or longer than 18 months.

\section{Methods}

A detailed description of the TEHAF study has been published elsewhere [11, 12]. In short, 382 patients were included in the CHF outpatient clinics of three hospitals, if diagnosed for $\mathrm{CHF}$, capable of providing informed consent, treated by a cardiologist and heart-failure nurse and being older than 18 years. Patients were excluded if operating the telemonitoring system was impracticable, the expected life span was 1 year, in case of chronic pulmonary disease Gold classification 3-4, or when receiving haemodialysis. One academic and two general hospitals participated in the study, with 172, 144 and 66 patients respectively. All hospitals delivered care according the relevant guidelines, although the place where care was delivered differed between hospitals. In the academic centre, patient contacts took place in the outpatient clinic and at home; in one general hospital (144 patients) patient contacts occurred in the outpatient clinic and in the other centre (66 patients) patients were visited at home.

Patients were randomly allocated to UC or TM, and followed for 1 year. Patients in the UC group received oral and written information about CHF, had easy access to the HFN and four pre-planned outpatient clinic visits during follow-up. Patients in the TM group received identical information, but had only two pre-planned outpatient clinics. 
Instead they received a telemonitoring device (Health Buddy ${ }^{\circledR}$, Sananet, Sittard, The Netherlands) at home.

The telemonitoring device had a display and four keys, and was connected to a telephone line. Patients received daily pre-set dialogues and questions about symptoms, knowledge and behaviour, which had to be answered by touching one of the keys. Subsequently the answers were transmitted to a server and made available via a server to the nurses' desktop. Responses were categorised into risk profiles, (low, medium, high) [13] allowing the nurse to quickly identify high-risk patients. Positive answers for symptoms were categorised as high-risk, and triggered immediate action by the heart-failure nurse. We created four sets of dialogues with different emphasis on symptoms or knowledge and behaviour [13]. At the start of the study all patients received the same initial set of dialogues, which was evenly balanced for symptoms and education. After three months the first evaluation of symptoms and education level occurred, whereupon patients were allocated to an educational or an intensive symptom-monitoring program. This was based on the number of high-risk alerts during the last 30 days before the end of a program. Following an admission for heart failure, patients were always allocated to an intensive symptom monitoring set of dialogues. Monitoring of vital signs was not part of the system. The study was approved by the appropriate ethics committees.

\section{Outcome measurements}

Effectiveness was expressed as quality adjusted life years (QALYs) gained. A QALY is calculated by multiplying the utility score of being in a certain health state by the time that the patient experienced that state. Utility scores were derived by conversion of the EQ-5D [14]. This is an instrument assessing five health-related quality of life (HRQoL) dimensions: mobility, self-care, daily activities, pain/discomfort and depression/anxiety. Patients at baseline and after 3, 6 and 12 months completed a postal questionnaire to measure EQ-5D. Based on preferences elicited from a general UK population, [15] EQ$5 \mathrm{D}$ status can be converted into utility scores, ranging from -0.59 (worst health state) to 1 (best health state).

\section{Costs}

The cost analysis was performed from the healthcare perspective, i.e. all costs inside the healthcare sector were included. Cost data were gathered by means of a 3-monthly prospective cost diary and provided by post with every questionnaire. Information was obtained at baseline, after 3, 6, 9 and 12 months. For calculation of the costeffectiveness, baseline costs were not included, because the data reflected information from the 3 months prior to the study baseline. The cost diary collected data regarding contacts with the general practitioner (GP), telephone and face-to-face contacts with 
the HFN and specialists, emergency room visits, ambulance transport, sessions with the physiotherapist and psychologist, and homecare including household, personal and nursing care. Data about in-hospital procedures and hospital admissions were gathered from the hospital registry systems of the three participating centres. The patients' pharmacist provided costs about delivered medication. If this information was not available, costs were based on the prescriptions. Medication costs were calculated for all HF medications. Prices for medication were derived from the Dutch Pharmacotherapeutic Compass [16]. Prices of in-hospital procedures were provided by the participating hospital financial departments. Because of the follow-up time of 1 year, no discounting was used. For the costs of hospitalisations and emergency room visits, GP, HFN, specialists, physiotherapist, psychological support and home care, prices were derived from a national cost manual [17]. When necessary, prices were converted to the price level of 2008 using the price index number provided by the Dutch Central Bureau for Statistics [18]. For the intervention group, supplier-derived telemonitoring costs were added, such as device rental, maintenance and telecommunication costs. In case of a contact from a caregiver with a patient, the participating centres were responsible for the telephone bills. Costs were rounded to the nearest Euro.

\section{Cost-effectiveness}

Cost-effectiveness was expressed as an Incremental Cost-Effectiveness Ratio (ICER), which was calculated as incremental costs divided by incremental effects. The ICER can be interpreted as the extra monetary resources needed for the intervention strategy to gain one extra QALY compared to UC.

\section{Data analyses}

Demographic interval and ratio variables were investigated for normality of distribution with the Shapiro -Wilk test. Missing QALY and costs data were imputed using SPSS multiple imputation [19]. Data from patients without a valid utility score were removed from the analysis. Cost data were generally skewed and not normally distributed. Therefore, a non-parametric bootstrap with 1000 replications to estimate confidence intervals was performed $[20,21]$. The 2.5 th and 97.5 th percentiles represent the confidence interval.

The results of the bootstrap iterations were presented in cost-effectiveness planes and cost-effectiveness acceptability curves (CEACs) [22]. The CEAC represents the probability that the intervention is cost-effective, for a range of thresholds for the willingness to pay (WTP) for one QALY. A CEAC is constructed by taking a certain WTP threshold and calculating the percentage of the 1000 bootstrapped ICERs that fall below that threshold, and therefore considered cost-effective at that threshold. By repeating this procedure for various thresholds, a curve is generated, with the WTP threshold on the 
$x$-axis and probability of the intervention being cost-effective on the $y$-axis. Severity of a disease co-determines the WTP threshold. While HF is considered a severe disease, for this analysis the threshold is conservatively assumed to be $€ 50,000$ [23]. Subgroup analysis was performed for the duration of $\mathrm{CHF}$, in accordance with previously published results. In addition, subgroup analysis was performed per participating centre [12]. Analyses were performed using a standard package (SPSS version 18).

\section{Results}

The mean age of the patients was 71 years, $59 \%$ were male, $64 \%$ lived with a partner and $57 \%$ were in NYHA class II (Table 1). More detailed information regarding patient characteristics has been published elsewhere [12].

Table 1 Baseline characteristics

\begin{tabular}{|c|c|c|c|c|c|}
\hline Variable & $\mathbf{N}$ & Total & Intervention (197) & Control (185) & $p$-value \\
\hline Age (yr) & 382 & $71.0 \pm 11$ & $71.0 \pm 11.9$ & $71.9 \pm 10.5$ & 0.621 \\
\hline$\geq 75$ & & $173(45)$ & $88(45)$ & $85(46)$ & 0.199 \\
\hline Gender Male & & $226(59)$ & $115(58)$ & $111(60)$ & \\
\hline Married / partner & 379 & $245(64)$ & $122(62)$ & $123(66)$ & 0.265 \\
\hline History of HF (months) & 382 & $31( \pm 38)$ & $32( \pm 38)$ & $29( \pm 38)$ & 0.413 \\
\hline HF history $<18$ months & & $196(51)$ & $98(26)$ & $98(26)$ & \\
\hline Ejection fraction & 374 & $38 \pm 13.7$ & $38 \pm 13.7$ & $38 \pm 13.6$ & 0.751 \\
\hline Ischemia & 382 & $190(50)$ & $99(50.3)$ & $91(49.2)$ & 0.835 \\
\hline NYHA-classification / no (\%) & 382 & & & & 0.404 \\
\hline NYHA II & & $219(57)$ & $110(56)$ & 109 (59) & \\
\hline NYHA III & & $153(40)$ & $79(40)$ & $74(40)$ & \\
\hline NYHA IV & & $10(3)$ & $8(4)$ & $2(1)$ & \\
\hline \multicolumn{6}{|l|}{ Medication } \\
\hline Diuretics & 380 & $333(87)$ & $170(86)$ & $163(88)$ & 0.783 \\
\hline ACE inhibitors & 378 & $217(57)$ & $113(58)$ & $104(57)$ & 0.826 \\
\hline ATII-antagonists & 373 & $123(33)$ & $67(35)$ & $56(31)$ & 0.459 \\
\hline Bèta-blockers & 379 & $310(82)$ & $161(82)$ & $149(81)$ & 0.689 \\
\hline Digoxin & 372 & $91(24)$ & $46(24)$ & $45(25)$ & 0.770 \\
\hline Charlson index & 382 & $2.5( \pm 1.5)$ & $2.6( \pm 1.5)$ & $2.4( \pm 1.4)$ & 0.358 \\
\hline
\end{tabular}

Values are presented as number (\%) or mean \pm SD 


\section{Health-related quality of life}

Data of 192 patients in the TM and 182 patients in the UC group were analysed. No significant differences were found at baseline. Utility scores improved by 0.07 points for the UC and 0.1 points for the TM group, but the difference between groups was not significant. This effect correlated with the QALY-score, which also showed no difference. The difference between the groups was -0.0031 QALY, with a 95\% confidence interval $(\mathrm{Cl})$ of -0.0552 to 0.0578 , indicating no difference in health-related quality of life. In addition the EQ-5D was assessed for the subgroup duration of CHF less or more than 18 months, and again there was no significant difference. For both the group as a whole and the subgroups, the EQ-5D rose consistently in the intervention group, in contrast to the UC group (Figure 1).

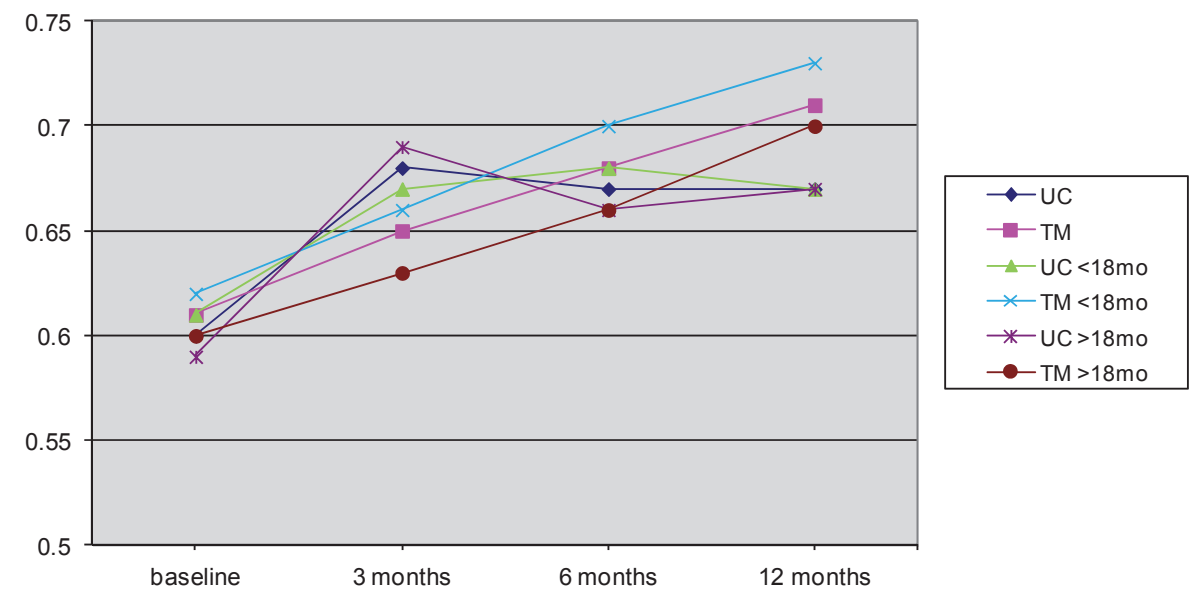

Figure 1 Mean EQ-5D utility scores for all assessments

\section{Costs}

The total costs were $€ 16,687$ ( $\mathrm{Cl} 14,041-19,114)$ in the TM group and $€ 16,561$ ( Cl $13,635-20,218$ ) in the UC group, see Table 2 . The difference between groups was $€ 126$, indicating no significant difference $(\mathrm{Cl}-4374-3763)$. None of the costs showed a significant difference between groups except for physiotherapy costs in the telemonitoring group, which were $€ 46$ ( $\mathrm{Cl}$ 9-101) higher. In the TM group the frequency of contacts with the HFN was higher, yet costs were lower as a result of fewer face-to-face contacts (€-31, Cl-88-145). 


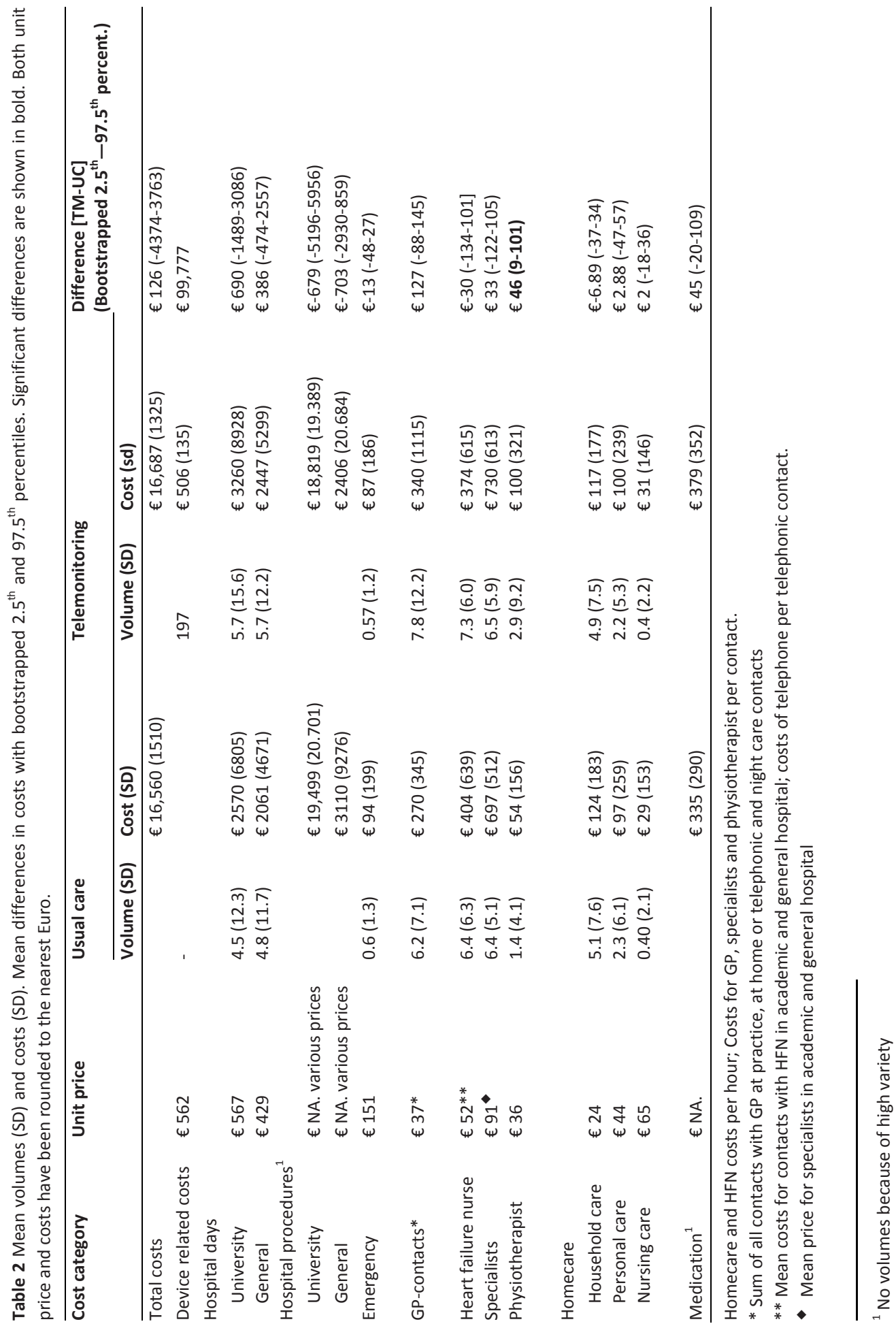




\section{Cost-effectiveness}

The ICER for TM versus UC amounted to $€ 40,321$ per QALY gained. The incremental cost-effectiveness plane for cost per QALY is shown in Figure 2. The fact that the incremental cost-effectiveness pairs are located around zero and equally spread over the four quadrants indicates substantial uncertainty, for both costs and QALYs. The probability of telemonitoring being cost effective may depend on the amount that society is willing to pay (WTP) to gain a QALY. However, within the WTP range chosen, the WTP does not influence this probability (Figure 3). At a threshold of $€ 50,000$ the probability of TM being cost-effective is $48 \%$.

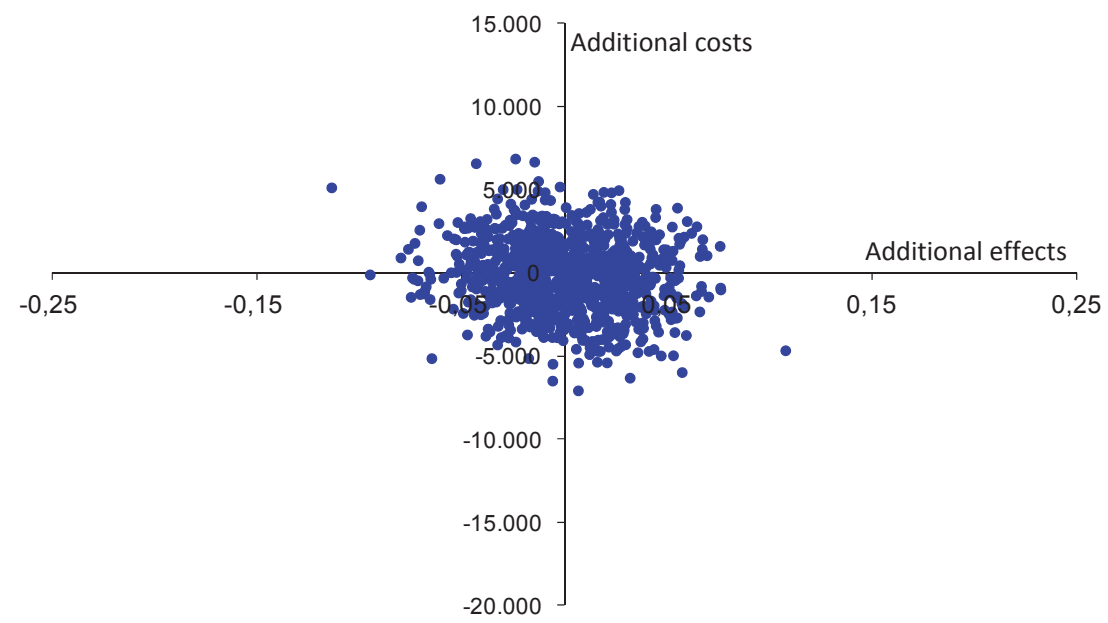

Figure 2 Incremental cost-effectiveness plane for cost per QALY (telemonitoring versus usual care)

\section{Cost-effectiveness}

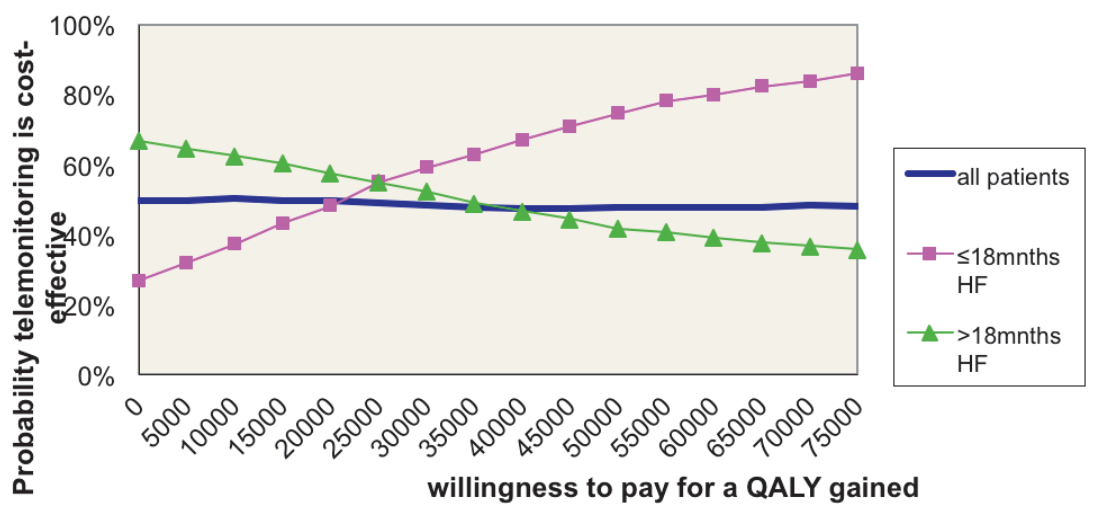

Figure 3 Cost-effectiveness acceptability curve for cost per QALY 


\section{Subgroup analyses}

Incremental cost effectiveness pairs in the subgroup of HF duration less than 18 months were located for $72 \%$ and $27 \%$ respectively in the upper- and lower right quadrant indicating that telemonitoring generated more QALYs and mostly at higher costs compared to UC ( $\mathrm{Cl}-4038$-8063) (Figure 4). For incremental costs per QALY, the probability of telemonitoring being cost-effective compared to UC therefore was $75 \%$ (Figure 3 ). In the subgroup of patients with $\mathrm{HF}$ duration more than 18 months, $90 \%$ of the pairs were located in the left quadrants of the ICER plane, indicating lower QALYs, mostly combined with lower costs, and a probability of being cost effective of $42 \%$ (Figure 4). Incremental cost effectiveness pairs from two centres (the university centre and general hospital 1) were located at the right quadrants indicating better health-related quality of life for the telemonitoring group. For the university centre, cost-effectiveness pairs were located in both right quadrants, indicating more QALYs with uncertainty of costs, whereas for general hospital 1, pairs were mostly located in the upper right quadrant, indicating more QALYs at higher costs for telemonitoring compared to the university centre (Figure 5). The respective ICERs for costs per QALY gained were $€ 22,216$ and $€ 23,051$. Cost effectiveness pairs for the remaining centre were mainly located in the lower left quadrant indicating lower QALYs at lower costs, with an ICER per QALY of $€ 55,256$.

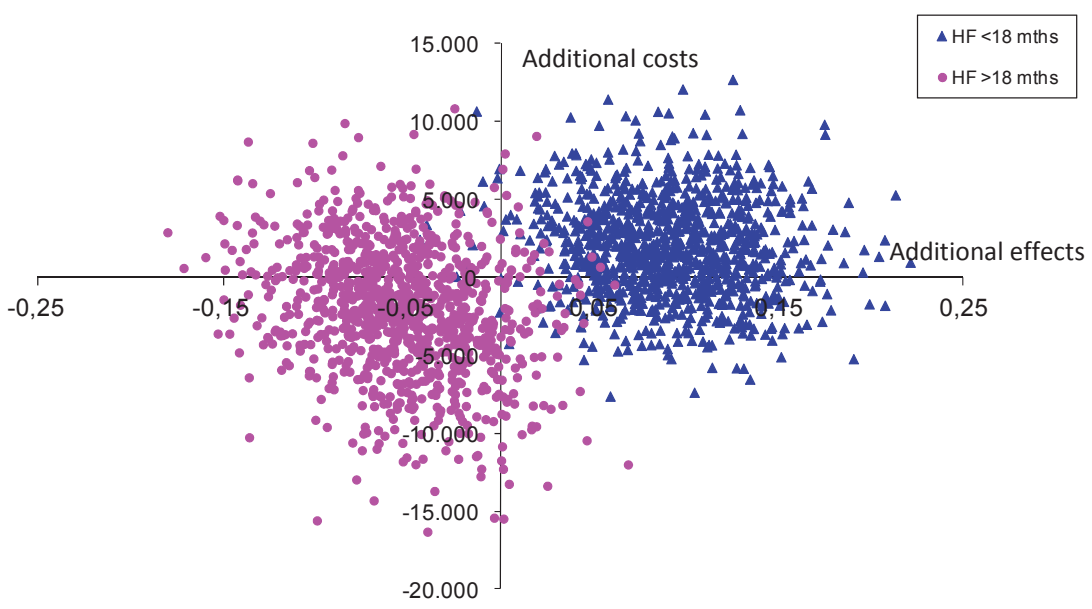

Figure 4 Incremental cost-effectiveness plane for cost per QALY (heart failure less and more than 18 months) 


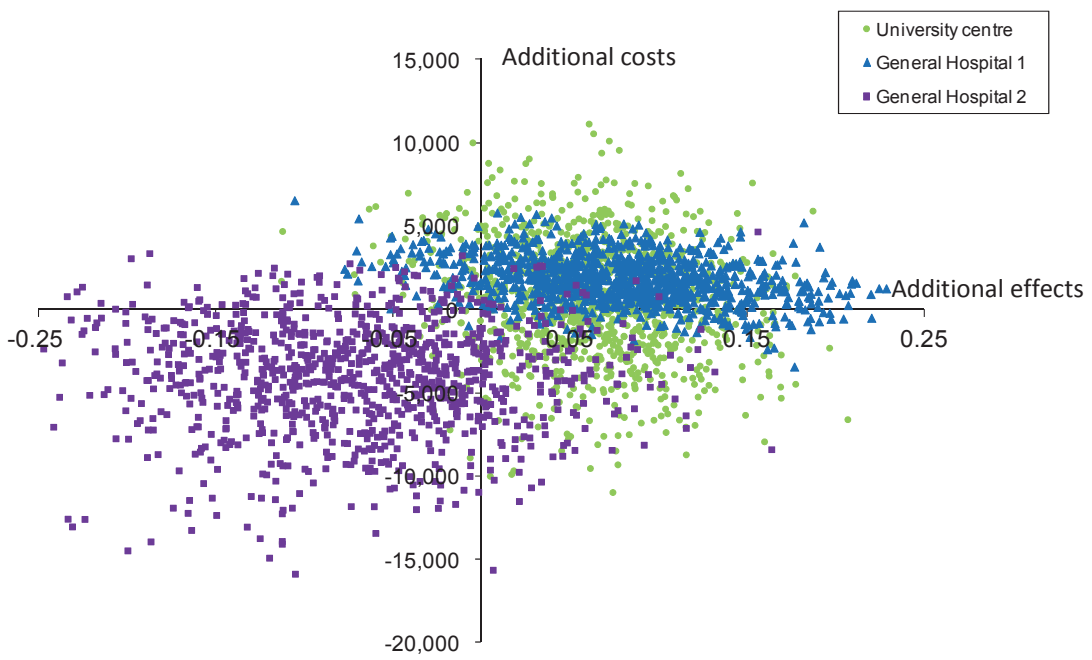

Figure 5 Incremental cost-effectiveness plane for cost per QALY (per participating centre)

\section{Discussion}

The incremental cost effectiveness analysis of the present study showed a high level of decision uncertainty for costs and QALYs. Therefore, for the group as a whole, it is not possible to draw an unambiguous conclusion. However, the subgroup analyses showed different effects between the three centres, of which two were in the same direction (Figure 5). All patients had contacts with the HFN, yet institutions had the opportunity to organise care according to their local procedures. Thus apparently the way that UC is organized may be a success or failure factor for telemonitoring to show costeffectiveness. In centre 1, as depicted in Figure 5, patient contacts took place both in the outpatient clinic and at the patients' home in case of poor mobility. In centre 2 , contacts between nurse and patient occurred only in the outpatient clinic, and in centre 3 patients referred to the nurse were mostly in NYHA class III or IV and were only visited at home. Centre 3 included the lowest number of patients (66). Subgroup analyses showed that for patients with less than 18 months of HF, telemonitoring is probably a cost-effective treatment option, as the probability of the intervention being costeffective was $75 \%$ at the prevailing WTP of $€ 50,000 / Q A L Y$.

Integration of rehabilitation is recommended in CHF guidelines [24]. In UC referral to a rehabilitation programme is often not part of structured care. In contrast, telemonitored patients with a low activity level were identified by the system and referred to the physiotherapist or a rehabilitation programme. This may have led to higher physiotherapist related costs. Although the number of contacts with the HFN was higher caused by the higher number of telephone contacts, the related costs were lower due to fewer face-to-face contacts [12]. Frequent telephone contacts related to risk alerts 
were part of the protocol to ensure the safety of patients. Medication information was not available via pharmacists in $25 \%$ of the cases, mostly due to confidentiality concerns. Data about in-hospital procedures and admissions were obtained via the hospital registration of the three participating centres, yet we had no insight into the manner that registration was performed.

In the cost-effectiveness analysis the healthcare perspective was chosen because most patients were, due to their age, not working. Hence, the potential productivity losses could be excluded from the analysis. Reports in the literature show economic impact results that are mainly based on the hospital costs related to admission for CHF, and do not include home care $[25,26]$. A systematic review [27] showed cost reductions ranging from $1.6 \%$ to $68.3 \%$. Cost savings were mainly attributed to reduced hospital expenditures related to CHF. One study also discussed the effect of telemonitoring on direct patient costs and found a 3.5\% reduction in travel costs for the TM group [28]. Our study examined hospital costs, and also costs for general practice, non-CHF hospital admissions and medication. Given the lower admission rate for CHF, [11] the findings of the present study are consistent with the general results of Seto's review [7]. Another review [8] addressed the lack of long-term economic follow-up studies and the high heterogeneity regarding interventions, study populations and duration of followup. Klersy et al. [8] included 21 RCTs in their meta-analysis. However, in contrast with our study, costs were considered related to hospital admissions only and hospital length of stay. They found a significant difference in costs for all hospitalisations favouring telemonitoring, yet no difference for costs regarding hospital length of stay. The inclusion of only hospitalised patients in their analysis hampers the comparison with our study. The WHOLE study [9] performed in 3230 patients with different chronic diseases, included patients in primary care and found a significantly reduced number of hospitalisations and mortality, yet without a difference in costs. Our results were similar to the WHOLE study [9] regarding the number of hospitalisations for CHF and difference in costs. A review by Augustin et al. [10] reported divergent results for morbidity and mortality and a tendency for lower costs. Mistry [11] criticised the reporting of the methodologies and findings of economic evaluations in a systematic review with 80 studies. It was reported that only one-third $(n=28)$ of the studies were RCTs and twothirds had follow-up lasting less than 2 years, therefore not allowing an assessment of the long-term effects. Furthermore, most of the studies did not give adequate details about their design or information on how costs were collected, calculated or reported. In addition, nearly half of the articles $(n=36)$ did not explicitly report the study perspective. Consequently, it was concluded that no conclusive evidence exists to show that telemedicine interventions are cost-effective compared to conventional health care and that is in accordance with our findings. Looking strictly at the CEACs (Figure 3), it seems that telemonitoring is the preferred strategy for patients with $\mathrm{CHF}>18$ months, because the curve for this subgroup starts at a relatively high point. This was caused by the fact that most of the bootstrapped ICER estimates for these groups were located in 
the lower left quadrant, i.e. although costs were saved, QALYs were lost. From a broad health economic view, this can be considered cost-effective, since the money saved here can be used differently to generate QALYs at a better cost/QALY rate. But for the present population, it still means that QALYs are lost. Looking in more detail at the costeffectiveness plane (Figure 4) it is suggested that in the subgroup with shorter duration of $\mathrm{CHF}$, health-related quality of life is gained from the telemonitoring intervention. Our data suggest that telemonitoring for this group can be considered cost-effective at a rate of $€ 50,000$ or more for a QALY.

\section{Limitations}

Imputation of data for the three centres was performed in $11 \%$ of the cases. The centre with 66 participants was more heavily affected by imputation because of group size and outliers in costs. The patients provided very valuable data by means of a prospective diary. Although, some uncertainty remains, a cost diary is the most reliable way to collect non-institutional data [29]. Not all data about delivered medication were available via pharmacists. In $25 \%$ of the cases medication use was gathered by the prescriptions, yet it is uncertain if this medication was delivered.

\section{Conclusion}

The overall incremental cost effectiveness analysis showed a high level of decision uncertainty. Unambiguous conclusions about the whole group cannot therefore be drawn. However, there was a relatively high probability for telemonitoring to be cost effective in the subgroup with shorter duration of CHF. The telemonitoring system seemed to adequately identify patients at low activity level, resulting in more frequent referrals to the physiotherapist, hence generating higher effectiveness and physiotherapy costs. Our data suggest that patients with shorter CHF duration should be considered for telemonitoring. 


\section{References}

1. Hoes AW, Mosterd A, Rutten FH, Poos MJJC. Does the number of patients with heart failure increase or decrease? In: Volksgezondheid Toekomst Verkenning, Nationaal Kompas Volksgezondheid. Bilthoven: RIVM 2006 [Dutch].

2. Lloyd-Jones DM, Larson MG, Leip EP, et al. Lifetime risk for developing congestive heart failure: the Framingham Heart Study. Circulation 2002; 106: 3068-72.

3. McMurray JJV, Stewart S. The burden of heart failure. The European Heart Journal Suppl 2002; 4(Suppl. D): $50-8$.

4. Zannad F, Agrinier N, Alla F. Heart failure burden and therapy. Europace 2009; 11(Suppl. 5): 1-9.

5. Berry C, Murdoch DR, McMurray JJ. Economics of chronic heart failure. The European Journal of Heart Failure 2001; 3: 283-91.

6. Cleland JG, Lewinter C, Goode KM. Telemonitoring for heart failure: the only feasible option for good universal care? The European Journal of Heart Failure 2009; 11: 227-8.

7. Seto E. Cost comparison between telemonitoring and usual care of heart failure: a systematic review. Journal of Telemedicine and eHealth 2008; 14: 679-86.

8. Klersy C, De Silvestri A, Gabutti G, Regoli F, Auricchio A. A meta-analysis of remote monitoring of heart failure patients. Journal of the American College of Cardiology 2009; 54: 1683-94.

9. Steventon A, Bardsley M, Billings J, et al. Effect of telehealth on use of secondary care and mortality: findings from the Whole System Demonstrator cluster randomised trial. British Medical Journal 2012; 344: e3874.

10. Augustin $U$, Henschke $C$. Does telemonitoring lead to health and economic benefits in patients with chronic heart failure?-a systematic review. Gesundheitswesen 2012; 74: e114-21 [German].

11. Mistry H. Systematic review of studies of the cost-effectiveness of telemedicine and telecare. Changes in the economic evidence over twenty years. Journal of Telemedicine and Telecare 2012; 18: 1-6.

12. Boyne JJ, Vrijhoef HJ, Crijns HJ, et al. Tailored telemonitoring in patients with heart failure: results of a multicentre randomized controlled trial. The European Journal of Heart Failure 2012; 14: 791-801.

13. Boyne JJ, Vrijhoef HJ, Wit R, Gorgels AP. Telemonitoring in patients with heart failure, the TEHAF study: study protocol of an ongoing prospective randomised trial. International Journal of Nursing Studies 2011; 48: 94-9.

14. EuroQol-a new facility for the measurement of health-related quality of life. The Euro Qol Group. Health Policy 1990; 16: 199-208.

15. Dolan P. Modeling valuations for EuroQol health states. Medical Care 1997; 35: 1095-108.

16. College voor zorgverzekeringen. Pharmacotherapeutic Compass. See http://www.fk.cvz.nl/ (last checked 7 May 2013) [Dutch].

17. Hakkaart-van Roijen L, Tan SS, Bouwmans CA. Manual for cost research. Methods and standard costprices for economic evaluation in health care. Actualised version 2010. Methoden en standaard kostprijzen voor economische evaluaties in de gezondheidszorg Geactualiseerde versie 2010 [Dutch].

18. Centraal Bureau voor de Statistiek. Statline. See http://statline.cbs.nl (last checked 7 May 2013).

19. Rubin DB, Schenker N. Multiple imputation in health-care databases: an overview and some applications. Statistics in Medicine 1991; 10: 585-98.

20. Briggs AH, Wonderling DE, Mooney CZ. Pulling cost-effectiveness analysis up by its bootstraps: a nonparametric approach to confidence interval estimation. Health Econonomics 1997; 6: 327-40.

21. Efron B, Tibshirani RJ. An Introduction to the Bootstrap. London: Chapman \& Hall, 1993.

22. van Hout BA, Al MJ, Gordon GS, Rutten FF. Costs, effects and C/E-ratios alongside a clinical trial. Health Economics 1994; 3: 309-19.

23. Zinnige en duurzame.See http://rvz.net/uploads/docs/ advies_Zinnige_en_duurzame_zorg.pdf (last checked 7 May 2013) [Dutch].

24. McMurray JJ, Adamopoulos S, Anker SD, et al. ESC Guidelines for the diagnosis and treatment of acute and chronic heart failure 2012. The European Heart Journal 2012; 33: 1787-847. 
25. Benatar D, Bondmass M, Ghitelman J, Avitall B. Outcomes of chronic heart failure. Arch Intern Med 2003;163:347-52

26. Johnston B, Wheeler L, Deuser J, Sousa KH. Outcomes of the Kaiser Permanente Tele-Home Health Research Project. Archives of Family Medicine 2000; 9: 40-5.

27. Kruijff AF, Hoevenaars CE. Telemonitoring, applications and possibilities in the Dutch health care. Zoetermeer: HFM; 1999 [Dutch].

28. Bradford WD, Kleit A, Krousel-Wood MA, Re RM. Comparing willingness to pay for telemedicine across a chronic heart failure and hypertension population. Journal of Telemedicine and eHealth 2005; 11: 430-8.

29. Goossens ME, Rutten-van Mölken MP, Vlaeyen JW, van der Linden SM. The cost diary: a method to measure direct and indirect costs in cost-effectiveness research. Journal of Clinical Epidemiology 2000; 53: 688-95. 



\section{CHAPTER 7}

\section{Effects of telemonitoring on heart failure patients' quality of life and depression:}

A randomised controlled trial

Josiane J.J. Boyne, Marieke D. Spreeuwenberg, Anton P.M. Gorgels, Gerjan De Weerd, Johannes Kragten, Hubertus J.M. Vrijhoef.

Submitted 


\section{Abstract}

Heart failure negatively influences patients' quality of life and depression. While the use of telemonitoring systems is increasing, knowledge about its effects on patients' quality of life and depression becomes important.

Methods: 382 patients were randomized to telemonitoring (TM) or usual care (UC). The presence of type-D personality, quality of life (KCCQ), and depression and anxiety (HADS) were measured by questionnaires. Data were compared within and between groups for baseline and post-measurements at 3, 6, and 12 months.

Results: Mean age was $71( \pm 11)$ years; $59 \%$ were male, $65 \%$ lived with a partner; $57 \%$ were in functional class II, $43 \%$ in Class III and IV. Mean ejection fraction was 0.38 and $50 \%$ had ischemic heart disease. Type D- personality appeared equal for groups. Quality of life was negatively affected by type-D personality for all dimensions of the Kansas City Cardiomyopathy Questionnaire (KCCQ) $(p<0.001)$. No between groups differences for quality of life, yet significant within differences were found for the sub score Quality of Life (QoL) ( $p=0.002)$ and Overall summary score (OVS) ( $p=0.022)$. The within groups difference of the sub score, self-efficacy, improved for TM $(p=<0.001)$ as well for UC $(p=0.028)$. Telemonitoring significantly reduced depression during whole follow-up. Anxiety was reduced after 3 and 6 months, but not at 12 months. For the TM-group the within difference for anxiety improved significantly between baseline and 12 months.

Conclusion: Telemonitoring has shown to reduce patients' depression and anxiety. No differences between groups were found for quality of life, yet significant differences for the sub scores QoL and OVS were found in the TM group between baseline and 12 months. Type-D negatively affects quality of life and therefore needs attention in daily practice.

Keywords: heart failure + telemonitoring + type-D personality + quality of life + anxiety † depression. 


\section{Introduction}

Depression and impaired quality of life (QoL) are major problems in patients with heart failure, and exposure to these factors is much higher compared with a community dwelling or age-matched population [1, 2, 3]. Depression due to a general medical condition is defined as a patient's clinical presentation, which is dominated by a persisting mood disorder, characterized by either or both depressed mood or considerably decreased interest or pleasure in nearly all activities, or a mood that is elevated, expansive or irritable [4]. Also cardiac conditions, such as atrial fibrillation are known to show elevated levels of depression and anxiety [5]. QoL is multidimensional and integrates objective and subjective indicators, a broad range of life domains and individual values. Dimensions may be categorized in physical, material, social and emotional wellbeing, and activity [6]. Both depression and poor emotional QoL can be predicted by Type-D $[7,8,9]$. Type-D personality is defined as 'the tendency to suppress emotional distress', and is a predictor of long-term mortality in CHD, independent of established biomedical risk factors [10].

With the increased application of telemonitoring in heart failure, knowledge about its effects on quality of life and depression becomes highly important. Several telemonitoring studies reported about the impact of telemonitoring on QoL [11, 12, 13, 14], yet limited studies reported about the impact of telemonitoring on depression in patients with heart failure $[15,16]$. Preliminary results about the impact on depression during the first 3 months of the randomised multicentre study discussed in this article (TEHAFstudy), showed a tendency to a decreased level of depression [17]. The TEHAF-study primarily focuses on the effects of telemonitoring on heart failure (re)admissions and mortality [18], and cost-effectiveness [19]. Secondary outcomes are: disease specific knowledge, self-care, self-efficacy, adherence, [20] depression and QoL. It was hypothesized that an intensive follow-up by means of telemonitoring (i.e. the Health Buddy ${ }^{\circledR}$ ) improves disease specific knowledge, self-care and self-efficacy, which, in turn positively influence QoL and reduces depression and anxiety. The current article presents longitudinal one-year follow-up results regarding the impact of telemonitoring on depression and QoL including the presence of Type-D in patients with heart failure.

\section{Methods}

\section{Population}

To compare telemonitoring with usual care, 870 consecutive patients with heart failure New York Heart Association (NYHA) class II-IV were invited to participate in the TEHAFstudy, during their visit at the outpatient clinic of either of three hospitals in the South of the Netherlands, of whom 488 refused or were ineligible (figure 1) flowchart). Pa- 
tients were asked to fill out several questionnaires during study time [21], and were informed that refusing participation had no consequences for their further treatment. Heart failure was defined as at least one episode of fluid retention requiring diuretics, either with an echocardiographic left ventricular ejection fraction $\leq 40 \%$ or a preserved ejection fraction with diastolic dysfunction. Further inclusion criteria were age $\geq 18$ years, capable of providing informed consent, and being treated by a heart-failure nurse together with a cardiologist. Patients were excluded, if operating the telemonitoring device, the Health-Buddy ${ }^{\circledR}$, was physically or cognitively impracticable, if suffering from Chronic Obstructive Pulmonary Disease (COPD) Gold-classification 3 or 4, if receiving hemodialysis, or in case of a disease with an expectedly shortened life span [21]. Approval was obtained from the Medical Ethical Committee of the participating centers, according to the declaration of Helsinki [22] and written informed consent was obtained before randomization. The TEHAF-study is registered at Clinicaltrials.gov (NCT00502255).

\section{Study design}

From October 2007 until December 2008, 382 patients were enrolled and assigned to a study arm, usual care or usual care plus telemonitoring, using a computer-generated randomization procedure, with stratification per center. Patients of both groups received identical oral and written information, and had an easy access to the heart failure nurse. Patients of the usual care group had four, and patients of the telemonitoring group had two planned outpatient clinic visits during follow-up. Moreover, the latter group received a telemonitoring device. The Health Buddy ${ }^{\circledR}$ has a liquid crystal display and four keys and was connected to a landline phone. Every day, a pre-set dialogue was communicated about symptoms, knowledge and behaviour, being answered by touching one of the keys. Patients' answers were sent via a protected server to the nurses' desktop. Incorrect answers to a knowledge or behaviour issue were automatically corrected by the device and visualised in the display, aiming that patients' disease knowledge would increase. Responses were transferred into risk profiles, (low, medium, high) [21] allowing the nurse to quickly identify high-risk patients. A heart failure nurse and a nurse assistant led the process. Positive answers for symptoms triggered immediate responses by the heart failure nurse. The nurse assistant was responsible for educational and general high risks, such as symptoms of depression [21]. To meet with personal specific needs on treatment or education, patients could be allocated to one of the four sets of dialogues with variable emphasis on symptoms or knowledge and behaviour [20]. All patients started with the same initial set of dialogues, which was evenly balanced for symptoms and education. After three months the first evaluation of symptoms and education level occurred, with the intention to continue with the best fitting next set of dialogues. Evaluation was based on the number of high-risk alerts during the last 30 days before the end of a program. Beside this, re-allocation to main- 
tain with the best fitting dialogues set was possible at any moment [21]. Following an admission for heart failure, patients were always re-allocated to an intensive symptom monitoring set of dialogues. Monitoring of vital signs was not part of the system.

\section{Measurement instruments}

Demographic variables (age, gender, living situation) and clinical variables (New York Heart Association (NYHA) functional class, left ventricular ejection fraction, ischemic heart disease, atrium fibrillation (AF), type-D personality) were measured.

This article reports effects on QoL, measured by the Kansas City Cardiomyopathy Questionnaire (KCCQ)[23], and depression, measured by the Hospital Anxiety and Depression Scale (HADS) [24]. The DS-14 consists of 14 questions, measuring negative affectivity and social inhibition. Scores are ranged on a Likert scale from 0-4 points. Type $D$ personality is indicated if both scores were equal or more than 10 points [25].

QoL was measured by the KCCQ. The Kansas City Cardiomyopathy Questionnaire (KCCQ) is a 23-item questionnaire that quantifies physical limitations (question 1), symptoms (frequency [questions 3, 5, 7 and 9], severity [questions 4, 6 and 8] and recent change over time [question 2]), self-efficacy and knowledge (questions 11, 12), social interference (question 16) and QoL (questions 13-15). To facilitate interpretability, two summary scores were developed, the overall summary score (OVS) and clinical summary score (CSS), which are built up from different (sub) scores [23]. The OVS exists of the physical limitation score, total symptom score, quality of life score and the social limitation score; the CSS exists of physical limitation score and the total symptom score.

The Hospital Anxiety and Depression Score (HADS) measuring anxiety and depression, is a 14 items questionnaire consisting of 7 questions for both, depression and anxiety. Scores are ranged on a 4-points Likert scale, with a total score range between 0-21 points [23]. Cut-off point for anxiety or depression disorder is 10 points and higher.

\section{Sample size}

The sample size of the TEHAF-study was built on the hospitalisations for heart failure. Expected was a 50\% reduction in heart failure admissions [21].

\section{Data analysis}

Demographic interval and ratio variables were investigated for normality of distribution with the Shapiro-Wilk Normality Test. If normally distributed, means and standard deviations are given. Student-t and Mann-Whitney test is used to estimate differences of baseline variables. Student-t test is also used to assess differences between AF and anxiety and depression, and AF and QoL. Categorical variables are presented as fre- 
quencies and percentages. Correlations between type-D, and anxiety and depression or QoL, and between anxiety and depression and quality of life, were tested by the Pearson correlation test.

Chi-square is used to assess differences for type-D personality between the usual care and telemonitoring groups. Student-t test is used to assess differences between type-D personality and QoL and depression. The effects between groups on QoL, and anxiety and depression in time (baseline, T3, T6, T12) were assessed with generalised estimating equations analysis (GEE). GEE was used to correct for the dependency of the observations in time and for the difference of the time periods between the follow-up measurements. A structured covariance matrix was used in the GEE analysis. As independent variables three dummy variables for time, group (usual care versus intervention), and interaction effects between group and the dummy variables of time were included. The method of GEE is often used to analyse longitudinal and other correlated response data [26]. GEE takes into account the correlational nature of repeated measures data within subjects, and securing minimal loss of patients due to incomplete data. Data imputation is not executed because when using GEE to analyse a longitudinal dataset, imputation of missing data has no value above non-imputation [26]. Analyses were corrected for baseline differences. To analyse within group effects between baseline and after 12 months regarding QoL, anxiety and depression Wilcoxon nonparametric test was used. SPSS version 18 was used for all data analyses. P-values < 0.05 are considered statistically significant.

\section{Results}

\section{Baseline characteristics}

Three hundred eighty two patients met the criteria and were allocated to the intervention group (197) and to the usual-care group (185). Patients' mean age was $72( \pm 11)$ and $46 \%$ were $\geq 75$ years old; $59 \%$ were male, $65 \%$ lived with a partner; $57 \%$ were in functional class II, $40 \%$ in Class III $3 \%$ in class IV. Mean left ventricular ejection fraction was 0.38 and $61 \%$ were $\leq 0.45 ; 50 \%$ had ischemic heart disease. Study arms were balanced regarding baseline characteristics (Table 1), except for AF. No differences were found for anxiety and depression, or QoL among patients with AF or other heart rhythm. Follow up was incomplete in $81(21 \%), 43$ in the usual-care and 38 in the intervention arm, due to death, increasing physical impairment, stress or losing motivation. 
Table 1 Patient characteristics

\begin{tabular}{|c|c|c|c|c|}
\hline Variable & $\mathbf{N}$ & Intervention (197) & Control (185) & $p$-value \\
\hline Age & 382 & $71.0 \pm 11.9$ & $71.9 \pm 10.5$ & 0.621 \\
\hline Range $^{*}$ & & $32-72-91$ & $37-74-93$ & \\
\hline$\geq 75$ & & $88(44.7)$ & $85(46.5)$ & 0.199 \\
\hline Gender & 382 & & & 0.747 \\
\hline Male & & $115(58.4)$ & $111(60.0)$ & \\
\hline Female & & $82(41.6)$ & $74(40.0)$ & \\
\hline Married / partner & 379 & $122(62.6)$ & $123(66.8)$ & 0.265 \\
\hline Education & 363 & & & 0.589 \\
\hline Primary school & & 63 & 59 & \\
\hline Second.sch. /Low vocational training & & 91 & 71 & \\
\hline Middle Vocational training & & $19(10)$ & $23(13.3)$ & \\
\hline High vocational / university & & $17(8.9)$ & $20(11.6)$ & \\
\hline History of HF (m) & 382 & $32( \pm 38)$ & $29( \pm 38)$ & 0.413 \\
\hline Range ${ }^{*}$ & & $1-18-240$ & $1-15-293$ & \\
\hline NYHA-class / no (\%) & 382 & & & 0.404 \\
\hline NYHA II & 219 & $110(28.8)$ & $109(28.5)$ & \\
\hline NYHA III & 153 & $79(20.7)$ & $74(19.4)$ & \\
\hline NYHA IV & 10 & $8(2.1)$ & $2(0.5)$ & \\
\hline Blood pressure & 382 & & & \\
\hline Systolic & & $125 \pm 21.9$ & $128 \pm 24.0$ & 0.156 \\
\hline Diastolic & & $72 \pm 12.5$ & $74 \pm 12.2$ & 0.193 \\
\hline Heart rate & 382 & $77 \pm 15.1$ & $75 \pm 13.8$ & 0.252 \\
\hline Heart rhythm & 382 & & & \\
\hline Sinus rhythm & & $96(48.7)$ & $113(61.1)$ & 0.015 \\
\hline Atrial fibrillation & & $62(31.5)$ & 35 (18.9) & 0.007 \\
\hline Pacemaker rhythm & & $36(18.3)$ & 35 (18.9) & 0.817 \\
\hline Charlson index & 382 & $2.6( \pm 1.5)$ & $2.4( \pm 1.4)$ & 0.358 \\
\hline Type-D personality & 360 & $67(36.4)$ & $68(39.8)$ & 0.667 \\
\hline
\end{tabular}

\section{Prevalence of Type D personality}

Respectively 184 and 176 patients answered the DS-14 questionnaire for the type-D personality. No difference in prevalence of type-D personality was found between the groups. In the intervention group 67 (36.4\%) and in the usual care group 68 (39.8\%) of the patients belongs to the category with type-D personality. Overall, no correlation was found between type-D-personality and anxiety $(p=0.681$, Pearson $=-.022$ ) or depression $(p=0.443$, Pearson $=0.041)$, whereas all dimensions of $Q o L(p<0.001)$ were negatively affected by type-D without differences between study groups. 


\section{Effects on quality of life}

Uncorrected for baseline value, the overall score (OVS) and the clinical summary score (CSS) tend to differ between the telemonitoring group and the usual care group after one year, yet no difference remained after correction for baseline scores (Table 2). The same result was found for self-efficacy, a sub-score that was not included in the summary score. 
Table 2 Effects on quality of life

\begin{tabular}{|c|c|c|c|c|c|}
\hline & & Baseline & $3 \mathrm{~m}$ & $6 \mathrm{~m}$ & $12 \mathrm{~m}$ \\
\hline \multirow[t]{4}{*}{ Physical limitation (PLS) } & UC & 53.9 & 53.7 & 53.6 & 52.4 \\
\hline & TM & 55.8 & 57.9 & 57.1 & 56.5 \\
\hline & $P$-value & 0.533 & 0.148 & 0.230 & 0.189 \\
\hline & BL-correct & & 0.080 & 0.187 & 0.306 \\
\hline \multirow[t]{4}{*}{ Symptom burden score (SBS) } & UC & 66.0 & 68.9 & 68.2 & 66.9 \\
\hline & TM & 69.0 & 74.6 & 72.2 & 71.8 \\
\hline & $P$-value & 0.233 & 0.019 & 0.130 & 0.076 \\
\hline & BL-correct & & 0.107 & 0.314 & 0.542 \\
\hline \multirow[t]{4}{*}{ Symptom Frequency Score (SFS) } & UC & 64.5 & 66.6 & 67.7 & 66.0 \\
\hline & TM & 66.5 & 72.7 & 69.5 & 69.3 \\
\hline & $P$-value & 0.460 & 0.019 & 0.511 & 0.253 \\
\hline & BL-correct & & 0.007 & 0.923 & 0.789 \\
\hline \multirow[t]{4}{*}{ Self-efficacy score (SES) } & UC & 75.7 & 80.5 & 79.5 & 79.1 \\
\hline & TM & 80.9 & 85.6 & 86.3 & 85.0 \\
\hline & $P$-value & 0.018 & 0.015 & 0.001 & 0.010 \\
\hline & BL-correct & & 0.320 & 0.122 & 0.255 \\
\hline \multirow[t]{4}{*}{ Quality of life (QOL) } & UC & 58.6 & 64.3 & 63.0 & 60.9 \\
\hline & TM & 62.8 & 67.6 & 68.5 & 67.8 \\
\hline & $P$-value & 0.142 & 0.255 & 0.059 & 0.028 \\
\hline & BL-correct & & 0.997 & 0.247 & 0.177 \\
\hline \multirow[t]{4}{*}{ Total symptom score (TST) } & UC & 65.2 & 67.1 & 67.9 & 66.4 \\
\hline & TM & 67.8 & 73.6 & 70.9 & 70.4 \\
\hline & $P$-value & 0.314 & 0.014 & 0.250 & 0.136 \\
\hline & BL-correct & & 0.020 & 0.542 & 0.619 \\
\hline \multirow[t]{4}{*}{ Social limitation score (SLS) } & UC & 52.7 & 57.7 & 55.8 & 53.7 \\
\hline & TM & 57.1 & 62.0 & 63.1 & 61.0 \\
\hline & $P$-value & 0.171 & 0.169 & 0.025 & 0.030 \\
\hline & BL-correct & & 0.685 & .0109 & 0.181 \\
\hline \multirow[t]{4}{*}{ Overall summary score (OVS) } & UC & 57.6 & 60.7 & 60.0 & 58.2 \\
\hline & TM & 61.0 & 65.2 & 64.7 & 63.8 \\
\hline & $P$-value & 0.174 & 0.071 & 0.061 & 0.037 \\
\hline & BL-correct & & 0.238 & 0.164 & 0.208 \\
\hline \multirow[t]{4}{*}{ Clinical summary score (CSS) } & UC & 59.7 & 61.7 & 62.8 & 62.1 \\
\hline & TM & 61.9 & 66.8 & 66.3 & 67.4 \\
\hline & $P$-value & 0.365 & 0.053 & 0.149 & 0.057 \\
\hline & BL-correct & & 0.015 & 0.303 & 0.394 \\
\hline
\end{tabular}

OVS=PLS \& TST \& QOL \& SLS; CSS = PLS \& TST; TST = SFS \& SBS

$\mathrm{BL}$-correct $=$ after correction for baseline variables 
From patients completing the KCCQ-questionnaire at baseline and after 12 months (272) within group differences were calculated. No within group difference was found for the CSS. For OVS significantly higher score was demonstrated in the TM group $(p=0.022, Z=-2.290)$, whereas no difference was found for UC ( $p=0.790, Z=-.267)$. QoL, being a sub score of the OVS showed similar changes, with $p=0.002(Z=-3.149)$ compared to $p=0.239(Z=-1.178)$ for respectively TM and UC. For the sub-score self-efficacy a significant improvement was found for both groups with $p<0.001$ and $p=0.028$ respectively for the TM and UC group.

\section{Effects on anxiety and depression}

No difference was found regarding depression prevalence at baseline, with a registration of $42 \%$ ( 79 on 186 ) in the telemonitoring group and $41 \%$ (69 on 167) in the usual care group.

A significant difference for anxiety in favour of the telemonitoring group was found after 3 and 6 months, irrespective of correction for baseline values (Table 3). However, this effect disappeared after 12 months. For depression a significant different effect was found only after six months in favour of the telemonitoring group. After correction for the baseline values a favourable effect was found during whole follow-up.

Table 3 Effects on anxiety and depression

\begin{tabular}{lcccc}
\hline & T0 & T3 & T6 & T12 \\
\hline Anxiety & & & & \\
Usual care & 8.26 & 8.27 & 8.19 & 8.04 \\
Intervention & 7.93 & 7.49 & 7.43 & 7.63 \\
$\quad$ difference & -.327 & -.784 & -.766 & -.411 \\
$\quad \begin{array}{l}\text { P-value } \\
\text { After BL-correction }\end{array}$ & .344 & .028 & .028 & .226 \\
Depression & & .041 & .053 & .65 \\
Usual care & & & & 7.66 \\
Intervention & 7.11 & 7.12 & 7.28 & 6.78 \\
$\quad$ difference & 6.96 & 6.44 & 6.23 & -.88 \\
$\quad$-value & -.159 & -.674 & -1.05 & .074 \\
$\quad$ After BL-correction & .725 & .128 & .030 & .028 \\
\hline
\end{tabular}

Also for anxiety and depression within group differences were calculated among patients completing questionnaires at baseline and after 12 months. After 12 months anxiety was significantly lower in the telemonitoring group ( $p=0.041, Z=2.043)$, whereas no difference was found for depression $(p=0.41, Z=0.818)$. The usual care group 
demonstrated a tendency to an increased depression ( $p=0.089, Z=-1.703)$, and no difference for anxiety ( $p=0.229, Z=-1.203)$.

\section{Quality of life and depression}

A negative correlation is found between the sub-score of $Q$ oL and depression $(p=0.025$, Pearson -.115) and QoL and anxiety ( $p=0.036$, Pearson -.107), meaning that the presence of anxiety as well as depression is related to lower QoL. No significant correlation between anxiety and depression and OVS or CSS was found.

\section{Discussion}

In this study it was found that telemonitoring positively influences depression and anxiety, meaning that telemonitored patients were less depressed during whole follow-up, and less anxious after 3 and 6 months. The difference in depression indicates that telemonitoring seems to slightly decrease patients' moods. Our finding of $42 \%$ depressed patients was comparable with the prevalence range of $9 \%$ to $54 \%$ in a Caucasian population as reported in a recent meta-analysis [3]. Mean depression level of all patients at baseline was slightly higher compared to the preliminary results in 101 patients investigated at three months after start of the study. However, the same course is demonstrated for the results after 3 months, being a slight decrease of depression in the intervention group and the same level of depression in the usual care group [17].

Initially, positive results were found for QoL yet after correction for baseline, differences disappeared. The effects on the self-efficacy were congruent with the selfefficacy findings described elsewhere [20]. Telemonitoring improves the communication between patient and health care professional; this may result in an increased selfefficacy.

The TEHAF-study primarily focused on the effects of telemonitoring on heart failure (re)admissions and mortality, and cost-effectiveness. No significant differences were found for hospitalisations and mortality, yet the number of contacts with the heart failure nurse was significantly lower for patients using telemonitoring. Sub-analysis showed differences for some sub-groups as living with partner and heart failure duration less than 18 months [18]. No difference between groups was found for costs, however sub-group analyses showed that telemonitoring is cost-effective in patients with heart failure duration for less than 18 months [19]. Also, a significant improvement was found for knowledge and self-care, and for some domains of adherence [20].

Myers [12] performed a non-randomised study with a follow-up time of 2 months and compared the results of 83 telemonitored patients with historical patients receiving usual care. Reported results included pre- and post-test results of the telemonitoring group, measured by the SF-36. They found an improved QoL in seven of the param- 
eters, yet could not determine whether the change was directly related to telemonitoring. The results of the current study may considered to be due to telemonitoring because characteristics of patients were comparable, type-D personality included, and correction for baseline values was performed. Noteworthy in the study of Myers [12] was the relative high number of patients $(n=19)$ not completing this short study in 2 months. Seven patients (37\%) withdrew while they were anxious and upset, which was in contrast with our study with a $18 \%$ withdrawal rate during the follow-up of one year. Benatar [11] followed patients for 3 months and compared the outcomes of 216 patients receiving home nurse visits versus nurse telemanagement. QoL was measured with the Minnesota Living with Heart Failure Questionnaire (MLHFQ) and depression with the HADS. They found an improved QoL for both groups when compared pre- en post-intervention, yet no differences between groups. This finding implies that telemonitoring has the same effect on QoL as face-to-face contacts between patient and care professional. Depression showed an improvement between groups in favour of the telemonitoring group comparable with our study results. Goldberg e.a. [27] provided 138 patients, with a mean age of 59 years, for 6 months with a telemonitoring system of the second generation, existing of an electronic scale and individualised questions about symptoms; almost $75 \%$ of the patients were in NYHA class III. No significant effects in QoL were measured within groups, however in the telemonitoring group QoL trended towards improvement. No between groups differences were described. Within 48 hours post discharge Woodend e.a. [28] equipped 121 patients with heart failure with a telemonitoring system. Mean age was $66( \pm 11)$ years and most patients were in NYHA class III. The intervention consisted of 3 months video conferencing with a nurse, daily transmission of weight and blood pressure, and periodic transmission of 12-lead electrocardiogram. Measurements were performed at baseline, after 3 and 12 months. Conferences between nurse and patient were more frequent in the first few weeks after discharge. QoL was measured with the SF-36. For both groups QoL improved significantly after one year. Between groups a significant difference in favor of the videoconference group was found after 3 months, disappearing after one year. This may be interpreted that telemonitoring has effects during the monitoring time, yet effects were disappearing on the longer term. This may suggest that patients may continuously need the system to retain the effects on QoL. Unfortunately, authors did not report which care was delivered after the 3 months of videoconference, which in this context is an important issue. The most principal differences with our study were the post discharge inclusion and the six-year younger mean age which both independently may have influenced the results. Another multi-centre randomised trial is studied [13] with a follow-up of 6 months in 315 patients. Mean age was $76.5( \pm 7)$ years and $60 \%$ were female. QoL was measured by the SF-36 and the KCCQ. No differences between groups were found for SF-36 neither for the KCCQ. Koehler e.a. [29] provided 354 patients, mean age $67( \pm 10.7)$ years, with a telemonitoring device of the third generation telehealth and followed them for 24 months. They investigated QoL with the SF-36 ques- 
tionnaire and depression with the PHQ-9. No effects were found for depression, and an overall benefit was found for one of the QoL subscales, the first being in contrast with our effects on depression. The WSD-telehealth trial [30] included 1,650 patients with COPD, diabetes or heart failure in 365 general practices, in four primary care trusts. Patients were followed with second-generation telehealth devices. Measurements were performed at baseline, after 4 and 12 months. QoL was measured by the SF-12 and EQ-5D questionnaires, anxiety by the STAI (brief state-trait anxiety inventory) and depression CESD-10. Analysing the data, no disease specific distinctions were made. No differences were found for QoL, neither for anxiety or depression.

As mentioned earlier, the Health Buddy ${ }^{\circledR}$ system is a telemonitoring system from the first generation. Several devices belonging to the first, second and third generations are discussed. No structurally improved effects on QoL or depression have been found in studies using higher generation devices. Despite this is not the focus of this study, one may remark that the increased possibilities due to the evolution of telemonitoring systems has shown to lack influence regarding the effects on QoL and depression. At the other hand, underutilization of telemonitoring may occur due to a lacking clarity about the best fitting program for individual patients and equally so that the caregivers are lacking experience in using telemonitoring [31].

\section{Limitations}

The power of this study was calculated on a reduction of hospitalisations. Therefore this study may be insufficiently powered to detect differences in QoL; besides $21 \%$ of our study population did not finish the study. The follow-up time of 12 months may be insufficient to realise improvements in QoL and depression.

This study was performed to detect differences between groups. If within-group differences were found without significant different between groups, they are not necessarily attributable to the kind of care delivery. The use of standard questions by researchers can lead to "structural bias" and false representation, where the data actually reflect the view of the researcher instead of the participating subject [32, 33, 34]. Preset answers will not necessarily reflect how people really feel about a subject and in some cases might just be the closest match to preconceived hypotheses. As a consequence, the results of a quantitative questionnaire design may be statistically significant but at risk to be practically insignificant and their clinical relevance may be unclear, especially in aspects as quality of life and depression [32, 33, 34].

\section{Practical implications of this study}

The Health Buddy ${ }^{\circledR}$ system has shown to reduce anxiety for a short term and to control depression. Therefore, it may be useful to apply telemonitoring to anxious patients to 
reduce anxiety and to control depression. This may particularly be meaningful for patients waiting for a referral to a professional or a mental health caregiver.

The finding that type-D personality influences QoL resonates the need of defining personality, in order to detect this as a risk factor for diminished quality of life $[13,14$, 16].

Telemonitoring systems should be improved in their ability to pay attention for anxiety and depression, and integrate in depth dialogues or guidance how to deal with depressive symptoms or anxiety. This may easily enhance the positive effects of telemonitoring and alleviate the burden on patients and their environment, on health care resources and costs.

\section{Conclusion}

The Health Buddy ${ }^{\circledast}$ system focusing on patients' experiences, has proven to be suitable to positively influence some aspects of QoL, to reduce patients' depression and to reduce patients' anxiety on the short run. Furthermore, it was found that QoL is negatively affected by the presence of Type-D personality, and that depression and anxiety negatively affect the sub score QOL. 


\section{References}

1. Lesman-Leegte I, Jaarsma T, Coyne JC, Hillege HL, Dirk J. Van Veldhuisen, Robbert Sanderman. Quality of life and depressive symptoms in the elderly: A comparison between patients with heart failure and ageand gender-matched community. Journal of cardiac failure 2009; 15: 17-23.

2. Lesman-Leegte I, Jaarsma T, Sanderman R, Linssen G, Van Veldhuisen DJ. Depressive symptoms are prominent among elderly hospitalised heart failure patients. The European Journal of Heart Failure 2006; 8: 634-40.

3. Rutledge T, Reis VA, Linke SE, Greenberg BH, Mills PJ. Depression in Heart Failure: A Meta-Analytic review of prevalence, intervention effects, and associations with clinical outcomes. Journal of the American College of Cardiology 2006; 48 (8).

4. American Psychiatric Association KE. Diagnostic and statistical manual of mental disorders. Fourth Edition, Text revision. Washington DC' American Psychiatric Association; 2000.

5. Thrall G, Lip GY, Carroll D, Lane D. Depression, Anxiety, and Quality of Life in Patients With Atrial Fibrillation. Chest 2007; 132(4): 1259-1264.

6. Felce D, Perry J. Quality of life: Its definition and measurement: Research in Developmental Disabilities 1995; 16(1): 51-74.

7. Pedersen SS, Herrmann-Lingen C, de Jonge P, Scherer M. Type D personality is a predictor of poor emotional quality of life in primary care heart failure patients independent of depressive symptoms and New York Heart Association functional class. Journal of Behavioral Medicine 2010 Feb; 33(1): 72-80.

8. Pedersen SS, Denollet J. Type D personality, cardiac events, and impaired quality of life: a review. European Journal of Cardiovascular Prevention and Rehabilitation 2003; 10: 241-248.

9. Starrenburg AH, Kraaier K, Pedersen SS, van Hout M, Scholten M, van der Palen J. Association of Psychiatric History and Type D Personality with Symptoms of Anxiety, Depression, and Health Status Prior to ICD Implantation. International Journal of Behavioral Medicine 2012; DOI 10.1007/s12529-012-9244-3.

10. Denollet J, Sys SU, Stroobant N, Rombouts H, Gillebert TC, Brutsaert DL. Personality as independent predictor of long term mortality in patients with coronary heart disease. Lancet 1996; 347 (8999): 417421.

11. Benatar D, Bondmass M, Ghitelman J, Avitall B. Outcomes of chronic heart failure. Archives of Internal Medicine 2003; 163: 347-352.

12. Myers S, Grant RW, Lugn NE, Holbert B, Kvedar JC. Impact of home-based telemonitoring on the care of patienst with heart congestive failure. Home Health Care Management \& Practice 2006; 18: 444-451.

13. Soran OZ, Piňa IL, Lamas GA, Kelsey SF, Selzer F, Pilotte J, Lave JR, Feldman AM. A randomised clinical trial of the clinical effects of enhanced heart failure monitoring using a computer-based telephonic monitoring system in older minorities and women. Journal of Cardiac Failure 2008; 14: 711-717.

14. Scalvini S, Capomolla S, Zanelli E, Benigno M, Domenighini D, Paletta L, Glisenti F, Giordano A. Effect of home-based telecardiology on chronic heart failure: costs and outcomes. Journal of telemedicine and telecare 2005; 11(suppl.1): S1:16-18.

15. Schwarz KA, Mion LC, Hudock D, Litman G. Telemonitoring of heart failure patients and their caregivers: a pilot randomized controlled trial. Progress of Cardiovascular Nursing 2008; 23(1): 18-26.

16. Delaney C, Apostolidis B. Pilot testing of a multicomponent home care intervention for older adults with heart failure: an academic clinical partnership. Journal of Cardiovascular Nursing 2010; 25(5): E27-40.

17. Ramaekers BLT, Boyne JJJ, Gorgels APM, Vrijhoef HJM. Adherence among telemonitored patients with heart failure to pharmacological and nonpharmacological recommendations. Telemedicine and e-health 2009: 15; 517-524.

18. Boyne JJ, Vrijhoef HJ, Wit R, De Weerd G, Kragten J, Gorgels AP. Tailored telemonitoring in patients with heart failure: results of a multicentre randomized controlled trial. The European Journal of Heart Failure 2012; 14: 791-801.

19. Boyne JJ, Asselt AD, Vrijhoef HJ , De Weerd G, Kragten J , Gorgels AP. Cost-effectiveness of telemonitoring versus usual care in patients with heart failure. Journal of Telemedicine and Telecare first published on July 9, 2013: doi:10.1177/1357633X13495478. 
20. Boyne JJ, Vrijhoef HJ, Spreeuwenberg M, De Weerd GJ, Johannes Kragten , Gorgels AP. Effects of telemonitoring on heart failure patients' knowledge, self-care, self-efficacy, and adherence: a randomized controlled trial. European Journal of Cardiovascular Nursing 2013; online 29 April 2013: DOI 10.1177/1474515113487464.

21. Boyne JJ, Vrijhoef HJ, Wit R, Gorgels AP. Telemonitoring in patients with heart failure, the TEHAF study: Study protocol of an ongoing prospective randomised trial. International Journal of Nursing Studies 2011; 48: 94-9.

22. World Medical Association. Declaration of Helsinki: ethical principle for medical research involving human subjects. 59th WMA General Assembly, Seoul 2008; www.wma.net/e/policy/b3.htm

23. Green CP, Porter CB, Bresnahan DR, Spertus JA. Development and evaluation of the Kansas City Cardiomyopathy Questionnaire: a new health status measure for heart failure. Journal of the American College of Cardiology 2000; 35 (5): 1245-55.

24. Zigmond AS, Snaith RP. The Hospital Anxiety and Depression Scale. Acta psychiatrica Scandinavica 1983; 67: 361-370.

25. Denollet J. DS14: Standard assessment of negative affectivity, social inhibition, and type D personality. Psychosomatic Medicine 2005; 67: 89-97.

26. Twisk J, de Vente W. Attrition in longitudinal studies: How to deal with missing data. Journal of Clinical Epidemiology 2002; 55: 329-337.

27. Goldberg LR, Piette JD, Walsh MN, Frank TA, Jaski BE, Smith AL, Rodriguez R, Mancini DM, Hopton LA, Orav EJ, Loh E. Randomized trial of a daily electronic home monitoring system in patients with advanced heart failure: The Weight Monitoring in Heart Failure (WHARF) trial. American Heart Journal 2003; 146: 705-12.

28. Woodend K, Sherrard H, Fraser M, Stuewe L, Cheung T, Struthers C. Telehome monitoring in patients with cardiac disease who are at high risk of readmission. Heart \& Lung 2008; January/february.

29. Koehler F, Winkler S, Schieber M, Sechtem U, Stangl K, Böhm M, Boll H, Baumann G, Honold M, Koehler K, Gelbrich G, Kirwan BA, Anker S. Impact of Remote Telemedical Management on Mortality and Hospitalizations in Ambulatory Patients With Chronic Heart Failure: The Telemedical Interventional Monitoring in Heart Failure Study. DOI:10.1161/circulationaha.111.01847329.

30. Cartwright M, Hirani SP, Lorna Rixon L, Beynon M, Doll H, Bower P, Bardsley M, Steventon A, Knapp M, Henderson C, Rogers A, Sanders C, Fitzpatrick R, Barlow J, Newman SP. Effect of telehealth on quality of life and psychological outcomes over 12 months (Whole Systems Demonstrator telehealth questionnaire study): nested study of patient reported outcomes in a pragmatic, cluster randomised controlled trial. British Medical Journal 2013; 346: 653.

31. Boyne JJ, Vrijhoef HJ. Implementing Telemonitoring in Heart Failure Care: Barriers from the Perspectives of Patients, Healthcare Professionals, and Healthcare Organizations. Current Heart Failure Reports 2013;10 (3). DOI: 10.1007/s11897-013-0140-1.

32. Brians, Craig Leonard et al. Empirical Political Analysis: Quantitative and Qualitative Research Methods. 8th ed. Boston, MA: Longman, 2011.

33. McNabb, David E. Research Methods in Public Administration and Nonprofit Management: Quantitative and Qualitative Approaches. 2nd ed. Armonk, NY: M.E. Sharpe, 2008.

34. Singh, Kultar. Quantitative Social Research Methods. Los Angeles, CA: Sage, 2007. 


\section{CHAPTER 8}

\section{Implementing telemonitoring in heart failure}

\section{care:}

Barriers from the perspectives of patients, healthcare professionals and healthcare organisations

Josiane J.J.Boyne, Hubertus J.M. Vrijhoef

Invited author for Current Heart Failure Reports 2013;(10)3 


\section{Abstract}

The increasing prevalence of chronic diseases, such as heart failure, presents a substantial challenge to healthcare systems. Telemonitoring is believed to be a useful instrument in the delivery of heart failure care. However, a widespread use of telemonitoring is currently failing for various reasons. This article provides an overview of the barriers for the implementation of telemonitoring in heart failure patients from the perspectives of its users: patients, healthcare professionals and healthcare organisations. In doing so, identified barriers are grouped according to the perceived attributes of innovation by Rogers. Recommendations are provided as to how research can improve the implementation of telemonitoring in heart failure.

Keywords: Telemonitoring + Heart failure + Implementation + Barriers + Patient + Healthcare professional + Healthcare organisation. 


\section{Introduction}

Chronic diseases, such as heart failure, have a negative effect on peoples' lives and those who care for them [1]. As the population ages, the prevalence of heart failure increases, which presents substantial challenges to our social and healthcare systems $[2,3]$. High-quality care for patients suffering from chronic diseases as heart failure is characterized by productive interactions between caregivers and patients that consistently provide the assessments support for self-management, optimization of therapy, and follow-up associated with good clinical and patient outcomes [4]. Wagner et al. noticed that, "these interactions do not necessarily require face-to-face visits" [4]. Moreover, given the concerns about the shortage in the number of nurses and physicians in various developed countries [5], alternative ways to establish productive interactions between patients and caregivers are explored. Patients with heart failure mostly are elderly people, suffering from comorbidities, at risk for frequent hospitalisations and with an increased risk for mortality [6]. On the other hand, elderly may suffer from typical elderly diseases as foot problems, arthritis, cognitive impairment, impaired vision and hearing [7], all negatively influencing their autonomy. Consequently, an independent visit to a caregiver by a patient with heart failure, without support from (in)formal caregivers, may become an enormous effort that is increasingly less possible.

Telemonitoring is believed to be instrumental in making sure that patients get the right care at the right time, in the right setting. It includes the collection of clinical data and the transmission of such data between a patient at a distant location and a practice team through electronic information processing technologies [8]. Since its introduction in the previous century, telemonitoring in heart failure has been evaluated in many countries, with inconsistent results in terms of its impact on outcomes and costs [9-11, $12 \bullet \bullet, 13-16]$. Notwithstanding, these inconsistent findings telemonitoring can be considered as safe to be introduced in daily heart failure care. Moreover, telemonitoring may be a solution to support patients in their autonomy, giving them advice and instructions without face-to-face contact [17]. However, due to barriers on patient and organisational levels, a widespread diffusion of telemonitoring in heart failure has not been reached. This manuscript seeks to provide insight into current struggles with the implementation of telemonitoring of patients with heart failure, aiming to identify arenas for a more thoughtful implementation. According to Rogers [18], the variance in the rate of adoption of an innovation can be explained by five attributes of innovation: the degree to which an innovation is perceived as being better than the idea it supersedes (relative advantage); the degree to which an innovation is perceived as consistent with the existing values, past experiences, and needs of potential adopters (compatibility); the degree to which an innovation is perceived as relatively difficult to understand and use (complexity); the degree to which an innovation may be experimented on a limited basis (trialability); and the degree to which the results of an innovation are visible to others (observability) [18]. By evaluating recently published papers on tele- 
monitoring in heart failure and chronic illness care, we identified the main barriers for the implementation of telemonitoring from the perspectives of patients, healthcare professionals and healthcare organisations, and coded these according to the perceived attributes of innovation by Rogers [18]. From this overview, we made recommendations on how research can improve the implementation of telemonitoring in heart failure and chronic illness care.

\section{Patient-related barriers}

\section{Relative advantage}

An important barrier to use technology is that if participants do not perceive immediate benefits from using a telemonitoring system, they are unlikely to engage with it. $\mathrm{Pa}$ tients with heart failure already doing well in taking responsibility for their own health care, for example through high medication compliance, may perceive telemonitoring technology as nuisance and intrusive [19]. Due to the novelty of telemonitoring, suppliers largely have one single system offered to all patients with heart failure. However, most patients, as well as healthcare professionals, prefer a more tailored approach [20]. Patients' interest in using telemonitoring may lower after a while; yet, if there is no other program or version available, patients will discontinue because there is no longer a challenge and/or they do not longer feel comfortable. A Dutch feasibility study about telemonitoring in heart failure patients [21] assessed the unfulfilled needs of patients with heart failure and caregivers with a standardized program. Based on these findings [21], the program was adapted from the original more fixed program to better address the needs of individual patients [22]. This resulted in a high patient satisfaction and compliance in daily use of the adapted, more personalized system [15]. It is known that elderly have increased comorbidities, have more medical problems, and are intensive users of health care [23]. A problem regarding comorbidities may be that a particular disease-related telemonitoring program insufficiently covers comorbidities. The lack at multiple disease programs may withhold patients as well as caregivers to use or encourage telemonitoring. It would be useful to develop telemonitoring programs covering combinations of diseases, as for example, heart failure and chronic obstructive pulmonary disease (COPD) and/or diabetes.

\section{Compatibility}

It was found that unexpected messages or advices that contradicted a patient's experience caused them to disbelieve it and not follow the advice [24]. If, for example, a patient with heart failure receives advice to decrease the dose of diuretics in case of dizziness and patients' experience is that it has no effect, he will not follow the advice. There- 
fore, advising a patient to initiate action needs to be supported by a personalized explanation for the recommended change in action, in order to convince the patient to actually adapt his behaviour. Also, a perceived lack of security with personal medical data has been reported being a barrier to use telemonitoring [25].

\section{Complexity}

Some studies demonstrated high technical complexity for the home-based selfmanagement systems, especially if there was a significant degree of inconvenience in data entry by patients $[25,26]$. Due to patients' characteristics, such as decreased concentration, elderly impairments and their unfamiliarity with telemonitoring, usability of the system has to be clear and simple, while complex systems may cause stress and fright. To enhance the use of telemonitoring in heart failure and elderly care, it is important to clearly define the expected benefits and how to work with a simply usable technology.

Poor device usability, insufficient training how to use technology, lack of computer skills and low self-efficacy $[27,28]$ generally has been reported among patients using telemonitoring. From a review about telemonitoring, it was found that in general, age is negatively correlated with acceptance, and $68 \%$ of the included studies found that acceptability increased with higher education, suggesting that lower education is a barrier for the acceptance of telemonitoring [29]. The findings that elderly are less likely to accept telemonitoring is probably due to fewer computer skills [30, 31], less computer familiarity and/or illiteracy among elderly [30,31]. They perceive less comfort, efficacy and control over computing technologies, resulting in negative perceptions, which can decrease the acceptance of telemonitoring [29]. Also, it was found that age is directly related to the need for more assistance with the technology [32], and that computer anxiety may negatively influence the acceptance of telemonitoring [33, 34]. Other studies report a lack of understanding based on health illiteracy and innumeracy [35-37]. Patients had difficulty in comprehending the medical jargon [35], whereas several studies mentioned lack of experience with computers and with the Internet as a significant barrier for using telemonitoring [38-40]. Due to the mentioned geriatric ailments as forgetfulness, concentrating problems, and visual or cognitive limitations in elderly, they may be hindered fluently using a telemonitoring device [41, 42]. Generally, it was found that women reported a higher computer anxiety than men, suggesting that gender is a moderator for the acceptance of telemonitoring [43, 44]. All mentioned barriers also apply to patients with heart failure.

\section{Trialability}

A common technological problem when using telemonitoring is the lack of reliability of the patients' Internet connection [45]. The living environment of patients may play a 
role in the uptake of telemonitoring. Patients living in nursing homes demonstrated to be less satisfied with technology than patients at home, probably because telemonitoring is mostly developed to be used in the home situation $[46,47]$. This also affects patients with heart failure who often live in nursing homes. While visual problems and loss of hearing in elderly patients may influence user convenience, lightning and the environment are very important. Poor lighting could cause readability problems and a noisy environment could be disturbing, being translated as physical discomfort when using a computer-based (health) information system [48]. Until today, the majority of patients use a telemonitoring system within the context of a study. In most of such cases, the use of telemonitoring remains subsidized for patients, lacking reimbursement for continuation [25]. Another important issue may be the affection of new technology in the home situation. Home is no longer the same when it becomes electronically connected with the broader network of healthcare, including telemedical centres, hospitals and general practitioners' offices. Patients may feel unsafe in their home after it has become an extended health care institution. Long-term effects about this issue are unknown [49].

\section{Observability}

Another barrier is the indistinctness about which patients benefit most from which telemonitoring system [15]. Currently, it is unclear which patients with heart failure have, or have not, to be equipped with telemonitoring and also how long the use of the equipment should last [50]. Questionable is to what extent the patient himself is leading this process, or what the role is of the caregiver, organisation, supplier and/or payer. Clarity about the best fitting system for an individual would be helpful and enhance patients' acceptance of telemonitoring. This would offer them the opportunity to make an informed decision about the use of telemonitoring. Patient profiles might be helpful in matching individual patients with a telemonitoring program or device. Patient profiles may depend on stage or duration of the disease [26], medical status as severity of illness [46, 51] and comorbidities, cognition [42], patient education [41] and/or low literacy [29]. Using patient profiles is required to enhance the results of telemonitoring, which in turn will influence the motivation of patients and healthcare professionals to implement it in daily life.

\section{Organisational and professional barriers}

\section{Relative advantage}

The relative weakness of research and conflicting evidence may be a possible explanation of the lacking willingness or acceptability to introduce telemonitoring into daily 
care for patients with heart failure [9-11, 12••, 13-16]. Care providers may have the idea that the care for elderly heart failure patients with telemonitoring will be more laborious because of a more and intensive follow-up [51], which in turn is believed to lead to increased care consumption and higher costs. The aims of telemonitoring often are not fully agreed or shared between all actors involved. A recently performed Dutch study showed that professionals had high perceptions and expectations of working with telemonitoring in heart failure, yet these were not positively reflected in their experiences. Expectations such as improved self-care, improved quality of care, treating more patients, decreased workload and lowering costs were unfulfilled [50]. The central aim of telemonitoring is often unclear. More attention needs to be given about the main aim of early detection. The system is often more determined by the availability of sensor devices than by specific clinical aims [52・•]. Monitored variables such as heart rate, blood pressure and weight are supplemented by symptom-related scores or questions, but with little effort to really detect early deterioration in individual heart failure patients. Telemonitoring is focused on easy data collection, rather than specifying data with predictive value. Otherwise, there is no consensus among clinical professionals about the diagnostic characteristics for impending heart failure, and identification of clinical goals need to be agreed upon [52••]. Despite it is being well-known that effective self-management is essential in patients with heart failure, the provision of feedback from the telemonitoring system is lacking. To ensure potential implementation, a wide range of stakeholders, especially patients and clinicians, need to be engaged in the design process $[52 \bullet \bullet]$.

Healthcare professionals and healthcare organisation often expect telemonitoring to be one of the solutions for the shortage of health care staff, as well as for remaining or even increasing productivity. Further, healthcare organisations starting up with telemonitoring expect advantages from the beginning. They seem to neglect that building up experience to work efficiently with telemonitoring takes time. Also, once implementing, they are faced with an enormous collection of data and often lack a clear aim to use these data meaningfully in daily practice. For the most part, clear protocols about how to deal with data or alerts in daily practice are lacking. Despite the numerous collected data, there still remains the problem that important questions to clinicians and nurses cannot be answered by telemonitoring due to a lacking or inefficient data analysis. Because of such inexperience, it still takes involved caregivers such as heart failure nurses quite some time to check all data on a daily basis, and to find a way to implement this task into their daily activities. It is therefore important that healthcare providers and vendors of telemonitoring set clear aims and discuss the availability of real time data [53]. Finally, the process of care delivery is often not adapted at the moment that telemonitoring gets implemented. Consequently, telemonitoring often remains an add-on to existing care, instead of a substitute or complement for face-to-face contacts, for example $[51,54]$. 


\section{Compatibility}

Medical personnel might refuse to use telemonitoring systems due to fear of loss of power, or lack of knowledge how to operate the system, and some nurses' fear to become redundant $[26,54]$. Also, caregivers may argue that, due to their particular specialization in heart failure, they will fail in case of the presence of comorbidities. After implementation of telemonitoring, caregivers were more concerned than patients about increased costs, poor hardware quality, poor security, confidentiality, inconvenience to patients, associated moral and ethical issues and uncertainty about responsibility [55].

\section{Complexity}

Nurses are well educated and practiced at using patient information to identify highrisk patients and deterioration, but the use of remote information is relatively new and unknown. Specific knowledge and skills are required for the delivery of care in this way and therefore nurses and clinicians need to be educated [56•]. Another important factor is the lack of a dedicated project manager when implementing telemonitoring in daily practice, and the time to carry out telehealth work is often underestimated. Some organisations have difficulties in gaining access to computers for staff involved in telehealth. Also mentioned as a barrier, is senior staff at board level insufficiently understanding telehealth in terms of how it might drive innovation of healthcare delivery. This gets reflected in the marginal role of telehealth in strategic decisions on the level of healthcare organisations [54]. Another important barrier is the lack of interoperability, meaning there is no interaction or information exchange between different systems. This leads to a situation in which information is not, or not in time, available to the healthcare provider. For example: a patient with heart failure using telemonitoring measures his body weight, blood pressure and often answers a set of questions about his health behaviour on a daily basis. Based on this information, the healthcare providers are able to monitor the health status of the patient over a distance and make treatment decisions. However, care providers often lack easy access to the patients' information collected with the telemonitoring system. The telemonitoring information can be found in the telemonitoring system, whereas the other medical information (e.g. medication overview, medical history) is stored in the hospital information system or electronic patient record [57]. Due to this situation, clinicians are discouraged and not enthusiastic for using telemonitoring. Moreover, an increased interoperability would enhance the possibilities for an increased collaboration between all involved caregivers, e.g. between heart failure nurse, general practitioner and cardiologist. 


\section{Trialability}

Currently, telemonitoring using healthcare organisations each have to develop their own methods and protocols, mostly on-going in the process of dissemination. This may lead to confusion and lack of clarity about responsibilities, including the chance of failures or mistakes resulting in undesired outcomes for patients being exposed to telemonitoring. It would be meaningful to develop guidelines and/or protocols including information on how to take the correct clinical decisions; for example, with hierarchies of responses and responders related to severity of the alert [53]. It is widely assumed that telemonitoring is based on automated data streams and analysis, generating appropriate alerts for clinical staff; however, this is not the reality. Current systems rely on human judgment, guided by agreed threshold levels: when a variable exceeds the limit, an alert is raised. The decision of further actions heavily relies on nurses. Automated detection algorithms are mostly lacking in the detection of heart failure deterioration. Especially in patients with heart failure, the automatically identification of a drift from an individual baseline is essential; however, it still is a challenge in daily practice $[52 \bullet \bullet]$. Also, it would be helpful when guidelines and protocols present information on patient profiles (indicating the degree of readiness of patients, healthcare professionals and healthcare organisations for safe use of telemonitoring) and providing directions on how to deal with heart failure alerts.

\section{Observability}

Uncertainties about heart failure patient profiles may withhold caregivers and organisations to scale or even to introduce telemonitoring in daily care, because of a lacking preview of the return on their investments. Existing health and social services, with their professional and procedural boundaries, have difficulties with the adoption of innovative methods. Heart failure telemonitoring creates new data, new responsibilities and accountabilities in multiple organisations. In daily practice, agreements about the responsibility for the clinical response on a telemonitoring-generated alert have to be closed between involved participants. Currently, insufficient attention is given as to how telemonitoring can be integrated with existing systems [52••]. A clear vision, objectives, action plans (strategy) and business models for telemonitoring are often lacking [54]. The presence of unclear business models reveals that vendors of telemonitoring systems and healthcare organisations have not found the right business model that fosters market penetration. Such business models might include a telecare centre or services for medical pre-screening of data. The business model should also clearly define to whom the service is sold and how the revenue model looks like from the perspective of involved stakeholders [26]. In the current situation, short-term funding finances most telehealth projects. Missing reimbursement and lacking recurrent funding is one of the main limitations in successful implementation [26, 54]. Also, long-term plans on service provision are lacking; projects are mostly limited to one year and do 
not have a clear vision about the most appropriate length of time for using telemonitoring by patients [54]. For the treatment of patients with chronic diseases such as heart failure, a long-term strategy is a cornerstone in achieving the desired outcomes, e.g. the prevention of disease related complications.

The barriers for the implementation of telemonitoring in chronic illness care from the perspectives of patients and health care providers and organisations are summarized in Table 1.

Table 1 Overview of patient and healthcare organisational/professional related barriers that inhibit the implementation of telemonitoring

\begin{tabular}{|c|c|c|}
\hline Barriers* & Patient related & Healthcare provider/ organisation related \\
\hline $\begin{array}{l}\text { Relative } \\
\text { advantage }\end{array}$ & $\begin{array}{l}\text { Lack of tailored heart failure telemonitoring } \\
\text { services }\end{array}$ & $\begin{array}{l}\text { No shared aims; expectation to experience } \\
\text { advantage at the start; conflicting research; } \\
\text { unavailability of real time data; no clear } \\
\text { protocol for how to analyze data; lacking } \\
\text { patient profiles }\end{array}$ \\
\hline Compatibility & $\begin{array}{l}\text { Perceived lack of security for data } \\
\text { exchange; advised ctions and behavior } \\
\text { change lack clarification }\end{array}$ & $\begin{array}{l}\text { Fear of losing power; fear of becoming } \\
\text { redundant }\end{array}$ \\
\hline Complexity & $\begin{array}{l}\text { Inconvenience in data entry; high technical } \\
\text { complexity; high age; low education; illiter- } \\
\text { acy; innumeracy; fewer computer skills; } \\
\text { fewer computer familiarity; computer } \\
\text { anxiety; geriatric ailments; gender; } \\
\text { presence of comorbidities }\end{array}$ & $\begin{array}{l}\text { Lack of knowledge how to use telemonitor- } \\
\text { ing; lack of change and implementation } \\
\text { management; problems with interoperability } \\
\text { of systems; marginal role in strategic deci- } \\
\text { sions }\end{array}$ \\
\hline Trialability & $\begin{array}{l}\text { Unreliable internet connection; living envi- } \\
\text { ronment; pilot phase }\end{array}$ & $\begin{array}{l}\text { Lacking algorithms, lacking guidelines and } \\
\text { protocols for implementation and safe use of } \\
\text { telemonitoring }\end{array}$ \\
\hline Observability & $\begin{array}{l}\text { Lacking clarity about best fitting telemoni- } \\
\text { toring system for individual }\end{array}$ & Lacking business models \\
\hline
\end{tabular}

* Barriers are coded according to the perceived attributes of innovation by Rogers [10].

\section{Discussion}

This article aims to identify and code the barriers of implementing telemonitoring in heart failure according to the perceived attributes of innovation. Tanriverdi et al. [58] categorized barriers of the implementation of telemonitoring into the more general clusters of technical barriers, economical barriers, organisational barriers and behavioural barriers. All users of telemonitoring being heart failure patients, healthcare organisations or healthcare professionals experience a variety of factors inhibiting the dissemination of telemonitoring in daily practice. Moreover, barriers for the implementation of telemonitoring in heart failure resonate well with all five perceived attributes 
of innovation by Rogers [18]. This reveals the magnitude of the challenge to improve the implementation of telemonitoring; it requires a multi-faceted strategy to increase the use of telemonitoring and ultimately to contribute to the quality of heart failure care delivery. We recommend those, implementing telemonitoring in daily practice, to use models for innovation and implementation. We collected data on barriers of the implementation of telemonitoring in heart failure care from a sample of studies designed primarily to evaluate the feasibility or effectiveness of telemonitoring and not designed as implementation studies. Nonetheless, the included studies did report on the role of multiple barriers, often to comment on the study findings. In most cases, however, no empirical data were reported regarding the barriers for implementation of telemonitoring. When looking critically at the literature about the implementation of telemonitoring, most literature addresses this topic by looking at telemonitoring as a product or service. Further, most papers in this field report whether the new product of telemonitoring works. Given that telemonitoring in heart failure care is instrumental in achieving productive interactions between patients and healthcare teams, it is debatable whether not approaching telemonitoring as process innovation. We believe that telemonitoring in heart failure should be regarded as a new delivery method. This includes significant changes in techniques, equipment and/or software used in healthcare [60]. In order to support the implementation of telemonitoring in chronic heart failure care, future research should spend more attention on how telemonitoring of patients with heart failure work, and the role of the context in which it gets implemented. Therefore, we recommend a shift toward implementation science in order to ask the questions that will help healthcare providers and researchers see further in navigating toward improvement [60]. Given the slow uptake of telemonitoring in daily practice and the presence of multiple barriers, we recommend more systematic study of the implementation of telemonitoring, the impact of innovation and/or implementation strategies and the translation of such strategies across settings.

\section{Conclusion}

In conclusion, the existing literature suggests that multiple barriers impact the implementation of telemonitoring in heart failure care. As a result, the full potential of telemonitoring in heart failure has not been reached in daily practice. To move from suggestions to proof about the barriers for the implementation of telemonitoring, research needs to be designed differently to provide useful insight in how to improve the process of heart failure care delivery by means of telemonitoring as part of a systems approach. 


\section{References}

Papers of particular interest, published recently, have been highlighted as:

- Of importance

•- Of major importance

1. Luttik ML, Jaarsma T, Veeger N, Tijssen J, et al. Caregiver burden in partners of Heart Failure patients; limited influence of disease severity. The European Journal of Heart Failure 2007; 9: 695-701.

2. O'Connell. The economic burden of heart failure. Clinical Cardiology 2000; 23(Suppl HI): 111-6-111-10.

3. McMurray JJV, Stewart S. The burden of heart failure. The European Heart Journal Supplement 2002; 4(Suppl D): D50-8.

4. Wagner EH, Austin B, Davis C, et al. Improving Chronic IllnessCare: Translating Evidence Into Action. Health Affairs 2001; 20: 64-78.

5. http://www.oecd-ilibrary.org/sites/health_glance-2009-en/03/index.html?contentType=\&itemld=/content/chapter/health_glance-2009-31-en\&containerltemld=/content/serial/19991312\&accessltemlds=/ content/book/health_glance-2009-en\&mimeType=text/html. Accessed on March 23, 2013.

6. Mosterd A, Hoes AW. Clinical epidemiology of heart failure. Heart 2007; 93(9): 1137-46.

7. Griffith L, Raina P, Wu H, Zhu B. Stathokostas. Population attributable risk for functional disability associated with chronic conditions in Canadian older adults. Age Ageing 2010; 39: 738-45.

8. http://www.touchpointcare.com/telehealth_definition.php. Accessed on March 23, 2013.

9. Klersy C, De Silvestri A, Gabutti G, Regoli F, Auricchio A. A meta-analysis of remote monitoring of heart failure patients. Journal of the American College of Cardiology 2009; 54: 1683-94.

10. Inglis SC, Clark RA, McAlister FA, Ball J, et al. Structured telephone support or telemonitoring programmes for patients with chronic heart failure. Cochrane Database Systematic Reviews 2010; 8: CD007228. doi:10.1002/14651858.CD007228.pub2.

11. Clark RA, Inglis S, Mc Allister F, et al. Telemonitoring or structures telephone support programmes for patients with chronic heart failure: systematic review and meta-analysis. British Medical Journal 2007; 334: 942-5.

12. $\bullet$ Steventon A, Bardsley M, Billings J, et al. Effect of telehealth on use of secondary care and mortality: findings from the Whole System Demonstrator cluster randomised trial. British Medical Journal 2012; 344:e3874. This outstanding extensive study highlights the effects of telemonitoring on patients with various chronic diseases.

13. Dendale $P$, De Keulenaer G, Troisfontaines $P$, et al. Effect of a telemonitoring-facilitated collaboration between general practitioner and heart failure clinic on mortality and rehospitalizationrates in severe heart failure: the TEMA-HF 1 (Telemonitoring in the MAnagement of Heart Failure) study. The European Journal of Heart Failure 2012; 14: 333-40.

14. Boyne JJJ, Vrijhoef HJM, Crijns HJGM, et al. Tailored Telemonitoring in patients with heart failure: Results of a multicenter randomized controlled Trial. The European Journal of Heart Failure 2012; 14: 791-801.

15. Chaudhry S, Mattera J, Curtis J, et al. Telemonitoring in patients with heart failure. New England Journal of Medicine 2010; 363: 2301-9.

16. Koehler F, Winkler S, Schieber M, et al. Impact of Remote Telemedical Management on Mortality and Hospitalizations in Ambulatory Patients With Chronic Heart Failure. Circulation 2011; 123:1873-80.

17. Oudshoorn N. Diagnosis at a distance: the invisible work of patients and healthcare professionals in cardiac telemonitoring technology. Sociology of Health \& Illness 2008; 30(2): 272-88.

18. Rogers EM. Diffusion of innovations (5th ed). New York: Free Press; 2003.

19. Artinian NT, Harden JK, Kronenberg MW, et al. Pilot study of a Web-based compliance monitoring device for patients with congestive heart failure. Heart Lung 2003; 32: 226-33.

20. Boyd CM, Darer J, Boult C. Clinical practice guidelines and quality of care for older patients with multiple comorbid diseases implications for pay for performance. Journal of American Medical Association 2005; 294: 6. 
21. Vrijhoef HJM, Janssen-Boyne JJJ, Engering G, et al. The Health Buddy: telemonitoring system for patients with heart failure. The European Journal of Heart Failure 2006; Supplement vol. 5(1): p. 174.

22. Boyne JJ, Vrijhoef $\mathrm{HJ}$, de Wit R, et al. Telemonitoring in patients with heart failure, the TEHAF-study: Study protocol of an ongoing prospective randomised trial. International Journal of Nursing Studies 2011; 48: 94-9.

23. Kane RL, Kane RA. Ageism in healthcare and long term care. Generations 2005; 29: 49-54.

24. Anhoj J, Nielsen L. Quantitative and qualitative usage data of an Internet-based asthma monitoring tool. Journal of Medical Internet Research 2004; 6: e23.

25. Gruber HG, Wolf B, Reihe M. Innovation Barriers for Telemonitoring. IFMBE Proceedings 2009; 25: 48-50.

26. Jimison H, Gorman P, Woods S, et al. Barriers and Drivers of Health Information Technology Use for the Elderly, Chronically III, and Underserved. Rockville (MD): Agency for Healthcare Research and Quality (US); 2008 Nov. (Evidence Reports/Technology Assessments, No. 175.) Available from: http://www.ncbi.nlm.nih.gov/books/NBK38653/ Accessed on March 23, 2013.

27. Kaufman DR, Patel VL, Hilliman C, et al. Usability in the real world: Assessing medical information technologies in patients' homes. Journal of Biomedical Informatics 2003; 36: 45-60.

28. Stoop AP, Van 't Riet A, Berg M. Using information technology for patient education: Realizing surplus value? Patient Education Counselling 2004; 54: 187-95.

29. Or CKL, Karsh BT. A Systematic Review of Patient Acceptance of Consumer Health Information Technology. Journal of the American Medical Information Association 2009; 16: 550-60.

30. Czaja SJ, Charness N, Fisk AD, et al. Factors predicting the use of technology: Findings from the center for research and education on aging and technology enhancement (create). Psychology and Aging 2006; 21: 333-52.

31. Evangelista LS, Strömberg A, Westlake C, et al. Developing a web-based education and counseling program for heart failure patients. Progress in Cardiovascular Nursing 2006; 21: 196-201.

32. Kressig RW, Echt KV. Exercise prescribing: computer application in older adults. Gerontologist 2002; 42: 273-7.

33. Venkatesh V. Determinants of perceived ease of use: Integrating control, intrinsic motivation, and emotion into the technology acceptance model. Systems research and information Science 2000; 11: 342-65.

34. Ellis RD, Allaire JC. Modeling computer interest in older adults: The role of age, education, computer knowledge, and computer anxiety. Human Factors 1999; 41: 345-55.

35. Earnest MA, Ross SE, Wittevrongel L, et al. Use of a patient accessible electronic medical record in a practice for congestive heart failure: patient and physician experiences. Journal of American Medical Information Association 2004; 11: 410-7.

36. Yeh YT, Chiu YT, Liu CT, et al. Development and evaluation of an integrated patient-oriented education management system for diabetes. Studies of Health Technology Informatics 2006; 122: 172-5.

37. Zimmerman L, Barnason S, Nieveen J, et al. Symptom management intervention in elderly coronary artery bypass graft patients. Outcomes Management 2004; 8: 5-12.

38. Ralston JD, Revere D, Robins LS, et al. Patients' experience with a diabetes support programme based on an interactive electronic medical record: qualitative study. British Medical Journal 2004; 328(7449): 1159.

39. Van den Brink JL, Moorman PW, de Boer MF, et al. Involving the patient: a prospective study on use, appreciation and effectiveness of an information system in head and neck cancer care. International Journal of Medical Informatics 2005; 74: 839-49.

40. Feil EG, Glasgow RE, Boles $S$, et al. Who participates in Internetbased self-management programs? A study among novice computer users in a primary care setting. Diabetes Education 2000; 26: 806-11.

41. Strömberg A. The crucial role of patient education in heart failure. The European Journal of Heart Failure 2005; 7: 363-9.

42. Lober WB, Zierler B, Herbaugh A, et al. Barriers to the use of a personal health record by an elderly population. Annual Symposium Proceedings/AMIA Symposium 2006; 514-518.

43. Gilroy FD, Desai HB. Computer anxiety: Sex, race, and age. International Journal of Man- Machine Studies 1986; 25: 711-9. 


\section{CHAPTER 8}

44. Igbaria M, Chakrabarti A. Computer anxiety and attitudes towards microcomputer use. Behavior and Information Technology 1990; 9: 229-41.

45. Cruz-Correia R, Fonseca J, Lima L, et al. Web-based or paperbased self-management tools for asthma patients' opinions and quality of data in a randomized crossover study. Studies in Health Technology and Informatics 2007; 127: 178-89.

46. Chae YM, Park HJ, Cho JG, et al. The reliability and acceptability of telemedicine for patients with schizophrenia in Korea. Journal of Telemedicine and Telecare 2000; 6: 83-90.

47. Mekhjian H, Turner JW, Gailiun M, et al. Patient satisfaction with telemedicine in a prison environment. Journal of Telemedicine and Telecare 1999; 5: 55-61.

48. Stanney KM, Smith MJ, Carayon P, et al. Human computer interaction. In: Salvendy G, editor. Handbook of Industrial Engineering: Technology and Operations Management. 3rd ed. New York: John Wiley and Sons; 2001: p. 1192-236.

49. Oudshoorn N. How places matter: telecare technologies and the changing spatial dimensions of healthcare. Social Studies of Science 2012; 42(1): 121-42.

50. De Vries $A E$, Van der Wal MH, Nieuwenhuis MMW, et al. Health Professionals' Expectations Versus Experiences of Internet-Based Telemonitoring: Survey Among Heart Failure Clinics. Journal of Medical Internet Research 2013; 15(1): e4.

51. Lemay G, Azad N, Struthers C. Utilization of home telemonitoring in patients 75 years of age and over with complex heart failure. Journal of Telemedicine and Telecare 2013; doi:10.1177/1357633X12473917

52. • Elwyn G, Hardisty AR, Peirce,May C, Evans R, Robinson DK, et al. Detecting deterioration in patients with chronic disease using telemonitoring: navigating the 'trough of disillusionment'. Journal of Evaluation of Clinical Practice 2012; (18): 896-903. This paper gives a critical overview of the (non)readiness of the implementation of telemonitoring into daily care.

53. Hardisty AR, Peirceb SC, Preecea A, et al. Bridging two translation gaps: A new informatics research agenda for telemonitoring of chronic disease. International Journal of Medical Informatics 2011; 80: 73444.

54. Joseph V,West RM, Shickle D, Keen J, et al. Key challenges in the development and implementation of telehealth projects. Journal of Telemedicine and Telecare 2011; 17: 71-7.

55. Chang JY, Chen LK, Chang CC. Perspectives and expectations for telemedicine opportunities from families of nursing home residents Curr Heart Fail Rep and caregivers in nursing homes. International Journal of Medical Informatics 2009; 78: 494-502.

56. - BarrettDI. The role of telemonitoring in caring for older people with long-term conditions. Telehealth 2012; 24: 21-25. This manuscript extensively reflects on the possibilities of telemonitoring in daily care.

57. Burghouts A. Improving patient Improving patient information for telemonitoring in chronic heart failure. 2nd International Congress on Telehealth and Telecare. 2012; Vol 12.

58. Tanriverdi H, lacono CS. Diffusion of telemedicine: a knowledge barrier perspective. Telemedicine Journal 1999; 5: 223-44.

59. OECD/Statistical Office of the European Communities, Luxembourg (2005),Oslo Manual: Guidelines for Collecting and Interpreting Innovation Data, 3rd Edition, The Measurement of Scientific and Technological Activities, OECD Publishing. doi: 10.1787/9789264013100-en

60. Berwick D. The science of improvement. Journal of the American Medical Association 2008; 299: 1182-3. 
CHAPTER 9

General discussion 
CHAPTER 9

138 
"The Health Buddy ${ }^{\circledR}$ is a stimulant too me. I have the Health Buddy ${ }^{\circledR}$ for approximately half a year and am very satisfied. I have the feeling that they keep a watchful eye on my condition. For example: I need to weigh myself every day, but normally I don't do this. But now I do! The Health Buddy ${ }^{\circledR}$ helps me and stimulates me to do it well." (Quote from TEHAF-study participant)

\section{General discussion}

This thesis is about people suffering from heart failure, which is a diminished pump function as a complication of an underlying heart disease. Apart from the latter, the risk for $\mathrm{HF}$ increases with aging. Following on a longer lifespan and an improved survival of cardiac diseases it is expected that the number of patients with HF will increase over the next decades [1, 2]. In people between 60 and 70 years of age, 28 per1000 suffer from $\mathrm{HF}$, increasing to 153 per 1000 when 80 years and older. It is expected that the number of HF patients will increase with 47\% between 2005 and 2025 [2].

The increasing expenses of care for chronically ill patients in combination with decreased numbers of professional caregivers demands for a redesigning of care organisation [3], including a more active role for patients themselves. In 2007 the costs for HF care amounted to 455 million Euros in the Netherlands. In total, the expenses of care for $\mathrm{HF}$ were $6.6 \%$ of the cost of heart disease and $0.6 \%$ of total healthcare budget in the Netherlands. Almost $60 \%$ of the costs are due to hospitalisations [4].

By applying a specific mode of monitoring HF at a distance this study aimed to assess the impact of telemonitoring on patients' disease specific knowledge, self-care, self-efficacy and adherence, hospitalisations and mortality, quality of life and depression, and cost-effectiveness.

The main objective of telemonitoring in HF is early detection of disease deterioration and prompt medical intervention. This could lead to reduction of admission and readmission rates due to worsening $\mathrm{HF}$, the number of face-to-face contacts with care providers and mortality. Several systems have been developed and evaluated for this purpose. Systems can be classified to invasive and non-invasive systems, whereas the system at hand belongs to the non-invasive systems. More specifically, it consisted of pre-set dialogues about disease specific knowledge and behaviour, compliance and symptoms. Vital signs monitoring equipment was not included. The philosophy behind this telemonitoring system is that better disease specific knowledge leads to better selfcare resulting in improved clinical outcomes and an improved quality of life [5]. To study the effects of this telemonitoring system a multicentre randomised controlled trial was conducted. 


\section{Summary of the intervention}

Patients of the usual care group received oral and written information about chronic $\mathrm{HF}$, had an easy access to the HF-nurse and four pre-planned outpatient clinic visits during follow-up. Patients of the TeleMonitoring (TM) group received identical information, however had only two pre-planned appointments at the outpatient clinic. Instead, they received a TM device (The Health Buddy ${ }^{\circledR}$ ) at home. This telemonitoring system differs from other systems by more adjusting to patients' needs, by focusing on patient related aspects as severity of the disease and the level of disease specific knowledge and level of self-care.

The Health Buddy ${ }^{\circledR}$ (figure 1) device has a liquid crystal display and four keys, connected to a landline phone. Patients received daily pre-set dialogues and questions about symptoms, knowledge and behaviour, which had to be answered by touching one of the keys. Subsequently the answers were sent via a protected server to the nurses' desktop. During this process responses were transferred into risk profiles (low, medium, high) [6], allowing the nurse to quickly identify high-risk patients. Positive answers for symptoms were transferred into a high-risk alert, and aimed to trigger immediate action by the HF-nurse. In case patients gave an incorrect answer to a knowledge or behaviour issue, the device automatically provided the correct answer.

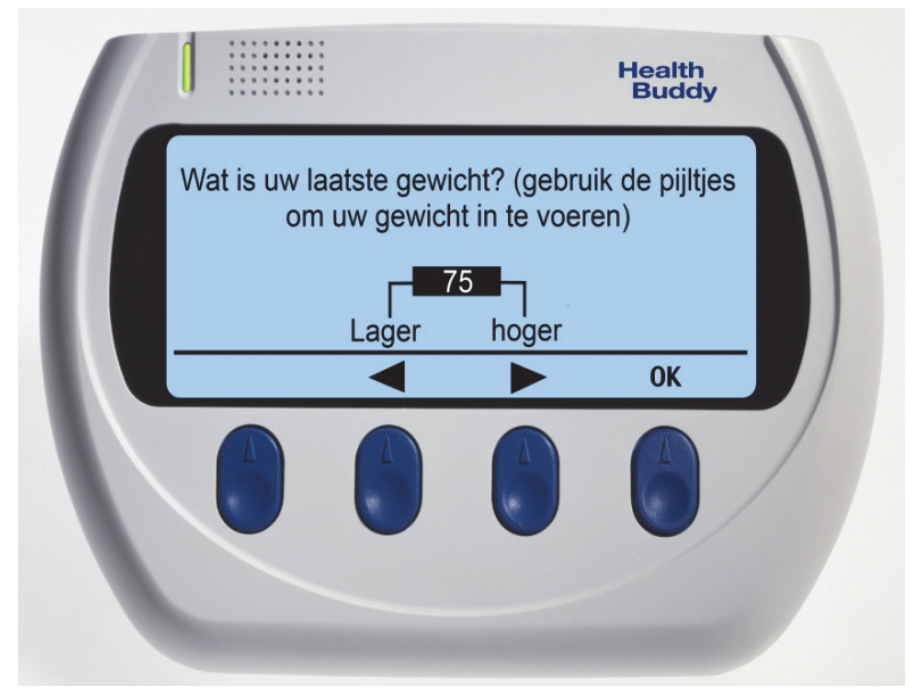

Figure 1 The Health Buddy ${ }^{\circledR}$

The tailored program content was developed to meet with personal specific needs on treatment or education. Therefore, four sets of dialogues with variable emphasis on symptoms or knowledge and behaviour were created [6]. The HF-nurse was expected to check all available data on a daily basis and to contact the patient in case of com- 
plaints. In case of clinical complexity the nurse was expected to contact the cardiologist. Care was delivered according to the European guidelines [7], however organisation of care was left to the participating centres. Therefore the nurses' input could differ between just patient education to full clinical evaluation (clinical history, physical examination, interpretation of lab results and adjustment of medication). Place of care delivery differed from outpatient clinic to home-visits, or both. The cardiologist, as medically responsible, supervised the clinical aspects, whereas the nurse was responsible for education, self-care and low threshold to care accessibility for all patients.

\section{Main findings of this thesis}

This multicentre study with a one-year follow-up investigated the results of 382 optimally treated patients from whom 197 were equipped with a Health Buddy ${ }^{\circledR}$ in their home situation. Mean age of the patients was $71.0( \pm 11)$ years and $65 \%$ lived with a partner. Patients were recruited at the HF outpatient clinic; more than half of the population had mild HF, classified as NYHA-classification II, indicating a stable HF population. No difference was found between study groups for the presence of type-D personality.

\section{Disease specific knowledge, self-care, self-efficacy and adherence}

Our study shows that technology, such as telemonitoring is an adequate tool to improve knowledge and support patients in their self-care (chapter 3 ). The reduced number of face-to-face contacts with the HF-nurse (chapter 4) in combination with the patients' increased level of knowledge and self-care creates opportunities for a transfer of educational tasks from the HF-nurse to a device, which may be important in the light of an increasing number of chronically ill patients and a decreasing number of caregivers. The acquired self-efficacy in the study group compared to care as usual is valuable because confidence to deal with problems is needed to get activated and to take dedicated decisions [5, 8]. Adherence to therapy was found difficult to influence, except for fluid restriction and daily weighing. The latter is important in those HF patients who have to be convinced about the relevance of lifestyle changes. Medication adherence was already high at baseline, leaving very limited opportunity for improvement. Compliance to daily use of the Health Buddy system was high: about $90 \%$.

Patient activation is defined as understanding one's own role in the care process and having the knowledge, skills, and confidence to take on that role [8]. Research indicates that patients who are more activated, are significantly more likely to adhere to treatment regimens, get preventive care, and participate to a greater degree in decisions about their care $[5,8]$. These patients are also more likely to engage in healthy behaviour and to seek out and use health information [8]. The keystones of patient 
activation and involvement are a dedicated knowledge and self-care, which can be provided by face-to-face contacts, group sessions, information leaflets and/or technology [9].

\section{Care consumption}

We found a high compliance in the daily system use, which probably is the result of the tailor-made programs, albeit tailoring at a group rather than at a patient level. The fundament of a telemonitoring success is that patients (and healthcare professionals) make adequate use of the system. Patients have to provide health care professionals with specific information in order to make adequate personalised health care related decisions. It was found that elderly are less likely to accept telemonitoring because they frequently lack technical and Internet skills $[10,11]$. However, the new generation of "young-elderly" between 65 and 80 years of age, are more active to find out how to live productively and how to maintain health for as long as possible, compared to the "oldelderly" as those aged $>80$ year [12]. As a consequence they are more active on the Internet and gain digital experience. The relative high compliance in our study contradicts general findings of a skills gap in elderly and point into the direction of involved and active elderly.

Between the telemonitoring and usual care group no statistically significant effects were found for HF-related hospital admissions or mortality, in-hospital days, all-cause admissions and admission days.

However, a subgroup analysis in either patients with a HF history less than 18 months, or patients having a pacemaker or in co-habiting patients, telemonitoring was found to have a positive effect, in terms of fewer admissions for HF. While subgroups were not pre-specified and the number of events was low, this result has to be considered as hypothesis generating.

Koehler et al. studied a comparable population of stable and optimally treated patients. That group used a vital sign monitoring system with electronic transfer of blood pressure, body weight and single lead ECG. They reported no difference in mortality and admission rate for HF between the study and control group [13].

We observed less face-to-face contacts with the HF-nurse in the telemonitoring group, which was in line with the fewer caregivers' contacts, found by Dar et al. Their reduced number of contacts comprised less clinic and emergency room visits, and unplanned HF admissions [14]. Their telemonitoring system consisted of transferring vital signs, using an electronic weighing scale, automated blood pressure device and pulse oxymeter. Additional to the reporting of vital signs, patients answered every morning four questions related to symptoms indicative of HF decompensation. Next to vital sign monitoring another contrast with our study was the inclusion of recently discharged 
patients after a hospitalisation for HF, whereas in our study patients were included attending a regular outpatient visit.

A meta-analysis [15] investigated the relation between the clinical outcomes and factors such as duration of telemonitoring, patients' characteristics and particular physiological variables. This meta-analysis included 7,530 patients, with an average age between 53.5 and 78.1 years. In this meta-analysis 33 studies were included. Different telemonitoring systems were used, ranging from simple telephonic support or nurse management $(21 \%)$ to automatic transfer of vital signs using an electronic scale, ECG, medication dispenser and monitoring of symptoms (79\%). Primary end points were: (1) the HF-related number of hospital admission days, and (2) the cumulative rate of HFrelated hospitalisation and all-cause mortality. It was demonstrated that telehealth had a significant overall effect on length of hospital stay (-1.4days), HF hospitalisation ($28 \%$ ) and all-cause mortality (-24\%). Interestingly it was found that mortality increased over time: the longer the duration the less effective telehealth was. Furthermore, it was found that age was a significant covariate for HF hospitalisation, telehealth being less effective in older people. Because no data were provided about the adherence to the systems evaluated, it is unclear whether telemonitoring is actually less effective in the elderly, or that it illustrates underuse of the system probably caused by age related unfamiliarity with telemonitoring. NYHA class was also a significant covariate related to increased mortality and HF hospitalisation, however systems using questionnaires on symptoms and monitoring heart rate significantly decreased these endpoints. ECG monitoring had a negative effect on HF hospitalisation, which might be the result of selection bias to more serious HF. In this meta-analysis no distinction was made between systems using monitoring of vital signs and those using monitoring symptoms and educational programs, as we used. The finding of decreased mortality may be due to the transfer of vital signs, which is in agreement with the result of Inglis et al. [16]. In our study we used a telephone-based system without transfer of vital signs and no reduction in mortality was found, also according to the findings in the review of Inglis [16]. The reduction in HF admissions is similar to our study, however in our study the length of stay in hospital was not reduced. The finding of Xiang et al. that NYHA class was related to an increased risk of hospital admissions was according to our (nonpublished) findings in a sub-analysis of patients with one single HF hospitalisation. Our observation that patients with HF longer than 18 months are at higher risk for hospitalisation is also in agreement with what was reported in the meta-analysis, possibly caused by HF severity progresses over time.

\section{Cost-effectiveness}

Our results (chapter 5) are in line with previous studies and were negative for the study group as a whole, meaning that there was no cost saving in the telemonitoring group 
over a period of 12 months. Nevertheless, sub-analyses for HF duration and for the participating centres were positive: patients with HF duration less than 18 months benefitted from telemonitoring, albeit at higher costs. This finding corresponds with the subgroup analysis regarding the reduced hospitalisations for HF (chapter 4). Higher QALY's at indefinable costs were present in the centres where patients were followed in the outpatient clinic. This was in contrast with the lower QALY's and lower costs in the centre with solely home visits. These findings may suggest that cost-effectiveness is dependent from patient profiles and organisation of daily care, however more research is needed to proof this assumption. Although evidence is available that some telemonitoring studies show positive results concerning morbidity and mortality reduction, studies regarding cost reductions in HF patients are insufficiently convincing $[17,18,19]$. This may be explained by the variance in telemonitoring systems and follow-up times used in the economic analyses [20].

\section{Type-D, quality of life and depression}

Type-D was determined at baseline, because of its impact on patients' outcomes such as quality of life and depression. No telemonitoring studies reported about type-D personality and therefore no comparison can be made with others studies, however the prevalence of type-D personality among a population in a rehabilitation program was comparable with $\pm 38 \%$ of the patients with type-D personality in our study [21].

The decrease of anxiety and depression was in line with our preliminary results, [22] however in that sub population at 3 months, the decrease was not significant. Our findings were also comparable with the results in the study of Delanay [23], however they studied a very small population of 12 patients with telemonitoring with a followup of 90 days, which was in contrast with our population and follow-up of one year. Moreover, their telemonitoring system concerned the transfer of vital signs and 5 structured questions about patients' symptoms, which also is in contrast with our study.

Patients with HF experience reduced health-related quality of life [HRQoL] [24] an elevated risk of depression [25] and premature mortality [26]. Telehealth has emerged as a promising approach and some studies have suggested that telehealth has the potential to improve HRQoL $[27,28,29]$ for HF patients. Studies showed partial improvements in quality of life. Woodend et al. found an increased QoL for both groups, and a significant improvement after 3 months only for the physical subscale in favour of the telemonitoring group; no effects between groups remained after one year. Hoban et al. [30] showed comparable results with improved outcomes only for some aspects of the Minnesota Living with HF scale. However, no hard conclusions about effects on HRQoL can be made, which is in line with our findings. Our finding regarding the prevalence of depression was comparable with the prevalence in other studies [25]. 


\section{Discussion of main aspects of the TEHAF study}

\section{Patient recruitment}

Eight months were anticipated to recruit patients. This timespan had to be extended to sixteen months due to insufficient recruitment results in one centre. This insufficient patient recruitment was due to the care delivery system in that particular centre, because not all patients were referred to the HF-nurse, which was one of the inclusion requirements. Also it was the smallest centre with a relatively low number of HFpatients. Subsequently, the other 2 institutions had to include more patients, resulting in an unequal distribution of patients over the three centres. Despite the delayed recruitment period and the unevenly distributed number of patients, populations of the three institutions were comparable.

\section{Usual care and face-to-face contacts with patients of the telemonitoring group}

Usual HF care was delivered according to the European Guidelines for HF [6], however the care setting and tasks of the HF-nurses were not predetermined. All cardiologists treated patients in the HF outpatient clinic, whereas the setting where nurses delivered care differed between the three centres. In one centre nurses followed patients in the outpatient clinic and if needed in the patient's home situation, in another centre nurses solely provided care to the patients in their home, and in the remaining centre nurses operated solely in the outpatient clinic. Tasks of the HF-nurse were not exactly defined. All nurses provided patient education and were attainable in case of complaints, yet in two centres nurses performed also clinical evaluation, such as taking of clinical history, physical examination, interpretation of lab results and adjustment of medication. This divergence of usual HF care setting and nursing tasks has to be considered as an advantage as it increases the external validity of the study results.

Although we believe that using the patient as the correct 'unit of analysis', a 'unit of analysis error' may have influenced outcomes. Divine [31] describes "the patient as the correct 'unit of analysis' when, for example, physicians (or nurse) administer a fixed diagnostic or treatment protocol. Each physician (or nurse) is interchangeable with other physicians and has negligible individual impact on patient management decisions or patient outcomes." In our study, we did not use a fixed treatment protocol, while centres were allowed to deliver care according to their own protocols, as far as they followed the European guidelines [7]. Moreover, the diversity in nursing tasks, and the diversity of participating cardiologists in several centres may have influenced the outcomes. Divine [31] states that 'when groups of patients have been differentially influenced by specific physicians, using the patient as the 'unit of analysis' violates the assumption of independence among observations, which is required for standard statistical tests to be valid'. As is done in most other studies, we used the patients as the 'unit 
of analysis', although theoretically it would have been preferable to involve one single study nurse and cardiologist. This however is practically impossible and also would have resulted in a significantly reduced external validity.

\section{Power analysis}

The power analysis of our study was based on data from the literature [32, 33, 34]. However the study populations in these studies regarded recently discharged patients indicating an increased risk for re-admission whereas patients included in our study had stable HF indicating a lower risk for admission. Therefore our power calculation led to some underestimation of the sample size, and possibly affected the robustness of the study results.

\section{Study group size}

Several studies investigating the effects of telemonitoring in patients with HF did not show positive results. A substantial part is due to under-powering [35] as was also the case in our study. Although not statistically different, the admission rate was $44 \%$ less in the telemonitoring group compared with the usual care group, which is a satisfying result considering the already optimally treated and stable study population.

Therefore we consider this marked reduction rate in the study arm as practically important.

\section{Study design}

Although telemonitoring could lead to improved outcomes such as mortality and HF admissions, it also intervenes on the organisational level. It replaces parts of the usual care, such as face-to-face contacts, time for education and support of self-care. Therefore non-inferiority regarding the endpoints mortality and HF admissions, but the demonstration of improvement of the HF organisation would already have granted the use of telemonitoring. Mortality as an endpoint would have required a larger study population. Therefore we designed our study with expectedly sufficient power to demonstrate differences in hospital admissions, but moreover focused on improvements of health care organisation and patient related aspects as knowledge and selfcare.

We also made the choice to include broad range of HF patients to achieve results with high external validity.

In future telemonitoring studies, we suggest non-inferiority designs regarding admission rate and mortality. We recommend focusing on studying the process of health care delivery, integration of healthcare, level of self-care, patient and caregivers' re- 
sponsibilities and patient related aspects such as satisfaction of care delivery and quality of life [36].

\section{Effect of the intervention on readmissions}

Particularly, patients with HF duration less than 18 months and patients re-admitted for $\mathrm{HF}$ seem to benefit from telemonitoring. The reduced re-admission rate is in line with other studies with positive results [37, 38, 39]. In contrast to our study, the latter studies included patients at the moment of discharge from a HF admission and likely derive their positive study results from the increased risk for re-admission in this population [40].

Our finding of benefits in patients with HF with a limited duration is explained by two considerations. First, our system focuses on education, and recently diagnosed patients are the most receptive to learn about their disease and to improve knowledge and self-care. In the early stage of HF intensive follow-up by a HF-nurse in combination with telemonitoring induced improved patients' compliance to therapy and lifestyle changes may have contributed importantly to prevent hospitalisation. Secondly, symptoms in patients with a relatively short duration of HF are generally less severe and more easily to treat by simply adjusting diuretics.

This system has proven to positively influence disease specific knowledge, self-care and self-confidence, yet only partly influences adherence. The latter refers to daily weighing and fluid restriction, both important aspects in the care for patients with HF. This observation is worrisome concerning the patients attitude regarding daily weighing in case telemonitoring is no(t longer) part of their treatment. This leads to the question whether it is justified to end telemonitoring, knowing that there is a risk for weighing non-adherence.

The telemonitoring system we studied was found to substitute nursing tasks such as education and support of self-care and self-confidence. Although a useful finding [41], it may also lead to less personalized health care, especially in systems with only automated data transmission and reply in combination with a minimum of contacts between caregiver and patient.

Caregivers have to wake for this pitfall by for example a face-to-face contact before connecting the patient to the telemonitoring system, to let the patient to become acquainted and to get his confidence.

The finding that Health related Quality of life (HrQoL) was not improved, except for the sub-score QoL, was somewhat unexpected. It could likely be explained by the fact that telemonitoring was a new tool and patients had to learn and to deal with telemonitoring. Moreover they also had to deal with their HF problem, i.e. the burden of their symptoms and the daily confrontation with their disease. The follow-up time was likely too short to experience an improved QoL. Otherwise it may also be a result from the 
power calculation, which was not calculated to detect differences in HrQoL, rather HFhospitalisations.

\section{Site of care delivery}

Usual care as performed in the three participating centres was delivered according to the guidelines. The site of care delivery (in the outpatient clinic, at home or both) was not pre-specified and left to the local practice. It was found that the setting of care delivery might have importance regarding cost effects. In the centre solely visiting patients in their home situation QALY's and costs declined. QALY's are derived from EQ5D comprising the 5 Health-related Quality of Life (HRQoL) dimensions: mobility, selfcare, daily activities, pain/discomfort and depression/anxiety. The lower QALY of patients in this particular centre may be traced back to one of these dimensions. Self-care or depression/anxiety are unlikely candidates however, because these dimensions improved. From our study, it remains unclear to which of the three other dimensions the observed decline in QALY's can be attributed.

To identify possible benefits of long-term effects regarding the site of care delivery, further research has to be done. The two other centres show improved QALY's at higher costs, suggesting positive patient perception however at slightly higher costs.

These findings suggest the importance of the site where care is delivered and needs to be taken into account when implementing this telemonitoring system or when designing new studies.

\section{Duration of follow up}

The relatively short duration of the study may have influenced the findings and therefore the results cannot be extrapolated to the long-term. Long-term evaluation of telemonitoring however is unattractive not only because of the related costs but also because of the fast developments in this field. Hence, to predict long-term effects of telemonitoring, special analysis techniques should be used $[42,43]$.

\section{Future development of the telemonitoring device}

This study evaluated a simple device without additional vital signs monitoring. The power of the intervention was that the tailor-made content of dialogues in combination with the underlying philosophy of more disease specific knowledge and self-care led to better adherence and less symptoms. Further elaboration of the system is required to meet to the needs of an individual patient, whereas research is required as to why some subgroups, in contrast to others, benefit from the system. 


\section{Effect on organisation of care}

Telemonitoring has to be considered as a novel care delivery method [36]. This requires changes in attitude from patients and caregivers and adjustment of the organisation of care. For an efficient and cost-effective use, patients and involved caregivers need to feel comfortable in using telemonitoring. Apart from telemonitoring different sources remain necessary to inform patients. From the caregivers' side, updates about further developments regarding telemonitoring are required. Evaluation of the data, obtained by the system is needed for future improvements. Based on the implementation of telemonitoring the organisation of outpatient care needs to be redesigned and finances restructured.

\section{Final conclusion}

This study demonstrates that the use of this specific telemonitoring device resulted, for the total group, in less anxiety and depression, improved disease specific knowledge and self-care, and an increased compliance for important aspects as daily weighing and fluid restriction, in combination with less face-to-face contacts. For a subgroup of the population i.e. patients with heart failure less than 18 months, less hospitalisations for HF were found.

\section{Advice for practice}

The delivery of high-quality standard care may be threatened by epidemiologic and demographic developments. Telemonitoring has proven to be comparable to the current high-standard usual care, and its implementation into daily practice has become increasingly accepted. However, as highlighted above, telemonitoring has for various reasons not yet received its full potential. Therefore, it is advised to implement telemonitoring in daily care and gaining experience concomitant with further development of existing systems, aiming at the most possible individualisation of the care delivered. As stated above telemonitoring should be considered as a novel care delivery method [36]. This requires changes in attitude from patients and caregivers and adjustment of the organisation of care.

In the management of chronic diseases, such as heart failure, several care providers are involved. Telemonitoring can play a role to improve communication between these professionals and also with the patient. It particularly increases the possibilities to improve collaboration between all caregivers regardless from their setting. For that purpose caregivers have jointly to decide about the to be collected data, to develop integrated protocols about the respective responsibilities, handling of patient information, and the interchange and safety of patient data. 
Given the frequent multi-morbidity, combined contents have to be developed allowing cooperation between different disciplines.

Patients' participation in the development of protocols should be encouraged. Health care organisations should provide the structural and financial basis, and the requirements for employee education, safety of patient data, and interoperability of data systems.

From the other side over-dependency from telemonitoring systems should be avoided both at the professional and at the patient's level. At the point in time the patients' condition is stable and sufficient disease specific knowledge and self-care is obtained, ending telemonitoring should be considered. Caregivers should avoid the risk of relying to heavily on the information of the telemonitoring system only; therefore it is not preferable to appoint nursing or medical staff for telemedicine only. Nursing tasks have to exist of a mix of e-health-care and face-to-face contacts.

Non-adherence is another consideration using telemonitoring. These nonresponders risk deterioration of HF condition and avoidable readmissions. Early identification of this problem in a particular patient is important and appropriate steps should be taken.

Finally, there is a need for informal caregivers' attention or support, while they may be overloaded when patient care is increasingly moved to a patients' home situation.

Existing literature including this study showed that telemonitoring without transfer of vital signs does positively influence the level of knowledge and self-care, decrease anxiety and depression, reduces heart failure related hospital admissions, yet is not or less able to influence mortality, however our study was indeed not powered to reduce mortality. In contrast some studies using vital signs monitoring systems indeed have found to reduce mortality. Therefore it is advised to combine both approaches into one single system. Such a combined approach will expectedly result in empowered, wellinformed and responsible patients and in reduced numbers of hospital admissions and mortality.

\section{Advice for policy}

Telemonitoring studies showed that telemonitoring is comparable to usual care [44], and may therefore be considered ready for implementation in daily practice. In this process policymakers play an important role.

To increase acceptability, professional organisations have to include telemonitoring into their guidelines and accept telemonitoring as part of integral and safe care. Currently, hospitals mostly have a funding agreement with a local health care insurance [45]. To implement e-health on a large scale, barriers as lack of a financial structure need to be solved by policymakers and health care insurances. Also, patient- or client organisations have to take their responsibility to accept and promote e-health [46]. 
Chronic care delivery is shifting from specialist to generalist, and from generalist to patient and informal caregivers. There will be an increasing need for interchangeable information. Currently, health care systems are not sufficiently equipped for this. Therefore, all involved stakeholders are prompted to invest in communicating systems in order to improve communication and optimally utilize available information [47]. Telemonitoring and interchangeable information will support health care professionals and patients to create a continuum of health care, and make it easier to make patient centred arrangements and facilitate shared responsibility.

The next generation of patients with HF will be accustomed with digital information and data exchange. This new type of care consumer will be more actively involved into the care process and will have an own responsibility in maintaining an optimal physical condition, in avoiding of behaviour negatively influencing their disease and in noticing early signs of deterioration. Telemonitoring could be a tool to support patients, to monitor symptoms and to intervene at an early stage. To be prepared for this new patient generation, there is a need to develop smart sensors and devices [48].

One of the pitfalls of an increased availability of health care is the concomitant increase of the demand for it. Technical developments could be a solution to support self-care, relieving health care professionals not always being able to meet with the patients' demands. Development of self-care has to be more publicly discussed with patients and patient organisations in order to have a shared perspective and shared expectations [36].

\section{Advice for future research}

The finding of less hospital admissions in a sub-population of patients with HF shorter than 18 months gives rise to HF-duration as a pre-specified condition in following research.

Cost-effectiveness was found to be influenced by the way care is delivered and organised. This makes it relevant to pre-specify ways of care delivery and organisation in following studies in order to determine best practice.

More knowledge about patient profiles is required in order to get optimal outcomes from telemonitoring. Therefore future research will need to focus on patient profiles, taking into account patient's severity of illness, co-morbidities, age, educational level, self-care abilities, social class and other important individual aspects. As far as we know telemonitoring exposure has not been investigated yet; future research about patient profiles may incorporate the exposure time needed for an individual patient.

To support the implementation of telemonitoring in chronic illness care, future research should spend more attention to how telemonitoring in patients with chronic conditions works, and the role of the context in which it gets implemented. A shift to- 
ward implementation science is recommended to further improve the use of this modality [49].

\section{Finally}

In the near future patients' role will change and patients will become better-informed and more active care consumers. They will obtain information not only from their caregivers but also from the internet, patient associations and health communities. By introduction of the internet in health care, patients expect access to health care information 24 hours a day, seven days a week. Patients will increasingly use the internet and social media to get their information and the best available care. Moreover, patients will soon drive the use of devices such as telemonitoring.

Also patients will increasingly be more mobile and this requires adaptation of the organisation of e-health care. Current E-health applications will increasingly be catching up by $\mathrm{M}$-health services (mobile health) [48]. Internet-care will become as usual as telebanking and attainable at any time at any place.

Organisation of traditional health care needs to be redesigned. Telemonitoring is a likely candidate to be a game changer in this transformation process. In order to be accepted by daily users, technology providers need to involve patients and health care professionals when developing new products, whereas organisational management needs to be involved to get implementation support [50]. To anticipate on these changes, professional education has to be adapted by integrating issues as how to deal with telemonitoring, telemonitored patients and digital patient information. Especially interactive technology and communication will become highly important. For instance, in HF patients assessing a patient's condition at a distance or without physical examination will be a future challenge. Therefore innovative communication methods have to be practiced, and a comprehensive knowledge of symptoms and syndromes will be, more than ever, a crucial requirement.

Patients, health care professionals and health care organisations: be prepared .... .... there is no turning back! 


\section{References}

1. McMurray JJ, Stewart S. Heart failure: epidemiology, aetiology, and prognosis of heart failure. Heart 2000; 83: 596-602.

2. http://www.nationaalkompas.nl/gezondheid-en-ziekte/ziekten-en-aandoeningen/hartvaatstelsel/hartfalen/trend/

3. http://www.rijksoverheid.nl/onderwerpen/werken-in-de-zorg/tekort-zorgpersoneel-tegengaan'

4. Slobbe LC, Smit JM, Groen J, Poos MJCC, Kommer GJ. Kosten van ziekten in Nederland 2007. Trends in de Nederlandse zorguitgaven 1999-2010. Bilthoven: RIVM, 2011.

5. Grumbach K, Bodenheimer T, Lorig K, Holman H. Patient Self-management of chronic disease in primary care. Journal of the American Medical Association 2002; 288(19): 2469-2475.

6. Boyne JJ, Vrijhoef HJ, Wit R, Gorgels AP. Telemonitoring in patients with heart failure, the TEHAF study: Study protocol of an ongoing prospective randomised trial. International Journal of Nursing Studies 2011; 48: 94-9.

7. Dickstein K, Cohen-Solal A, Filippatos G, McMurray JJ, Ponikowski P, Poole-Wilson PA, et al. ESC guidelines for the diagnosis and treatment of acute and chronic heart failure. The European Heart Journal 2012; 33: 1787-1847.

8. Hibbard JH, Stockard J, Mahoney ER, Tusler M. Development of the Patient Activation Measure (PAM): conceptualizing and measuring activation in patients and consumers. Health Services Research 2004; 39 : 1005-26.

9. Strömberg A. The crucial role of patient education in heart failure. The European Journal of Heart Failure 2005; 7: 363- 369.

10. Czaja SJ, Charness N, Fisk AD, et al. Factors predicting the use of technology: Findings from the center for research and education on aging and technology enhancement (create). Psychology and Aging 2006; 21: 333-52.

11. Evangelista LS, Strömberg A, Westlake C, et al. Developing a web-based education and counselling program for heart failure patients. Progress in Cardiovascular Nursing 2006; 21: 196-201.

12. Rivlin RS, Blacklow RS. Introduction to the symposium: Keeping the Young-Elderly Healthy. American Journal of Clinical Nutrition 2007; 86 (supplement).

13. Koehler F, Winkler S, Schieber M, Sechtem U, Stangl K, Böhm M, Boll H, Baumann G, Honold M, Koehler K, Gelbrich G, Kirwan BA, Anker S. Impact of Remote Telemedical Management on Mortality and Hospitalizations in Ambulatory Patients With Chronic Heart Failure: The Telemedical Interventional Monitoring in Heart Failure Study. DOI:10.1161/circulationaha.111.018473.

14. Dar O, Riley J, Chapman C, Dubrey S, Morris S, Rosen S, Roughton M, Cowie M. A randomized trial of home telemonitoring in a typical elderly heart failure population in North West London: results of the Home-HF study. The European Journal of Heart Failure 2009; 11: 319-325.

15. Xiang R, Li L, Xin Liu S. Meta-analysis and meta-regression of telehealth programmes for patients with chronic heart failure. Journal of Telemedicine and Telecare 2013: July 9; doi:10.1177/$1357633 \times 13495490$.

16. Inglis SC, Clark RA, McAlister FA, Stewart S, Cleland JG. Which components of heart failure programmes are effective? A systematic review and meta-analysis of the outcomes of structured telephone support or telemonitoring as the primary component of chronic heart failure management in 8323 patients: Abridged Cochrane Review. The European Journal of Heart Failure 2011; 9: 1028-1040.

17. Steventon A, Bardsley M, Billings J, et al. Effect of telehealth on use of secondary care and mortality: findings from the Whole System Demonstrator cluster randomised trial. British Medical Journal 2012; 344: doi: 10.1136/bmj.e3874.

18. Augustin $U$, Henschke $C$. Does telemonitoring lead to health and economic benefits in patients with chronic heart failure?-A Systematic Review. Gesundheitswesen 2012; May 21: [Epub ahead of print] German.

19. Mistry H. Systematic review of studies of the cost-effectiveness of telemedicine and telecare. Changes in the economic evidence over twenty years. Journal of Telemedicine and Telecare 2012; 18(1): 1-6. 
20. Klersy C, De Silvestri A, Gabutti G, Regoli F, Aurrichio A. A meta-analysis of remote monitoring of heart failure patients. Journal of American College of Cardiology 2010; 55(19): 2185.

21. Denollet J. DS14: Standard Assessment of Negative Affectivity, Social Inhibition, and Type D Personality. Psychosomatic Medicine 2005; 67: 89-97.

22. Ramaekers BLT, Boyne JJJ, Gorgels APM, Vrijhoef HJM. Adherence among telemonitored patients with heart failure to pharmacological and non-pharmacological recommendations. Journal of Telemedicine and e-health 2009; 15: 517-524

23. Delaney C, Apostolidis B. Pilot testing of a multicomponent home care intervention for older adults with heart failure: an academic clinical partnership. Journal of Cardiovascular Nursing 2010; 25(5): E27-40.

24. Hobbs FD, Kenkre JE, Roalfe AK, Davis RC, Hare R, Davies MK. Impact of heart failure and left ventricular systolic dysfunction on quality of life: a cross-sectional study comparing common chronic cardiac and medical disorders and a representative adult population. The European Heart Journal 2002; 23: 1867-76.

25. Rutledge T, Reis VA, Linke SE, Greenberg BH, Mills PJ. Depression in heart failure: A meta-analytic review of prevalence, intervention effects, and associations with clinical outcomes. Journal of American College of Cardiology 2006; 48: 1527-37.

26. Mosterd A, Hoes AW. Clinical epidemiology of heart failure. Heart 2007; 93(9): 1137-46.

27. Antonicelli R, Testarmata P, Spazzafumo L, et al. Impact of telemonitoring at home on the management of elderly patients with congestive heart failure. Journal of Telemedicine and Telecare 2008; 14: 300-5.

28. Artinian NT, Harden JK, Kronenberg MW, et al. Pilot study of a Web-based compliance monitoring device for patients with congestive heart failure. Heart Lung 2003; 32: 226-33.

29. Woodend AK, Sherrard H, Fraser M, Stuewe L, Cheung T, Struthers C. Telehome monitoring in patients with cardiac disease who are at high risk of readmission. Heart Lung 2008; 37: 36-45.

30. Hoban MB, Fedor M, Reeder S, Chernick M. The Effect of Telemonitoring at Home on Quality of Life and Self-Care Behaviors of Patients with Heart Failure. Home Healthcare Nurse 2013; 31(7): 368 -377.

31. Divine GW et al. The unit of analysis error in studies about physicians' patient care behavior. Journal of General Internal Medicine 1992; 7(6): 623-629.

32. Krumholz HM, Chen YT, Wang Y, Vaccarino V, Radford MJ, Horwitz RI. Predictors of readmission among elderly survivors of admission with heart failure. American Heart Journal 2000;139:72-77.

33. Aranda JM, Johnson JW, Conti JB. Current trends in heart failure readmission rates: analysis of Medicare data. Journal of Clinical Cardiology 2009; 32: 47-52.

34. Zaya M, Phan A, Schwarz ER. Predictors of re-hospitalization in patients with chronic heart failure. World Journal of Cardiology 2012; 26 (4): 23-30.

35. Christiakia DA. Interpreting negative results from an underpowered clinical trial. Archives of Paediatric and Adolescent Medicine 2006; 160.

36. Boyne JJ, Vrijhoef HJ. Implementing Telemonitoring in Heart Failure Care: Barriers from the perspectives of patients, healthcare professionals and healthcare organizations. Current Heart Failure Reports 2013; 10(3) DOI 10.1007/s11897-013-0140-1.

37. Giordano A, Scalvini S, Zanelli E, Corrà U, Longobardi GL, Ricci VA, Baiardi P, Glisenti F. Multicenter randomised trial on home-based telemanagement to prevent hospital readmission of patients with chronic heart failure. International Journal of Cardiology 2009; 131: 192-199.

38. Dendale P, De Keulenaer G, Troisfontaines P, Weytjens C, Mullens W, Elegeert I, Ector B, Houbrechts M, Willekens $K$, Hansen D. Effect of a telemonitoring-facilitated collaboration between general practitioner and heart failure clinic on mortality and rehospitalization rates in severe heart failure: the TEMA-HF 1 (Telemonitoring in the MAnagement of Heart Failure) study. The European Journal of Heart Failure 2012; 14:333-340.

39. Weintraub A, Gregory D, Patel AR, Levine D, Venesy D, Perry K, Delano C, Konstam M. A Multicenter Randomized Controlled Evaluation of Automated Home Monitoring and Telephonic Disease Management in Patients Recently Hospitalized for Congestive Heart Failure: The SPAN-CHF II Trial. Journal of Cardiac Failure 2010; 16: 285-292. 
40. Betihavas V, Davidson PM, Newton PJ, Frost SA, Macdonald PS, Stewart S. What are the factors in risk prediction models for rehospitalisation for adults with chronic heart failure? Australian Critical Care 2012; 25: 31-40.

41. Laurant et al. Substitution of doctors by nurses in primary care. Cochrane Database Systematic Reviews 2005; 18; (2): CD001271.

42. Briggs A, Sculpher M. An introduction to Markov modelling for economic evaluation. Pharmacoeconomics 1998; 13(4): 397-409.

43. Price MJ, Briggs AH. Development of an Economic Model to Assess the Cost Effectiveness of Asthma Management Strategies. PharmacoEconomics 2002; 209(3):183-194.

44. Wootton R. Twenty years of telemedicine in chronic disease management-an evidence synthesis. Journal of Telemedicine and Telecare 2012; 18: 211-220.

45. http://www.zorgvisie.nl/PageFiles/82726/001_1373967634841.pdf

46. http://knmg.artsennet.nl/Publicaties/KNMGpublicatie/Nationale-Implementatie-Agenda-eHealth-NIA2012.htm / KNMG-publicatie-Brochure-NIA-eHealth-7-6-2012-pdf.

47. White paper NICTIZ: hoe krijg ik telemonitoringgegevens beter beschikbaar? 23 April 2012 ID number 120006.

48. Van der Klauw DM, Rijken EMS, Rövekamp AJM, Molema JJW, Mooij R. Implementatie Handreiking Ondersteuning bij Chronisch Hartfalen. TNO R10904. 49. Berwick D. The science of improvement. Journal of the American Medical Association 2008; 299: 1182-3.

50. http://www.zorgwelzijn.nl/Ouderenzorg/Nieuws/2013/7/Zorgprofessional-traag-in-accepteren-nieuwetechnologie-1313610W/ 

CHAPTER 10

Summary

Samenvatting

Dankwoord

Curriculum vitae

International peer reviewed publications 


\section{Summary}

The purpose of this study was to assess if telemonitoring improves quality of care, in terms of less hospitalisations for heart failure with an equal mortality, and patient related aspects as knowledge, self-care and adherence compared with usual care in patients with heart failure.

In the majority of telemonitoring studies one standard programme is offered to all patients, hereby bypassing the demand of tailored care. In this randomised controlled trial, three centres in the South of the Netherlands participated. Two of the centres were general hospitals; the remaining was a university centre. Based on the experience from a feasibility study, four different programmes were developed with varying focus on patient education and support or on monitoring the HF symptoms. The study design and the tailor made aspects of the telemonitoring system are given in Chapter $\mathbf{2}$.

The system used in this study was the Health Buddy ${ }^{\circledR}$. The hypothesis of this study was that telemonitoring improves knowledge, self-care and adherence resulting in a decrease of HF admissions. Secondary endpoints were the combined endpoint of HF admission and all cause death, level of disease specific knowledge and self-care, selfefficacy, quality of life, depression and costs.

Chapter $\mathbf{3}$ describes the preliminary results of the impact of telemonitoring compared with usual care on patients' disease-specific knowledge, adherence and depression in 56 and 45 patients, receiving telemonitoring and usual care respectively. Before randomisation and 3 months afterwards onset of this trial, data were collected about disease specific knowledge, adherence and depression. Disease specific knowledge improved significantly in patients from two of the three hospitals. The remaining centre showed an increase of knowledge in both the study and the care as usual group. Adherence in terms of fluid restriction, daily weighing, physical exercising, and alcohol restriction improved significantly in the telemonitoring group. These preliminary results showed also that the use of telemonitoring resulted in a substantial but statistically non-significant decrease in depression.

Levels of disease specific knowledge, self-care, self-efficacy and therapy adherence during whole follow-up are described in Chapter 4. In the telemonitoring group selfefficacy improved significantly after 3 and 6 months, yet the difference disappeared after one year. The telemonitoring system was found to be useful as an education tool, because disease specific knowledge improved significantly in the telemonitoring group with concomitantly fewer contacts with the HF-nurse compared to usual care. In the telemonitoring group, adherence regarding daily weighing improved significantly, as well as compliance to fluid retention. Activity level improved after 3 months, importance of medication intake after 6 and 12 months. No effects were found regarding appointments, diet, smoking and use of alcohol. 
The positive effects on disease specific knowledge and self-care abilities in the telemonitoring group endorse the presumption that telemonitoring is suitable as an educational and supporting tool, creating possibilities to re-arrange care by substitution of nursing tasks.

The main results of the randomised trial are presented in Chapter 5. Hospitalisations for HF showed a trend to fewer admissions in the telemonitoring group, with respectively 18 (9.1\%) compared with 25 (13.5\%) patients, and a total number of 24 and 43 hospitalisations in the telemonitoring and usual care group. Mean time to first HF admission did not significantly differ between the groups, being 161 and 130 days for respectively the telemonitoring and usual care group. The combined endpoint of HF admission and all-cause mortality was similar for both. During follow-up, 18 (9.1\%) patients in the intervention group died against 12 (6.5\%) in the usual-care group [Cox regression analysis $P$ 0.82]. In the telemonitoring group patients had significantly less face-to-face contacts with the HF-nurse. Subgroup analysis showed important interactions for HF duration, ischemia, blood urea, haemoglobin level, heart rate, NYHA class, and systolic blood pressure. In case HF duration was less than 18 months the number of HF admissions was significantly less.

Participants' adherence was high with ninety per cent daily use of the telemonitoring system, possibly due to the tailor made programs.

Costs were derived from contacts with caregivers at the patients' home, general practice office, outpatient clinic and from hospital admissions and medication costs.

Effectiveness was expressed as QALY's gained and derived by conversion of the EQ5D. No differences in QALY's or annual costs per patient were found, as described in Chapter 6. At a threshold of $€ 50,000$ the probability of telemonitoring being costeffective was $48 \%$. Subgroup analysis showed higher expected cost-effectiveness for patients with HF less than 18 months, with a probability of being cost-effective of $72 \%$, which was not unexpected given the sub-analysis of the main results with less hospital admissions in the same group. The cost effectiveness analysis showed a high level of decision uncertainty, probably caused by the divergence between the participating institutions. In two institutions the cost effectiveness planes were mainly located in the same direction, whereas one centre showed divergent results. The most principal difference between the deviating hospitals was the organisation of care. It was concluded that it is too premature to draw an unambiguous conclusion regarding costeffectiveness for the whole group.

Impact on quality of life, depression and type-D personality is described in Chapter 7. The prevalence of Type-D personality was equal in both groups. Non-significant effects were found for quality of life except for the sub scores 'quality of life and selfefficacy'. Significant differences were found for anxiety and depression in favour of the telemonitoring group. Type-D personality seems to influence quality of life and therefore it is advised to assess its presence in patients with heart failure. 
This study proved that telemonitoring may be considered to be effective regarding some aspects: Patients' disease specific knowledge and self-care improved, depression was under control, HF -admissions (not significant) and face-to-face contacts with the HF-nurse decreased. These positive experiences legalise further implementation of this kind of telemonitoring.

However, implementation into daily practice was found to encounter some barriers. Therefore we studied possible barriers hindering this implementation. An overview of barriers on patient, health care professional and organisational level is described in Chapter 8. To achieve successful implementation, it is advised to pay attention at those barriers. 


\section{Samenvatting}

Deze studie werd uitgevoerd om vast te stellen of telemonitoring de kwaliteit van de zorg en patiënt gerelateerde aspecten zoals kennis, zelfzorg en therapietrouw verbetert, in vergelijking met gebruikelijke zorg bij patiënten met hartfalen.

De meeste telemonitoring systemen bieden één standaard programma aan, en gaan daarbij voorbij aan de specifieke behoeften van de individuele patiënt. Een gerandomiseerde studie naar het effect van telemonitoring werd uitgevoerd in drie ziekenhuizen in Zuid-Nederland; twee van de deelnemende centra waren algemene ziekenhuizen, één was een academisch ziekenhuis. Gebaseerd op de ervaringen van een eerder verrichte pilot studie, dat individualisering van de telezorg en dus meer maatwerk nodig was, ontwikkelden de onderzoekers vier verschillende programma's met een wisselende focus op ofwel educatie en ondersteuning van zelfzorg en gedragsverandering, of op het monitoren van klachten, of op beide aspecten. In hoofdstuk 2 wordt deze betreffende aspecten uiteengezet en de studieopzet weergegeven. De studie hypothese luidt dat telemonitoring kennis, zelfzorg en therapietrouw bevordert, en dat daardoor ziekenhuisopnamen voorkomen kunnen worden. Secundaire studieuitkomsten zijn het gecombineerd eindpunt van ziekenhuisopname wegens hartfalen en overlijden, ziekte specifieke kennis en zelfzorg, het vertrouwen hebben in het nemen van de juiste beslissingen (self-efficacy), kwaliteit van leven, depressie en kosten.

Hoofdstuk 3 beschrijft de voorlopige resultaten van het effect van telemonitoring op ziekte specifieke kennis, therapietrouw en depressie, gemeten in 56 en 45 patiënten van respectievelijk de groep die telemonitoring of die standaardzorg krijgt. Gegevens met betrekking tot ziekte specifieke kennis, therapietrouw en depressie werden verzameld en geanalyseerd bij aanvang en 3 maanden na het starten van het onderzoek werden geanalyseerd. Ziekte specifieke kennis verbeterde in twee van de drie centra. Het overige centrum liet een verbetering zien in beide groepen, met na drie maanden een hoger kennisniveau in de groep die standaardzorg kreeg. Therapietrouw aangaande vochtbeperking, dagelijks wegen, lichamelijke activiteiten en alcohol beperking verbeterde aanzienlijk in de telemonitoring groep. Deze voorlopige resultaten toonden ook dat het gebruik van telemonitoring leidde tot een substantiële, zij het statistisch niet significante, vermindering van depressie.

Hoofdstuk 4 beschrijft het niveau van ziekte specifieke kennis en zelfzorg, selfefficacy en therapietrouw. In de telemonitoring groep verbeterde self-efficacy significant na 3 en na 6 maanden, maar dit verschil verdween na 12 maanden. Het telemonitoring systeem bleek bruikbaar te zijn als middel om educatie aan te bieden, omdat de ziekte specifieke kennis van de patiënt significant verbeterde, terwijl er minder fysieke contacten plaatsvonden met de hartfalenverpleegkundige, in vergelijking met de standaardzorg. De therapietrouw in de telemonitoring groep verbeterde significant met 
betrekking tot het dagelijks wegen en het opvolgen van het advies voor een beperkte vochtinname. Na 3 maanden werd een toename aan activiteiten gemeten, en de therapietrouw wat betreft de medicatie nam toe na 6 en 12 maanden. Geen effecten werden gevonden ten aanzien van het nakomen van afspraken met zorgverleners, dieet, roken en alcoholgebruik. Aangezien het systeem regelmatig vraagt om het gewicht door te geven mag het dagelijkse wegen worden beschouwd als een logisch gevolg van het opvolgen van instructies via telemonitoring. De positieve invloed op ziekte specifieke kennis en de toename van het vermogen tot zelfzorg onderschrijven de aanname dat telemonitoring geschikt is als middel tot educatie en ondersteuning. Daarmee biedt het de mogelijkheid om de zorg te herschikken door substitutie van verpleegkundige taken.

De hoofdresultaten van deze studie worden gepresenteerd in Hoofdstuk 5.

Het aantal ziekenhuisopnamen wegens hartfalen toonde een (zij het niet significante) daling, met opnamen van 18 (9.1\%) en 25 (13.5\%) patiënten, en een totaal aantal opnamen van 24 en 43 in respectievelijk de telemonitoring en standaardzorg groep. De gemiddelde tijd tot de eerste opname, zijnde 161 en 130 dagen, verschilde niet significant tussen de groepen. Het gecombineerde eindpunt van hartfalenopname en overlijden, was voor beide groepen gelijk. Gedurende de studieperiode overleden 18 patiënten $(9.1 \%)$ in de telemonitoring groep en 12 (6.5\%) in de standaardzorggroep [Cox regressie analyse $P$ 0.82]. De groep die telemonitoring kreeg had significant minder (fysieke) contacten met de hartfalenverpleegkundige. Subgroep analyses toonden belangrijke interacties voor hartfalenduur, ischemie, ureum, hemoglobine, hartfrequentie, NYHA-klasse en systolische bloeddruk. Wat betreft hartfalenduur werd in de groep patiënten, die korter dan 18 maanden hartfalen hadden, significant minder opnamen voor hartfalen gevonden.

Negentig procent van de patiënten gebruikte het telemonitoring systeem dagelijks. Dit is hoog vergeleken met sommige andere studies, en mogelijk het gevolg van het maatwerk dat via de diverse programma's werd aangeboden.

In Hoofdstuk 6 worden de kosten beschreven die gemaakt werden voor contacten met zorgverleners in de thuissituatie, eerste lijn, poliklinische contacten, ziekenhuisopnamen, en kosten voor verrichtingen en medicatie. Deze werden vergeleken tussen beide studiegroepen. Effectiviteit werd uitgedrukt in QALY's en afgeleid van de EQ-5D. Bij een drempel van $€ 50,000$ bleek de kans dat telemonitoring kosten-effectief is $48 \%$ te zijn. Uit sub- analyses bij patiënten met korter dan 18 maanden hartfalen was de te verwachten kosteneffectiviteit $72 \%$. Dit was geen onverwachte bevinding gezien het lagere aantal opnamen in deze subgroep. De kostenanalyse toont een hoge mate van onzekerheid, mogelijk veroorzaakt door de verschillen tussen de diverse ziekenhuizen. Twee ziekenhuizen toonden nagenoeg vergelijkbare resultaten, maar een ziekenhuis week duidelijk af. Het belangrijkste verschil van het afwijkende ziekenhuis was de andere organisatie van de zorg. Op grond van deze bevindingen is het voorbarig een eenduidige conclusie met betrekking tot kosteneffectiviteit van telemonitoring. 
Het effect van Type-D persoonlijkheid en de invloed van telemonitoring op kwaliteit van leven en depressie wordt beschreven in hoofdstuk 7. Het voorkomen van Type-D persoonlijkheid was gelijk in beide groepen. Niet significante positieve effecten met betrekking tot kwaliteit van leven, werden aangetoond voor de sub-scores 'kwaliteit van leven en self-efficacy'. In de telemonitoring groep werden significant lagere angst en depressie waarden aangetoond. Type-D persoonlijkheid lijkt de kwaliteit van leven negatief te beïnvloeden. Daarom wordt geadviseerd de Type-D persoonlijkheid van een patiënt te bepalen.

Deze studie heeft aangetoond dat telemonitoring effectief is betreffende bepaalde aspecten. Het lijkt tot minder ziekenhuisopnamen te leiden in de subgroep met hartfalen, korter dan 18 maanden. Deze bevinding moet in een prospectieve studie worden bevestigd. Ziekte specifieke kennis en zelfzorg namen toe, angst en depressie name af of waren onder controle, fysieke contacten met de hartfalenverpleegkundige namen af. Deze positieve bevindingen staan implementatie van telemonitoring in de klinische praktijk toe. Echter, implementatie in de praktijk wordt gehinderd door een aantal barrières. Een overzicht van deze belemmeringen wordt gegeven voor het niveau van de patiënt, de professional en de zorg organisatie in hoofdstuk 8. Vooraleer tot implementatie over te gaan en deze zo succesvol mogelijk te laten verlopen, wordt geadviseerd om rekening te houden met genoemde aspecten. 



\section{Dankwoord}

Beste Ton en Bert, het feit dat jullie mijn promotoren zouden zijn, lag wat mij betreft voor de hand. Jullie hebben mij destijds beide begeleid bij mijn masteropleiding en samen hadden we reeds een pilot gedaan naar telebegeleiding. Beste Ton, wij kennen elkaar al heel veel jaren. Wie had destijds kunnen bevroeden dat jij ooit nog mijn promotor zou worden. Elkaar lang kennen heeft vele voordelen, en die hebben wij mooi meegenomen in dit traject. Daarom weet ik ook dat je af en toe wel eens getwijfeld hebt of het allemaal wel goed zou komen . . . Beste Bert, jij hebt letterlijk aan "telebegeleiding" gedaan, en met dit proefschrift hebben wij bewezen dat tele-begeleiding werkt. Ver weg en toch dichtbij door te bellen, mailen, skypen. . . . Bert en Ton, jullie zijn zeer waardevol voor me geweest, indien nodig een luisterend oor, goede adviezen en kritisch op een opbouwende manier. Ton en Bert, het voelde goed en we hebben dit samen tot een mooi einde gebracht. Wat jou betreft Bert, hopelijk gaat onze samenwerking gewoon verder. Ton, wij zullen ons beslist blijven zien, al zal het samen aan grote projecten werken er wellicht niet meer inzitten.

De eerstvolgende die ik wil danken is Hans Fiolet. Hans, jouw geloof en vertrouwen in de kracht van anderen is onbeschrijflijk, en stimuleert mensen om boven zichzelf uit te stijgen. Dank voor jouw niet aflatende steun, creativiteit in de breedste zin van het woord en je voortdurende bereidheid om mee denken en te investeren. Zonder jou was dit nooit gelukt!!

Gedurende mijn traject heb ik veel belangstelling genoten. Altijd wel mensen op de universiteit, in het ziekenhuis, op de transmurale zorg afdeling, op congressen en privé, die wilden weten hoe het ging en 'wanneer het klaar was. . .'. Nou mensen, het is zo ver: het is klaar! en ik wil dan ook iedereen danken die mij op deze of gene manier gesteund heeft in de afgelopen periode. ledereen persoonlijk in dit dankwoord benoemen zou te ver gaan, maar bij enkele mensen ga ik dat toch doen. Mijn directe collega's Ans, Maria, Nicole, Marianne, Lilian, Sonja, Ellen en Jacqueline en destijds Monique: jullie zijn geweldige meiden en fantastische collega's. Zonder jullie was dit echt niet gelukt, en ik ga mijn best doen er weer meer voor jullie te zijn. Jacq, ik stel zeer op prijs dat jij mijn paranimf wil zijn, bedankt hiervoor! Mijn collega's uit Sittard, Inge en Marion, en Vera en Theo uit Heerlen, dank voor alles! Niets was jullie te veel! Ook gaat mijn dank uit naar Gerjan De Weerd, Hans Kragten en Pieter Platteel. Dank dat jullie iets zagen in dit project en bereid waren met ons mee te doen.

Beste Jeroen, mijn maatje. Wij noemden elkaar al 'dr.' en 'dear Professor' lang voor het zo ver was of ooit zal zijn. Aan de titel waren we dus al gewend, alleen ik moest het nog waarmaken, althans de eerste titel. De laatste namen we er maar gewoon bij. . . . Wij waren echte maatjes en ik gun iedereen die dit traject aflegt een maatje zoals jij was. Onze 'SOS-jes' en 'tied veur e bekske!!' voor dit traject is nu voorbij, maar ik denk 
wel dat we het in stand moeten houden, ook al is dat in Zweden! Wij hebben samen heel wat kilometers gereisd, en met jou ben ik verder geweest dan met mijn eega. Ik heb hier hele goede herinneringen aan, en mooie foto's. . . moest ik je die niet nog doorsturen? Ook vonden we elkaar als er iets was met onze 'noonk'. . . maar daar zal ik hier niet verder over uitwijden.

Bij de dagelijkse uitvoering waren Petra, Monique, Pascal en Elly betrokken. Dames jullie waren geweldig, ik heb zo ongelooflijk geboft met jullie. Elly, jij bent een onuitputtelijke bron van energie en ideeën, creatief, gedreven en een logistiek wonder. Volgens mij zou jij de Excel file die je voor mijn studie ontwikkelde, zo kunnen verkopen . . . Toen je na het afronden van de dataverzameling bij me wegging, heb ik je al gevraagd om mijn paranimf te zijn. Nu is het dan zo ver, we zijn samen begonnen en we maken het samen af. Peter Reniers, Eveline, An en Veronique, jullie hebben veel werk gehad aan dit project, ook fijn voor jullie dat het klaar is, en dank voor alle energie die jullie hierin hebben gestopt. Nicole Lahaije, jij ook bedankt voor je warme belangstelling en voor alle energie die jij erin gestoken hebt, zoals het vernieuwen, verlengen en aanpassen van de arbeidsovereenkomsten toen alles toch meer tijd in beslag bleek te nemen dan gepland. Mijn collega's van cardiologie Nicole, Christian, Vanessa, Stephane, Bas, Sema en Sandra, dank voor jullie hulp en belangstelling. Harry, ook jij bedankt voor je belangstelling, hartelijkheid en bereidheid om mee te denken. Hanspeter, jij bedankt voor de vele discussies die we hadden, voor je vertrouwen en je respect. Het is fijn om met je te kunnen samenwerken, het product verder te verfijnen en te implementeren. Het feit dat we het niet altijd eens zijn met elkaar, is een positief element in onze samenwerking. Ook dank dat je de voorzittersrol van de eindpunt- en leescommisie op je wilde nemen. Tot slot, hebben velen hebben met ongeloof geluisterd als ik vertelde dat we samen een danscursus deden. Ik ben ik je daar zeer erkentelijk voor en heb daar veel plezier aan beleefd. Ook onze gesprekken tijdens de ritten heen en weer waren zeer waardevol. Ron, Tiny, Jos en Dirk, ook jullie bedankt voor de bereidheid om mijn proefschrift te willen lezen. Nicole, Wubbo en Jeroen, dank voor het doorploegen van de patiëntengegevens voor het vaststellen van de eindpunten. Marieke, Thea en Fred, bedankt voor de hulp bij statistische analyses en jullie geduld om het mij uit te leggen. Thea, jouw kennis over kosten is van grote waarde geweest! Collega's van de TMZonderzoeksgroep Inge, Marielle, Daisy, Joyce, George, Liesbeth en Yvonne, dank voor jullie belangstelling en Joyce, jij extra bedankt voor je hulp bij het opschonen van de data. Je bent een kei! Yvonne, voor jou is het einde nu ook heel dichtbij. Dank voor onze soms filosofische gesprekken en hilarische fietstochten, vooral na de jaarlijkse BBQ bij Hans. Volgend jaar sluiten wij de poort weer! Alle dames van de secretariaten, dank voor het plannen van de overleggen en het schuiven in de agenda's, met name Nadine en Julie, die hier vaak een hele klus aan hadden. Gerrie en Ezra, dank voor jullie steun en gezelligheid tijdens onze 'squarum avondjes'! Jan en Arjan, dank jullie voor jullie meedenken, creativiteit, welwillendheid om mee naar oplossingen zoeken en luisterend oor. Heel fijn en waardevol om zo een goed contact te hebben! 
Tot slot zijn er onze vrienden die ik van harte wil danken voor de voortdurende belangstelling en mijn familie die er altijd waren en zijn. Herman jij trad, evenals Jeroen, met regelmaat op als reserve-partner bij het dansen, wat een lol hadden wij! Fenomenaal was onze 'wechselschried', en de opmerkingen die jij maakte zorgden meer voor lachstuipen dan voor de juiste danspassen.

Ma en pa, jullie zijn al op leeftijd en vaak heb ik me afgevraagd of het wel goed was wat ik deed... ik had zo graag meer voor jullie betekent. Jullie hadden altijd belangstelling en vroegen telkens of het al opschoot. En pa om met jouw woorden te spreken 'maak ma voroet, straks ik kom dood'. Ik ben zo blij dat ik jullie allebei nog heb, en zo trots en dankbaar dat jullie dit kunnen meemaken. Heel hartelijk dank voor alles! Gelukkig hebben we al weer snel een nieuw (relatief) lange-termijn-doel gevonden...!!

Mam, jouw wereld vervaagt zo nu en dan, maar je bent zo trots en vertelt aan iedereen in jouw omgeving dat ik nog studeer en binnenkort 'dokter' ben. Verder is er mijn zus die ik dankbaar ben voor alles wat zij doet voor iedereen. Jan, ik hou van je!

Onze meisjes, Eefje en Lonneke, ik hou zielsveel van jullie en ben zo blij en dankbaar dat ik jullie heb. Jullie zijn mijn grootste cadeau ooit! Ik hoop dat ik jullie heb kunnen meegeven dat niets ertoe doet als je echt iets wil bereiken, ook leeftijd niet. Volg altijd je hart en doe wat je denkt dat je moet doen! Winand en Jacob, ik ben blij met jullie en het is fijn dat jullie er zijn. Ook jullie bedankt!

Mam, Eefje en Winand, dank voor jullie bijdragen aan de kaft van dit boekje. Mam, dank dat je model wilde staan voor de foto! Jouw haren staan nu vereeuwigd op de omslag. Eefje, jij bedankt voor je creativiteit in de vorm van de sprekende tekening.

Mijn laatste woord is voor Peter, mijn trotste en trouwste fan. Peter jij bent, denk ik, degene die het meest opgelucht is dat het voorbij is, en dat er tijd komt voor andere dingen.... Jij hebt je van je beste kant laten zien en ook jij hebt veel geleerd! Je bent een uitstekende kok gebleken, en wat mij betreft schuif ik graag nog lang bij je aan. Dank voor alles! 



\section{Curriculum Vitae}

Josiane Boyne was born on the $13^{\text {th }}$ of December 1953 in Rotem, Belgium. After three years secondary school in Kinrooi (B), she completed her education as a nursery nurse in Tongeren (B). In 1971 she went to the St. Annadal hospital in Maastricht to continue her education as a registered general nurse, which she finished in February 1975. Next, she followed her education as a specialised coronary care unit (CCU) nurse.

From 2000-2002 she followed her education as a nurse specialist at the HAN University of Applied Sciences (Hogeschool van Arnhem en Nijmegen). In September 2002 she started her education as a Master in Advanced Nursing Practice in chronic somatic diseases, which she successfully finished in 2004. Within the framework of this education she established the nurse outpatient clinic for Heart Failure patients in the Maastricht University Medical Centre. Her thesis research was about integrated care for patients with heart failure, where she compared patient outcomes prior and post heart failure nurse involvement in the patients' home situation. With the project of integrated care for patients with heart failure she won the Anna Reynvaen best practice award in 2003.

At about the same time she got involved in the feasibility study about Telemonitoring in Heart failure, and as a nursing expert she was involved in the adaptation of the telemonitoring system. This project won the best practice award of the Dutch Patient en Consumer Federation (NPCF) in 2005, and the NICTIZ Innovation Award in 2006. In 2007 the results of the feasibility study led to the multicentre randomised study (TEHAF-study), which is the topic of this thesis. In 2011 with this study she won the Nursing Investigator Award at the European Congress of Heart Failure. From 2009-2011 she followed the Ph.D. summer school of the European Academy of Nursing Science, and since 2012 she is involved in the Academy as a Scholar.

From 1975 until 2000 she worked at the CCU as a specialised nurse, and from 2000 till 2007 as a specialised nurse respectively nurse specialist. From 2004 to 2007 she combined her nursing- with management tasks, and from 2007 until today, she combined her management tasks with her work as a Ph.D. candidate. During her career she worked at St. Annadal, which later turned into the Maastricht University Medical Centre.

Furthermore, she was a member, secretary and chair of the National Association for Heart Failure Nurses and member of the National Society of Cardiovascular Nurses (2000-2013).

She was involved in the development of the $\mathrm{CBO}$, Dutch institute for Healthcare Improvement, guidelines for heart failure, and in several projects with $\mathrm{CBO}$, National IT Institute for Healthcare in the Netherlands (NICTIZ), e-Health.nu and Netherlands Or- 
ganisation for Applied Research TNO. Currently she is a member of the Research group of Nurse Specialists, within the Dutch Nursing Organisation (V\&VN).

She is also a member of the Heart Failure Association (HFA), the European Council of Nursing and Allied Professionals (CCNAP) of the European Society of Cardiology (ESC), and an active member of the CCNAP congress working group. Since 2012 she is appointed as a Nurse Fellow of the European Society of Cardiology.

Josiane likes biking, walking - especially with the dog - and reading. She lives in Bunde and is married with Peter Janssen, with who she raised two daughters, Eefje and Lonneke. 


\section{International peer reviewed publications}

Josiane J.J. Boyne, Marieke D. Spreeuwenberg, Anton P.M. Gorgels, Gerjan De Weerd, Johannes Kragten, Hubertus J.M. Vrijhoef. Effects of telemonitoring on heart failure patients' quality of life and depression: a randomized controlled trial. (submitted)

A.A. Latoszek-Berendsen, J.J.J. Boyne, A.P.M. Gorgels, H.J. van den Herik, A. Hasman. GASTINE: Intention-based DSS in practice; results of a validation test. Methods of Information in Medicine. (submitted)

Josiane J.J.Boyne, Hubertus J.M.Vrijhoef. Implementing Telemonitoring in Heart Failure Care. Barriers from the Perspectives of Patients, Healthcare Professionals, and Healthcare Organisations. Journal: Current Heart Failure Reports 2013;10 (3).

Josiane J.J. Boyne, Thea van Asselt, Hubertus J.M. Vrijhoef, Gerjan De Weerd, Johannes Kragten, Anton P.M. Gorgels. Cost-effectiveness of telemonitoring versus usual care in patients with heart failure. Journal of Telemedicine and Telecare 2013; 19(5); 242-248.

Josiane J.J. Boyne, Hubertus J.M. Vrijhoef, Marieke Spreeuwenberg, Gerjan De Weerd, Johannes Kragten, Anton P.M. Gorgels. Effects of telemonitoring on heart failure patients' knowledge, self-care, self-efficacy, and adherence: a randomised controlled trial. The European Journal of cardiovascular nursing. Published online 29 April 2013 as DOI: $10.1177 / 1474515113487464$.

Josiane J.J.Boyne, Hubertus J.M.Vrijhoef, Harry J.G.M.Crijns, Gerjan De Weerd, Johannes Kragten, Anton P.M. Gorgels. Tailored Telemonitoring in patients with Heart Failure: Results of a multicenter Randomised Controlled Trial. The European Journal of Heart Failure 2012; 14(7):791-801.

Josiane J.J.Boyne, Hubertus J.M.Vrijhoef, R.deWit, Anton P.M.Gorgels: Telemonitoring in patients with heart failure, the TEHAF-study: Study protocol of an ongoing prospective randomised trial. International Journal of Nursing Studies 2011; 48:94-99.

Smeulders ES, van Haastregt JC, Ambergen T, Stoffers HE, Janssen-Boyne JJ, UszkoLencer NH, Gorgels AP, Lodewijks-van der Bolt CL, van Eijk JT, Kempen GI: Heart failure patients with a lower educational level and better cognitive status benefit most from a self-management group programme. Patient Education and Counselling 2010; 81(2):214-21.

Smeulders ES, van Haastregt JC, Ambergen T, Uszko-Lencer NH, Janssen-Boyne JJ, Gorgels AP, Stoffers HE, Lodewijks-van der Bolt CL, van Eijk JT, Kempen GI: Nurseled self-management group programme for patients with congestive heart failure: randomised controlled trial. Journal of Advanced Nursing 2010; 66(7):1487-99.

Bram L.T. Ramaekers, Josianne J. Janssen-Boyne, Anton P.M. Gorgels, Hubertus J.M Vrijhoef. Adherence Among Telemonitored Patients with Heart Failure to Pharma- 
cological and Non-pharmacological Recommendations. Telemedicine and e-Health 2009; 15(6)

Smeulders ES, van Haastregt JC, Janssen-Boyne JJ, Stoffers HE, van Eijk JT, Kempen GI.Feasibility of a group-based self-management program among congestive heart failure patients. Heart Lung 2009; 38(6):499-512.

Smeulders ES, van Haastregt JC, Ambergen T, Janssen-Boyne JJ, van Eijk JT, Kempen GI. The impact of a self-management group programme on health behaviour and healthcare utilization among congestive heart failure patients. The European Journal of Heart Failure 2009;11(6):609-16.

\section{National peer reviewed Publications}

"Trazoheart": Dutch Companion of care innovation (2005: Supplement 19)

"Decompensatio Cordis": Nursing Vademecuum BSL (2002)

\section{Selection of Abstracts and Presentations}

2013

Annual Congress of Nurse Specialists, Papendal:

Invited speaker 'Nurse Specialist? And then.... ?'

E-health congress, Utrecht:

Invited speaker 'Results and lessons of a multicentre Trial'

European congress of Cardiology, Amsterdam:

Invited speaker: End-stage heart failure and palliative care.

European congress of Cardiology, Amsterdam:

Poster presentation: Cost-effectiveness analysis of telemonitoring versus usual care in patients with heart failure (the TEHAF-study).

European congress of heart failure, Lissabon:

Invited speaker, Telemonitoring in heart failure: what is needed to make this ready for routine use?

European congress of heart failure, Lissabon:

Poster presentation: Determinants of sodium intake among Dutch heart failure patients. 
Euro Heart care congress, Glasgow:

Oral presentation: Effects of telemonitoring on heart failure patients' knowledge, selfcare, self-efficacy, and adherence.

\section{2}

European congress of Cardiology, Munchen:

Poster presentation: The effects of telemonitoring on heart failure patients' knowledge, self-care, self-efficacy and adherence: a randomised controlled trial.

Telehealth Congress, London:

Poster presentation: Tailored Telemonitoring in Patients with Heart Failure: Results from a Multicenter Randomised Controlled trial (the TEHAF-study)

Congress of health and Technology, Papendal:

Invited speaker: Care for heart failure: How looks daily practice? (in Dutch)

Annual Congress of Nurse Specialists: 'Today is the future', Papendal:

Oral presentation: Effects of tailored care on disease specific knowledge, self-care and adherence in patients with heart failure. (in Dutch)

Congress of Cardiovascular Nurses CNAP, Copenhagen:

Invited speaker: Should we invest in Telemonitoring?

\section{1}

Annual International Congress of Cardiology (ICC-2011), Beijng:

Invited speaker: The effects of a tailored telemonitoring

system in patients with heart failure: The TEHAF-study

European Congress of Cardiovascular Nurses (CCNAP), Brussels:

Poster: The development of a peer-review system in heart-failure nursing

Medical Informatics Congress (MIC), Veldhoven:

Invited speaker: Telemonitoring in patients with heart Failure

Annual Geriatric Congress, Den Bosch:

Oral Presentation: Results of the TEHAF-study (in Dutch). 
National Heart failure congress, Zeist:

Poster presentation: Outpatient clinical pad for patients with heart failure in the MUMC (in Dutch)

European Congress of Heart Failure, Copenhagen:

Oral presentation in the late breaking session;

Oral presentation in the nursing session: Winner of the Nursing Investigator Award 2011.

American College of Cardiology, New Orleans:

Poster presentation: Main results of the Telemonitoring Study

in Heart Failure 